\title{
FABRICATION AND PROPERTIES OF HOT-PRESSED URANIUM MONONITRIDE
}
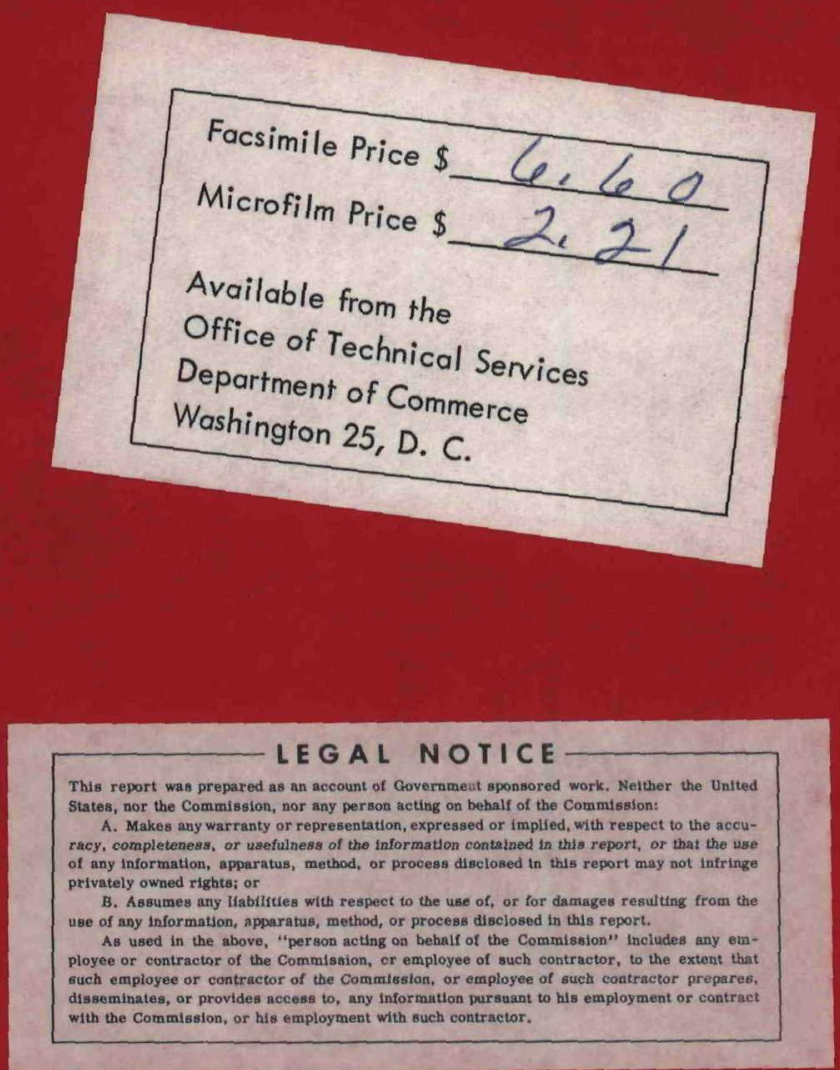

BATTELLE MEMORIAL INSTITUTE 


\section{LEGAL NOTICE}

This document was prepared under the sponsorship of the U. S. Atomic Energy Commission pursuant to the Joint Research and Development Program established by the Agreement for Cooperation signed November 8, 1958, between the Government of the United States of America and the European Atomic Energy Community (Euratom). Neither the United States, the U. S. Atomic Energy Commission, the European Atomic Energy Community, the Euratom Commission, nor any person acting on behalf of either Commission:

A. Makes any warranty or representation, express or implied, with respect to the accuracy, completeness, or usefulness of the information contained in this document, or that the use of any information, apparatus, method, or process disclosed in this document may not infringe privately owned rights; or

B. Assumes any liabilities with respect to the use of, or for damages resulting from the use of any information, apparatus, method or process disclosed in this document.

As used in the above, "person acting on behalf of either Commission" includes any employee or contractor of either Commission or employee of such contractor to the extent that such employee or contractor or employee of such contractor prepares, handles, disseminates, or provides access to, any information pursuant to his employment or contract with either Commission or his employment with such contractor.

Printed in USA

Price $\$ 1.75 \uparrow$

Avartable from the Office of Technical Service \{ U. S. Department- of Commeree

Washington 25, D.C. 0 


\section{DISCLAIMER}

This report was prepared as an account of work sponsored by an agency of the United States Government. Neither the United States Government nor any agency Thereof, nor any of their employees, makes any warranty, express or implied, or assumes any legal liability or responsibility for the accuracy, completeness, or usefulness of any information, apparatus, product, or process disclosed, or represents that its use would not infringe privately owned rights. Reference herein to any specific commercial product, process, or service by trade name, trademark, manufacturer, or otherwise does not necessarily constitute or imply its endorsement, recommendation, or favoring by the United States Government or any agency thereof. The views and opinions of authors expressed herein do not necessarily state or reflect those of the United States Government or any agency thereof. 


\section{DISCLAIMER}

Portions of this document may be illegible in electronic image products. Images are produced from the best available original document. 
Report No. BMI-1633

Joint U. S. -Euratom

Research and Development Program

AEC Contract $W-7405$-eng -92

FABRICATION AND PROPERTIES OF HOT-PRESSED URANIUM MONONITRIDE

by

Edward O. Speide1

Donald L. Keller

May 30, 1963

BATTELLE MEMORIAL INSTITUTE

505 King Avenue

Columbus 1, Ohio 
TABLE OF CONTENTS

$\underline{\text { Page }}$

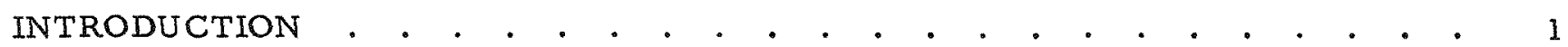

FABRICATION OF UN BY POWDER TECHNIQUES . . . . • . . . . . . $\quad 2$

Powder Preparation . . . . . . . . . . . . . . . . . . . 2

Powder Consolidation. . . . . . . . . . . . . . . . . . . 10

Vacuum Sintering . . . . . . . . . . . . . . . . . . . . 15

Isostatic Hot Pressing . . . . . . . . . . . . . . . . . 16

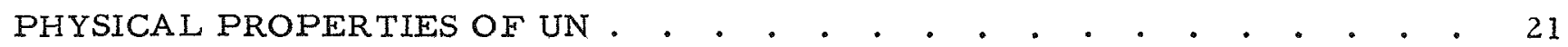

Thermal Expansion . • . . . . . . . . . . . . . . . . . 21

Thermal Conductivity . . . . . . . . . . . . . . . . . 27

Specific Heat . . . . . . . . . . . . . . . . . . . 36

Electrical Resistivity. • . . . . . . . . . . . . . . . . 40

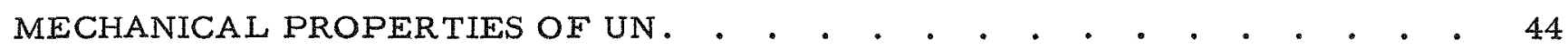

Elastic Properties. . . . . . . . . . . . . . . . . . . . 44

Hardness. . . . . . . . . . . . . . . . . . . . . 45

Hot Hardness . . . . . . . . . . . . . . . . . . 46

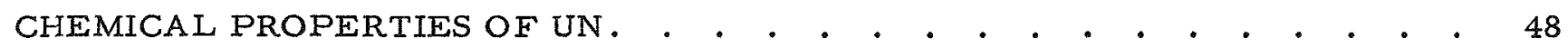

Solubility of Hydrogen . . . . . . . . . . . . . . . . . . . 48

Corrosion by Water . . . . . . . . . . . . . . . . . 54

Corrosion by NaK . . . . . . . . . . . . . . . . . . 60

ACKNOW LEDGMENT . . . . . . . . . . . . . . . . . . . . . 64

REFERENCES . . . . . . . . . . . . . . . . . . . . . . 64 


\title{
FABRICATION AND PROPERTIES OF HOT-PRESSED URANIUM MONONITRIDE
}

\author{
Edward O. Speidel and Donald L. Keller
}

\begin{abstract}
Dense UN specimens for property tests were fabricated primarily by an isostatic hot-pressing technique in which consolidated powder sealed in a refractory metal container was subjected to a 10,000-psi external gas pressure at 1480 to $1540 \mathrm{C}$ for 3 to $4 \mathrm{hr}$. The thermal conductivity of uranium mononitride increased from $0.04 \mathrm{cal} /(\mathrm{cm})(\mathrm{sec})(\mathrm{C})$ at $200 \mathrm{C}$ to $0.06 \mathrm{cal} /(\mathrm{sec})\left(\mathrm{cm}^{2}\right)(\mathrm{C})$ at $1000 \mathrm{C}$, which by an integrated thermal-conductivity criterion, makes it some eight times more effective than $\mathrm{UO}_{2}$ in transferring heat. Thermal-expansion coefficients of $9.0 \times 10^{-6}$ per $C$ and $9.9 \times 10^{-6}$ per $C$ over the ranges 20 to $800 \mathrm{C}$ and 20 to $1600 \mathrm{C}$, respectively, were measured. UN retained about 80 per cent of its room-temperature hardness at $1100 \mathrm{C}$. Above this temperature, the hardness dropped rapidly with increasing temperature. The specific heat in cal per $g$ mole can be conveniently described by the equation $C_{p}=13.32+1.19 \times 10^{-3} \mathrm{~T}$ $-2.10 \times 10^{5} \mathrm{~T}^{-2}$ over the range 273 to $1423 \mathrm{~K}$. Electrical conductivity dropped with increasing temperature, a metallic characteristic. Anomalies were noted in attempts to measure the hydrogen solubility and the resistance to water corrosion. $U N$ is apparently not attacked by $N a K$ within 1500 hr at temperatures up to $480 \mathrm{C}$.
\end{abstract}

\section{INTRODUCTION}

The United States and the European Atomic Energy Community (EURATOM), on May 29 and June 18, 1958, signed an agreement which provides a basis for cooperation. in programs for the advancement of the peaceful applications of atomic energy. This agreement, in part, provides for the establishment of a joint U.S. - Euratom Research and Development Program which is aimed at reactors to be constructed in Europe under the joint program.

The work described in this report represents the joint U.S. -Euratom effort which is in keeping with the spirit of cooperation in contributing to the common good by the sharing of scientific and technical information and minimizing the duplication of effort by the limited pool of technical talent available in Western Europe and the United States.

The purpose of the work, which was initiated during August of 1960, was to investigate the suitability of uranium mononitride for a power-reactor fuel. At the outset of the study uranium mononitride's high theoretical density of $14.32 \mathrm{~g}$ per $\mathrm{cm}^{3}$, as calculated from X-ray lattice parameters $(1)$, and its high uranium density of $13.52 \mathrm{~g}$ per $\mathrm{cm}^{3}$, as calculated for a fully dense compound with a one-to-one nitrogen-to-uranium atom ratio, were particularly attractive characteristics. Most other properties by which some prediction of its performance as a fuel could be based were either unknown or not well established.

(1) References at end. 
A phase diagram for the uranium-nitrogen system was not available, although the existence of three compounds had been established - the $\mathrm{NaCl}$-type face-centered-cubic uranium mononitride, $\mathrm{UN}(1-4)$; the body-centered-cubic sesquinitride, $\mathrm{U}_{2} \mathrm{~N}_{3}(1,2)$; and the cubic dinitride, $\mathrm{UN}_{2}(1,2)$. A hexagonal compound which was possibly a polymorphic form of $\mathrm{U}_{2} \mathrm{~N}_{3}$ had also been observed. (5)

Several suggested methods of synthesizing uranium nitride powders were summarized by Katz and Rabinowitch. (2) If uranium is reacted with nitrogen at 1 atm of pressure below $1000 \mathrm{C}$, a higher nitride powder in the single-phase field between $\mathrm{U}_{2} \mathrm{~N}_{3}$ and $U N_{2}$ is found. By heating this higher nitride to $1300 \mathrm{C}$ or above under a reduced pressure, several investigators $(2,3,6-8)$ had made UN powder by taking advantage of the fact that the mononitride is the only stable nitride under these conditions.

Chiotti ${ }^{(7)}$ measured the temperature at which melting of UN was observed under an atmosphere of ammonia. This temperature varied between 2575 and $2710 \mathrm{C}$ on five samples which contained a grain-boundary phase. The observed melting was probably incongruent. Newkirk and Bates $(9)$ reported an even lower melting temperature for UN, $2480 \pm 50 \mathrm{C}$.

As a class, nitrides are not noted for the ease in which useful bodies can be formed. Chiotti $(7)$ succeeded in forming small crucibles by cold pressing UN powder at 50,000 to $60,000 \mathrm{psi}$ and sintering at $2000 \mathrm{C}$. The densities of these crucibles were only 85 per cent of the theoretical UN density. Tripler and others $(8)$ obtained material 83 to 90 per cent of the theoretical UN density by sintering UN powder at $1850 \mathrm{C}$ in a vacuum furnace.

The only other published physical-property data for UN were Edwards ${ }^{\prime}(10)$ roomtemperature thermal-conductivity value of $0.01 \mathrm{cal} /(\mathrm{sec})\left(\mathrm{cm}^{2}\right)(\mathrm{cm} / \mathrm{C})$, obtained by a comparative-disk method and to which an assumed uncertainty of a factor of two had been assigned, and Kempter and Elliot's $(11)$ thermal-expansion coefficient of $8.61 \times 10^{-6}$ per $\mathrm{C}$ in the range 26 to $1000 \mathrm{C}$, obtained by $\mathrm{X}$-ray diffraction techniques.

A limited amount of data on the chemical properties and compatibility of UN with other materials were available. $(2,6,12-18)$ No mechanical-property data had been reported.

Although these investigations had aroused considerable interest it is obvious that the available information both about the preparation of UN materials and about the properties pertinent to power-reactor service was either too tentative or too incomplete to make a realistic appraisal of the potential of UN as a fuel material. The study undertaken was designed to rapidly obtain the basic data needed. A way of making high-density UN bodies suitable for property testing was developed, and evaluations of selected physical, mechanical, and chemical properties and of irradiation stability were carried out. The fabrication and property data obtained so far in this continuing work are presented in this report. The irradiation characteristics of UN will be the subject of a separate report.

\section{FABRICATION OF UN BY POWDER TECHNIQUES}

\section{Powder Preparation}

The properties of a finished powder product, as well as the performance of the material during pressing and sintering, depend to a large extent on the physical and chemical characteristics of the powder. These, in turn, depend on the method of powder preparation. 
$\underline{\text { Procedures }}$

The procedure by which practically all the UN powder was made involved heating uranium metal in pure nitrogen to form a higher nitride and then decomposing the higher nitride to form UN powder.

The nitriding apparatus is shown in Figure 1. Uranium metal is nibbled into small pieces (about $1 / 4$ by $1 / 4$ by $1 / 8 \mathrm{in}$ ). The nibbles are cleaned by pickling in a one-to-one $\mathrm{HNO}_{3}-\mathrm{H}_{2} \mathrm{O}$ solution, rinsed in acetone, dried, and charged into a mullite reaction tube. The tube is sealed to the system, evacuated, and then heated to $850 \mathrm{C}(1560 \mathrm{~F})$.

Matheson prepurified nitrogen with a dew point of minus $90 \mathrm{~F}$ and containing 99.996 per cent nitrogen, less than $0.001 \mathrm{w} / 0$ hydrogen and less than $0.001 \mathrm{w} / 0$ oxygen, is introduced into the system directly from the tank. The temperature is maintained at $850 \mathrm{C}$ (1560 F) during nitriding, which normally takes about $15 \mathrm{hr}$ for a $150-\mathrm{g}$ uranium charge. The nitrogen gas is kept just above a l-atm pressure by allowing a slight excess to escape through a mercury bubbler. The end of nitriding is determined by stopping the flow of nitrogen and noting the absence of a pressure decrease in the system on an openend manometer.

When nitriding ceases, the reaction tube is heated to and held at $1300 \mathrm{C}(2370 \mathrm{~F})$ until all the nitrogen gas which evolves is evacuated to a pressure of less than $5 \times 10^{-3}$ torr at temperature (the pressure in the cooled tube measures 6 to $7 \times 10^{-5}$ tor $r$ ).

After cooling, the tube is filled with argon or nitrogen and transferred to an argonatmosphere dry box where the UN powder is removed and stored.

Physical Characteristics

Particle Size and Size Distribution. Each batch of powder is usually screened through an 80-mesh (U. S. sieve series) screen to break up agglomerates of powder. Not less than $85 \mathrm{w} / 0$ of the batch readily passes this screen.

A screen analysis of the minus 80 -mesh fraction of one batch showed an average particle size of $66 \mu$. A screen analysis of the minus 100-mesh fraction of another batch also showed an average particle size of $66 \mu$.

Particle Shape. The irregularity of the powder particles is shown in Figure 2 which, being a metallographically polished section of a powder sample dispersed in resin mounting material, is a two-dimensional representation.

Porosity. It can be surmised from Figures 2 and 3 that most of the porosity is surface connected and results from spalling. This is somewhat confirmed by the microstructure in Figure 4 of a cold-pressed UN rod containing about 28 volume per cent voids into which molten copper was forced under pressure with little or no further relative movement of the UN particles. The cracks and pores that do not appear to be surfaceconnected in the two-dimensional microstructure are nevertheles silled with copper. 


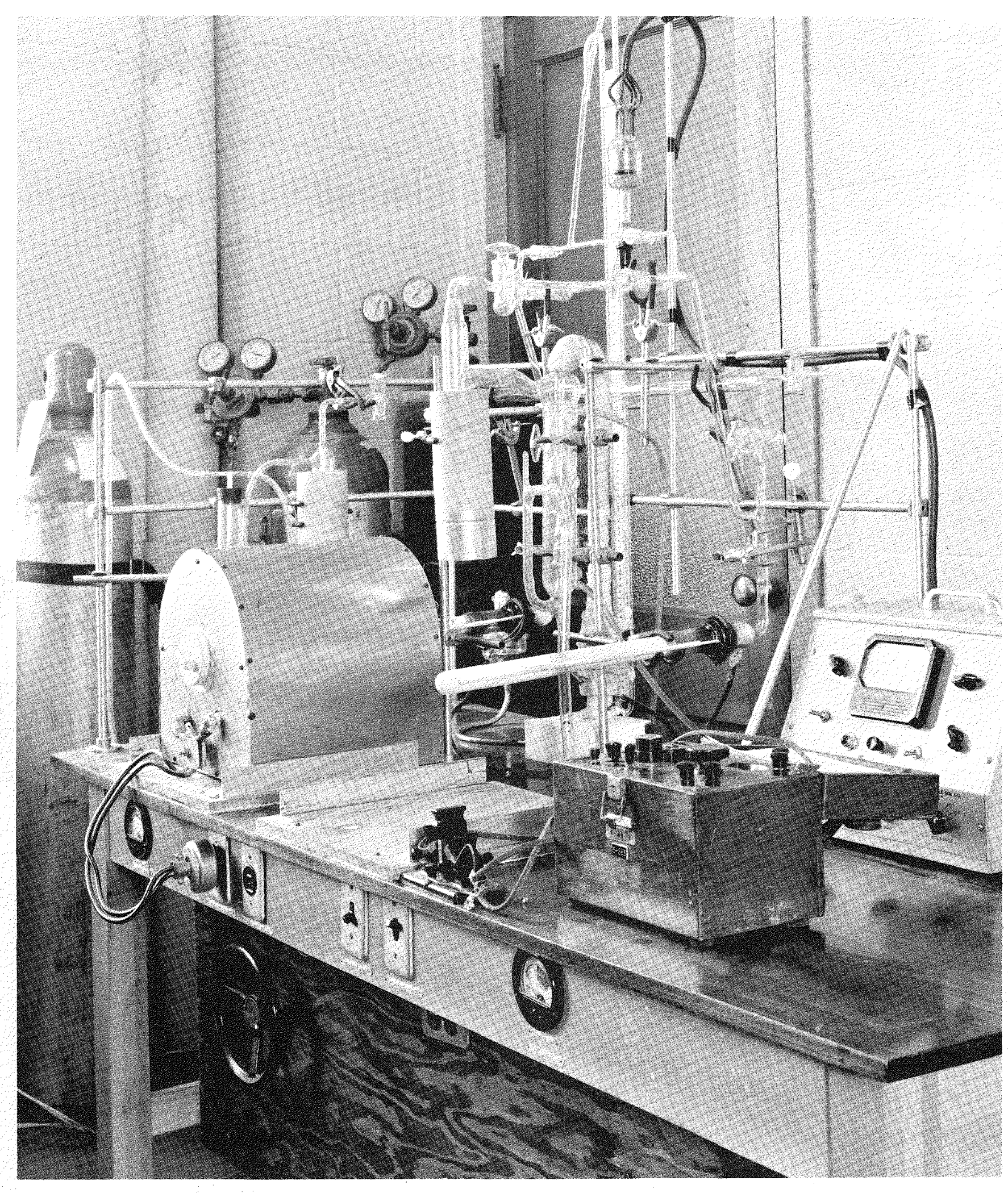

N57461

FIGURE 1. URANIUM NITRIDING APPARATUS 


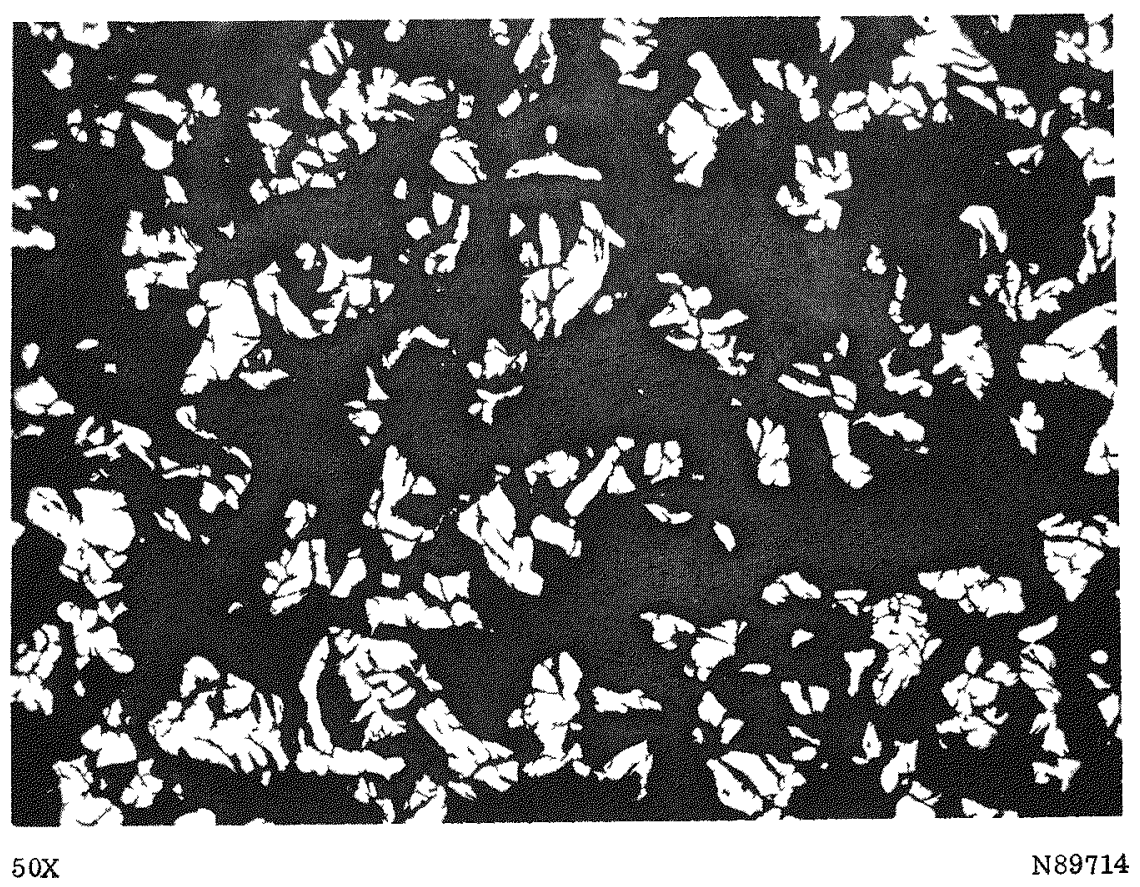

a. Powder Retained on an 80-Mesh Screen

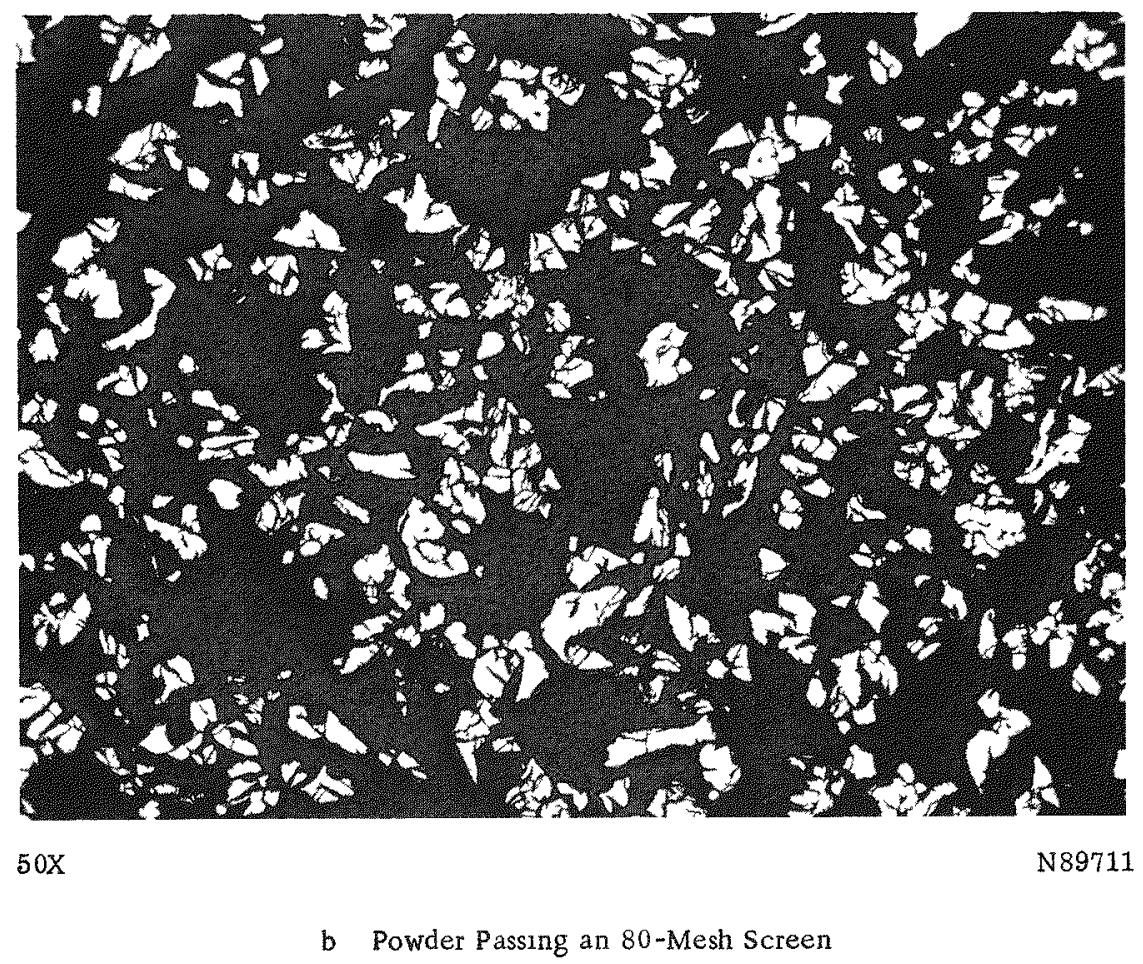

FIGURE 2. METALLOGRAPHICALLY POLISHED SECTIONS OF UN POWDER DISPERSED IN MOUNTING RESIN The irregularity of the as-produced powder particles is evident in these photomicrographs. 


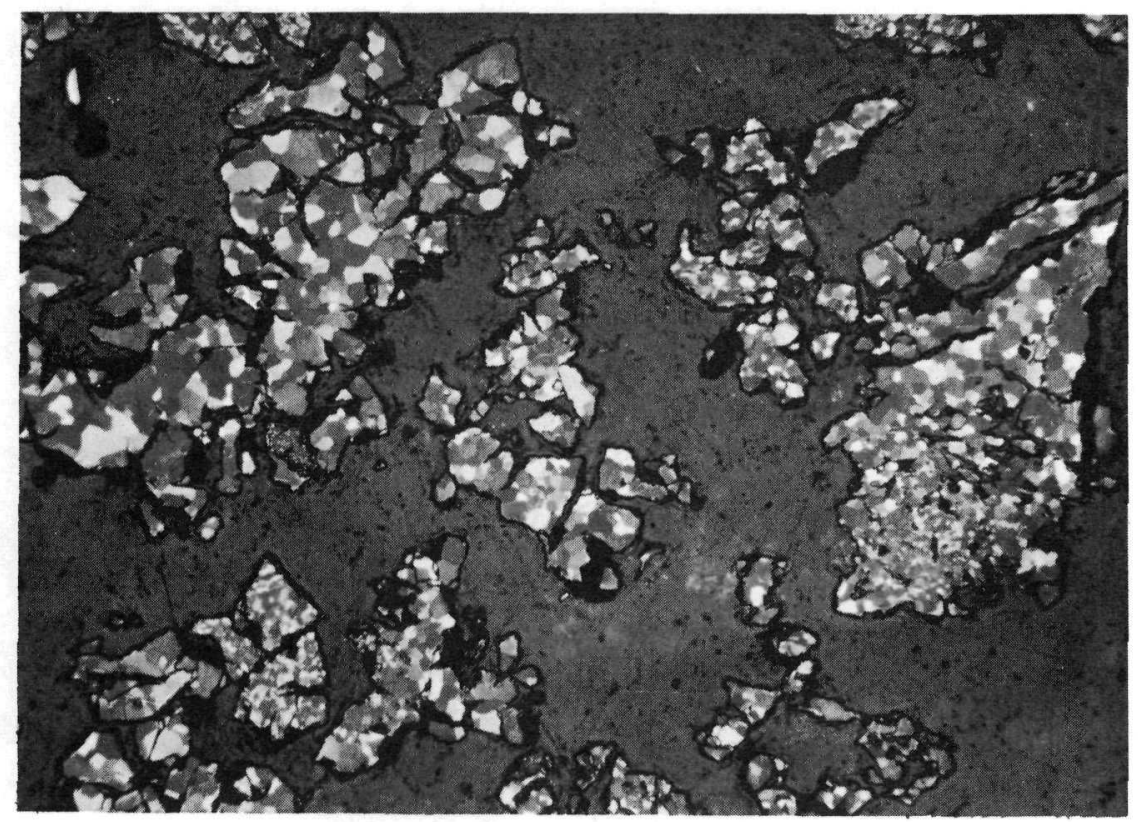

250X

$$
\text { Etchant: } 30 \mathrm{~cm}^{3} \text { lactic acid, } 10 \mathrm{~cm}^{3} \mathrm{HNO}_{3}, 2 \text { drops } \mathrm{HF}
$$

FIGURE 3. CONTRAST IN GRAIN SIZE OF UN POWDER PARTICLES Note the large variation in grain size even in what appears to be a single particle near the right edge of the picture.

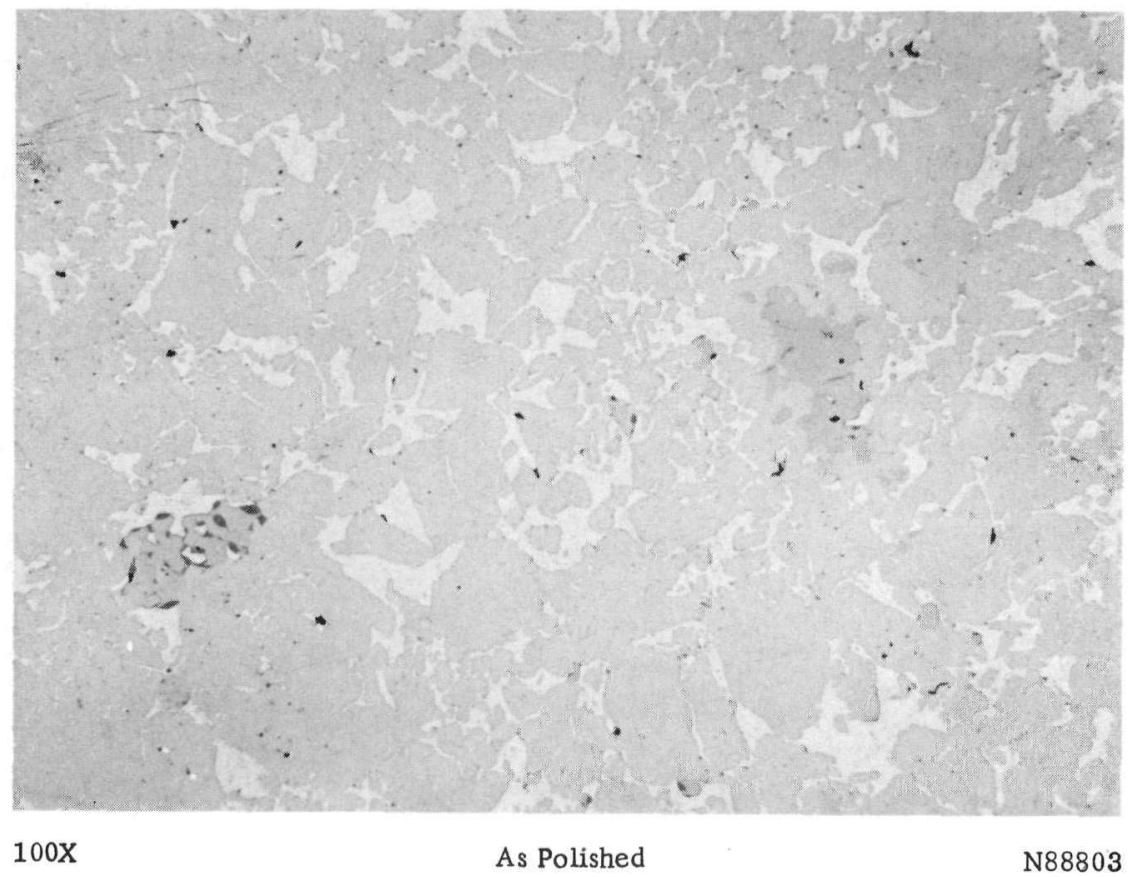

FIGURE 4. UN POWDER COMPACT IMPREGNATED WITH COPPER

Light phase is copper filling void regions in the UN. 
Microstructure. The powder particles are polycrystalline with grain sizes ranging from about 2 to $20 \mu$, with some as large as $125 \mu$. A contrast in grain sizes between particles of powder is evident in Figure 3.

\section{Chemical Characteristics}

Analyses. Chemical, vacuum-fusion, and X-ray analyses for several representative batches of powder are shown in Table 1 .

TABLE 1. SOME TYPICAL ANALYSES OF UN POWDER PREPARED FOR STUDY

\begin{tabular}{|c|c|c|c|c|c|c|c|}
\hline \multirow[b]{3}{*}{ Batch } & \multicolumn{5}{|c|}{ Analysis, w/o } & \multirow{3}{*}{$\begin{array}{l}X-R a y \\
a_{0} A\end{array}$} & \multirow[b]{3}{*}{ Remarks } \\
\hline & \multicolumn{3}{|c|}{ Chemical } & \multicolumn{2}{|c|}{ Vacuum Fusion } & & \\
\hline & Uranium & Nitrogen $(a)$ & $\overline{\text { Carbon }}$ & Oxygen & Hydrogen & & \\
\hline \multirow[t]{2}{*}{1} & \multirow[t]{2}{*}{$\cdots$} & \multirow[t]{2}{*}{5.47} & \multirow[t]{2}{*}{-} & 0.029 & 0.027 & \multirow[t]{2}{*}{--} & \multirow{2}{*}{$\begin{array}{l}\text { Minus } 100 \text {-mesh sample obtained by coning and } \\
\text { quartering of ten batches }\end{array}$} \\
\hline & & & & 0.011 & 0.002 & & \\
\hline 2 & $\cdots$ & 5.57 & - & - & -- & $\cdots$ & Minus 80 mesh \\
\hline 3 & - & 5.51 & -- & -- & -- & -- & $\begin{array}{l}\text { Minus } 80 \text { mesh, uranium contained } 0.2 \text { per cent } \\
\text { U } 235\end{array}$ \\
\hline 4 & $-\cdots$ & 5.54 & $-\cdot$ & $\cdots$ & - & - & $\begin{array}{l}\text { Minus } 80 \text { mesh, uranium contained } 5 \text { per cent } \\
\text { U } 235\end{array}$ \\
\hline 5 & 94.3 & $5.49(5.48)^{(b)}$ & 0.030 & 0.112 & 0.0008 & 4.889 & Minus 80 mesh \\
\hline 6 & 94.4 & $5.54(5.53)^{(b)}$ & 0.007 & 0.048 & 0.0006 & 4.890 & $\begin{array}{l}\text { Minus } 80 \text { mesh, uranium contained } 0.2 \text { per cent } \\
\text { U } 235\end{array}$ \\
\hline 7 & 94.4 & $5.57(5.39)^{(b)}$ & 0.007 & 0.068 & 0.0006 & 4.888 & $\begin{array}{l}\text { Minus } 80 \text { mesh, uranium contained } 5 \text { per cent } \\
\text { U } 235\end{array}$ \\
\hline 8 & -- & 5.39 & - & - & $-\infty$ & $\cdots$ & Minus 80 mesh, nitrided $65 \mathrm{hr}$ \\
\hline 9 & $\cdots$ & 5.53 & - & 0.053 & $-\cdots$ & $\cdots$ & Minus 80 mesh nitrided twice \\
\hline 10 & $\cdots$ & 5.52 & -- & - & $\infty$ & $\cdots$ & Plus 80 mesh from Batch 9 \\
\hline 11 & - & - & - & 1.00 & 0.038 & $\cdots$ & $\begin{array}{l}\text { Minus } 325 \text { mesh, uranium hydrided before } \\
\text { nitrided }\end{array}$ \\
\hline 12 & $\cdots$ & -- & - & 1.27 & 0.043 & -- & $\begin{array}{l}\text { Minus } 325 \text { mesh, uranium hydrided before } \\
\text { nitrided }\end{array}$ \\
\hline
\end{tabular}

(a) Modified Kjeldahl technique.

(b) Dumas method.

Impurities. UN has been the only phase detected in $\mathrm{X}$-ray diffraction patterns of the powder. Several phases which could be located and tentatively identified by metallographic techniques are shown in the microstructures of Figure 5. The UN particles are light tan as polished. The Knoop microhardness of the UN powder of the sample from which Figure $5 \mathrm{a}, 5 \mathrm{~b}$, and $5 \mathrm{c}$ was made ranged from 605 to 635 and averaged 621 KHN with a $25-\mathrm{g}$ load and $50 \mathrm{X}$ objective. The gray phase [(4) in Figure 5a] averaged $505 \mathrm{KHN}$. The $\mathrm{U}_{2} \mathrm{~N}_{3}$ looks blue-gray as polished and almost white as etched. Hardness measurements in particles like that of Figure $5 \mathrm{~d}$ but with varying amounts of the two phases ranged from 635 to $780 \mathrm{KHN}$. Other seemingly all blue-gray single-phase $\mathrm{U}_{2} \mathrm{~N}_{3}$ particles averaged $1139 \mathrm{KHN}$, although hardness values of 1308 to $1338 \mathrm{KHN}$ were obtained from the $\mathrm{U}_{2} \mathrm{~N}_{3}$ particle (1) of Figure $5 \mathrm{a}$. 


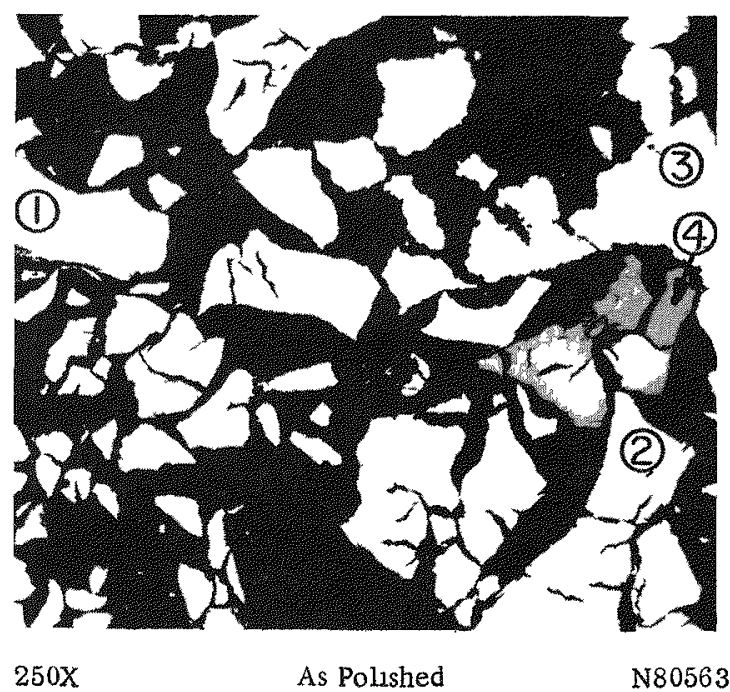

a. $\mathrm{U}_{2} \mathrm{~N}_{3}(1)$, UN(2), Uranum-UN(3), and Oxide (4)

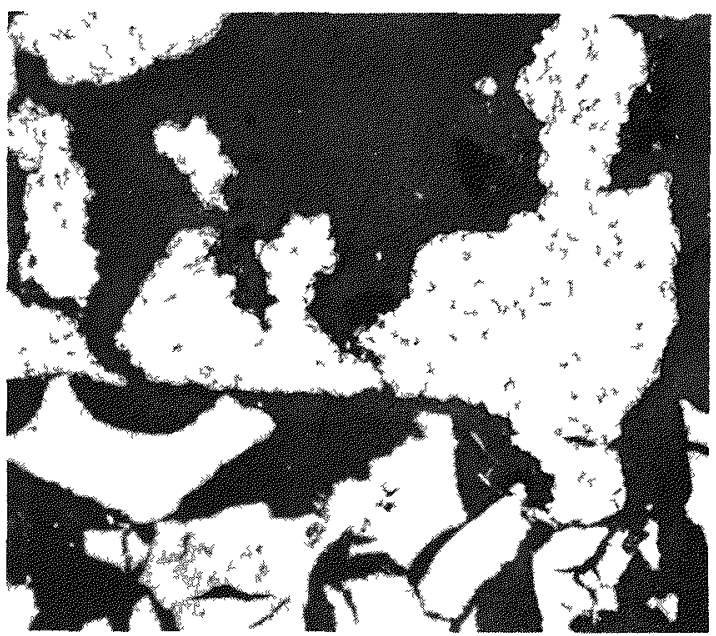

$500 \mathrm{X}$
Lightly Etched

N88866

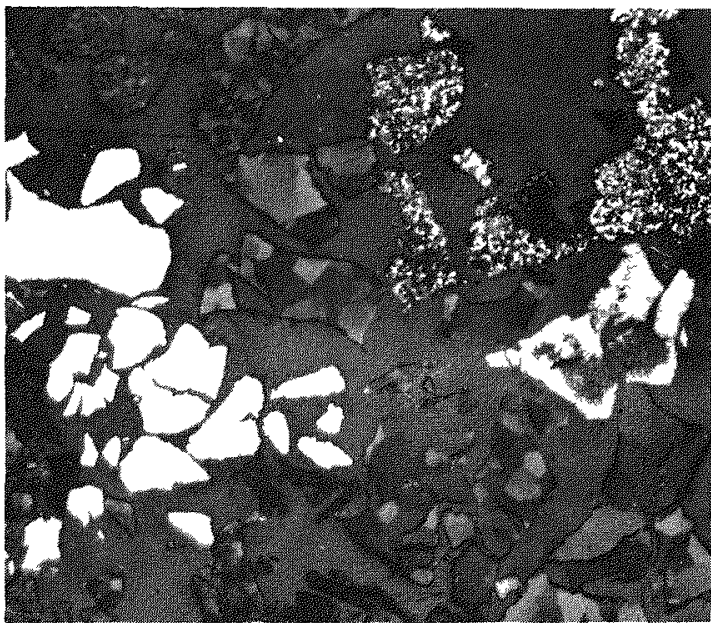

$250 \mathrm{X}$

Etched

N88865

b. Same Field After Etching

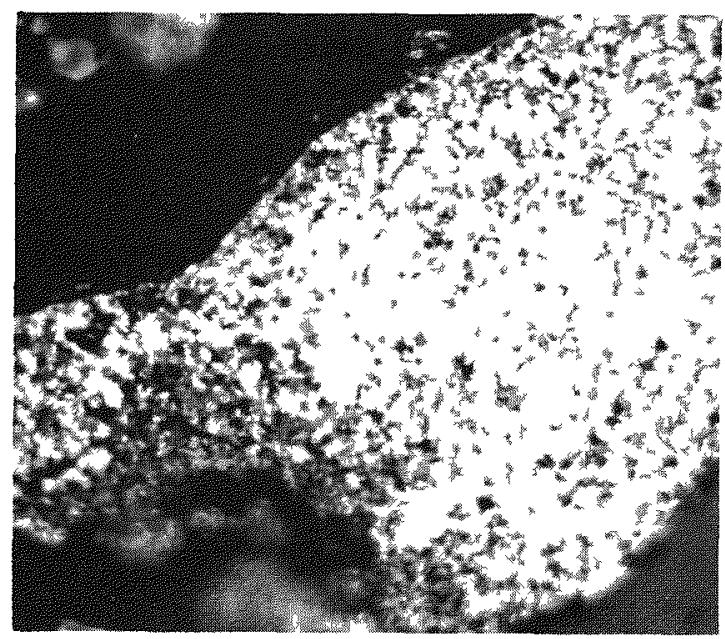

$1000 \mathrm{X}$

Etched

N89963

d $\quad \mathrm{UN}-\mathrm{U}_{2} \mathrm{~N}_{3}$

FIGURE 5. METALLOGRAPHIC APPEARANCE OF SOME IMPURITIES IN UN POWDER

The quantitative amounts in $\mathrm{a}$ and $\mathrm{b}$ are circumstantial.

Etchant $30 \mathrm{~cm}^{3}$ lactic acid, $10 \mathrm{~cm}^{3} \mathrm{HNO}_{3}$, and 2 drops $\mathrm{HF}$. 
Some Results of Modifications in the

Basic Powder Preparation Procedure

Analyses on some powder batches prepared by lengthening the nitriding step to $65 \mathrm{hr}$, by repeating the nitriding and denitriding steps, and by hydriding and dehydriding the nibbled uranium prior to nitriding are included in Table 1, Batches 8 through 12. Metallographic examination of the powders made by the first two modifications did not show that there were any significant differences between these powders and that produced by the normal procedure. The powder from the hydrided uranium was much finer. Nearly all of it readily passed through a $325-$ mesh screen, and as a consequence the oxygen content was significantly higher.

\section{Conclusions}

The metallographically detected impurities in the powder occur in discrete particles as shown in Figure 5 and in amounts usually much less than 3 volume per cent of the sample. It is surmised that with the large mass-volume increase and the scattering of powder particles in the reaction tube during nitriding, some particles are ejected from the temperature zone surrounding the bulk of the batch.

The nitrogen analyses obtained throughout this program on several batches of powder and on various fabricated specimens have been uncontrollable. One specimen with an analyzed nitrogen content as low as $5.24 \mathrm{w} / 0$ still had no metallog raphically detectable uranium in the microstructure. Eight batches of powder prepared on a previous program $(6)$ by an identical procedure varied from 5.41 to $5.55 \mathrm{w} / 0$ nitrogen. This inability to control the uranium-to-nitrogen atom ratios, as well as the nonreproducibility of measured X-ray lattice parameters suggested the possibility that UN might exist homogeneously over some composition range. The impurities existing as discrete particles were not expected to significantly affect the measured lattice parameters of the major UN phase. However, even with considerably more analytical data than those shown in Table 1, it was still not possible to show that the lattice parameter varied regularly as a function of the analyzed nitrogen content. Neither did it vary as a function of the analyzed carbon or oxygen, which could possibly substitute for some nitrogen in the lattice and thus affect the stoichiometric relationship of uranium to nitrogen. Several investigators have reported difficulty in analyzing for nitrogen in UN. Thus, the reliability of the analyses are still somewhat questionable.

The quite irregular and relatively large total surface area of the powder particles makes them susceptible to any effect that adsorbed gases might have during subsequent processing. This factor is believed to be partly responsible for the sometimes seemingly erratic results of vacuum-fusion analyses of powder samples. The trend (but not the real chemical ratios) of the higher hydrogen contents being as sociated with the higher oxygen contents, as would be expected if the powder adsorbs atmospheric moisture during handling, is observed in Table 1.

The very high oxygen content listed in Table $I$ for the powder made from hydrided uranium shows that the reduction in particle size obtained is accompanied by an increase in susceptibility to contamination during further processing. 
Because the larger particles in the normally produced powder are agglomerates of smaller particles, relatively little effort is required to crush about 90 per cent of a batch in a diamond mortar to a size that will pass a 325 -mesh screen.

Sieve-analysis comparisons of various batches were judged to be of limited value because the crushability and irregular shape of the powder made it difficult to determine how much reduction in particle size due to attrition occurred during screening and to know when all of the particles able to pass a given screen had actually done so. It will be seen later that the crushability of the coarser powder seems to be a governing factor in the cold compactibility.

\section{Powder Consolidation}

To be useful the powder must be formed into a coherent mass close to the desired shape and of sufficient strength to withstand handling in subsequent processing. It should have those characteristics (such as good interparticle contact) which allow subsequent processing (such as sintering) to be effective.

Procedures

Unidirectional Pressing. Cylindrical hardened-steel double-acting dies and laboratory-type hydraulic presses were utilized to press powders at up to 50 tsi of pressure.

Hydrostatic Pressing. To contain the powder for pressing, a metal tube with the inside diameter and length necessary to produce the desired dimensions of the pressed rod is cut, and a few small holes are drilled through the wall to allow passage of oil and air. This tube is lined with surgical rubber tubing, sealed at one end, and placed inside another metal tube, one end of which is connected to a vacuum pump. The loose end of the surgical tubing is stretched over the end of the outer tube, and the annulus is then evacuated, expanding the rubber against the inside surface of the inner tube. The powder is poured into the rubber tube to the required depth of fill while simultaneously vibrating the whole assembly. The inner tube is stoppered, removed from the assembly, and evacuated to $15 \mathrm{~mm}$ of mercury by means of a hypodermic needle inserted through the rubber stopper. A thin layer of cotton between the powder and the stopper prevents aspiration of the powder.

The loaded tube is immersed in an oil-filled pressure cylinder. Pressure is achieved by a plunger linked to a hydraulic press. The maximum pressure of the system is $50 \mathrm{tsi}$. After pressing, the surgical tubing is stripped off.

Loading of the powder and removal of the pressed rod is effected in an argon-filled dry box with the powder thus never exposed to the atmosphere.

Compaction by Vibration of the Powder. The powders were poured into a container tube which was simultaneously vibrated to facilitate powder packing. 
Swaging. Cold-pressed compacts were fitted into metal sheaths and end plugs Heliarc welded. The assemblies were outgassed in a small Tempco furnace through evacuation stems which were forge sealed at the completion of outgassing.

Explosive Compacting. Powders were compacted into metal cans by vibrating as above. The end plugs of the cans were electron-beam welded, thus sealing the powder in an evacuated container. The cans were wrapped in sheet explosive which was detonated within a housing submerged under water.

$\underline{\text { Results }}$

Unidirectional Pressing. Some typical results are shown in Table 2.

TABLE 2. REPRESENTATIVE PELLET DENSITIES OBTAINED BY PRESSING UN POWDER IN STEEL DIES

\begin{tabular}{|c|c|c|c|c|c|c|}
\hline $\begin{array}{l}\text { Powder Mesh } \\
\text { Size }\end{array}$ & $\begin{array}{c}\text { Approximate } \\
\text { Die Diameter, } \\
\text { in. }\end{array}$ & $\begin{array}{l}\text { Length-to- } \\
\text { Diameter } \\
\text { Ratio }\end{array}$ & $\begin{array}{l}\text { Pressing } \\
\text { Pressure. } \\
\text { tsi }\end{array}$ & Lubricant & $\begin{array}{l}\text { A verage } \\
\text { Density, } \\
g \text { per } \mathrm{cm}^{3}\end{array}$ & $\begin{array}{c}\text { Number } \\
\text { of } \\
\text { Pressings }\end{array}$ \\
\hline-80 & 0.500 & 1.02 & 30 & None & 10.5 & 2 \\
\hline-80 & 0.380 & 0.64 & 40 & Carbowax 6000 & 10.8 & 10 \\
\hline-80 & 0.375 & 0.83 & 40 & Carbowax 6000 & 10.5 & 14 \\
\hline-80 & 0.300 & 0.82 & 40 & Carbowax 6000 & 10.5 & 1 \\
\hline$=80$ & 0.470 & 1.06 & 40 & None & 10.7 & 5 \\
\hline-80 & 0.250 & 1.93 & 40 & None & 9.7 & 8 \\
\hline-80 & 0.375 & 0.79 & 50 & None & 10.6 & 3 \\
\hline$-60+200$ & 0.300 & 0.81 & 40 & Carbowax 6000 & 11.0 & 9 \\
\hline-100 & 0.250 & 0.68 & 40 & Carbowax 6000 & 10.9 & 7 \\
\hline-100 & 0.300 & 0.77 & 40 & Carbowax 6000 & 11.1 & 5 \\
\hline-100 & 0.500 & 0.78 & 50 & Camphor & 10.6 & 1 \\
\hline-400 & 0.380 & 0.50 & 40 & Carbowax 6000 & 10.0 & 1 \\
\hline-400 & 0.380 & 0.90 & 40 & Carbowax 6000 & 9.5 & 5 \\
\hline $\begin{array}{r}-100(75 \mathrm{w} / \mathrm{o})+ \\
-400(25 \mathrm{w} / \mathrm{o})\end{array}$ & 0.375 & 1.2 & 40 & Carbowax 6000 & 7.6 & 1 \\
\hline
\end{tabular}

Hydrostatic Pressing. No attempt was made to isolate and assess the effects of several variables on the hydrostatic pressing of UN powders. However, some useful general observations were recorded.

Minus 80-mesh UN powder that was vibrated into pressing tubes to densities ranging from 5 to $7.4 \mathrm{~g}$ per $\mathrm{cm}^{3}$ and hydrostatically cold pressed at 100,000 psi (50 tsi) gave

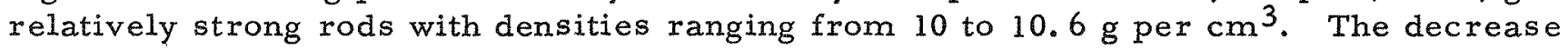
in diameter during pressing ranged from 15 to 25 per cent.

For best results, it was necessary to slowly pour the powder into the pressing tube while simultaneously vibrating the tube. If the flow of powder into the tube was interrupted before filling was completed but then continued, the pressed rod would not be joined at the plane where the discontinuity in pouring of the powder occurred. Nonuniform vibration of the pressing tube during filling resulted in warpage of the rod during pressing. 
During the application of about the first $75,000 \mathrm{psi}$ of pressure to minus $80-\mathrm{mesh}$ powder, the ram travel was sporadic and the pressure increase as indicated by the movement of the gage indicator was erratic. Above 75,000 psi, the pressure increase was smooth.

Although the pressed rods could be easily broken back down to powder, the material, once pressed, could not be successfully repressed.

In the case of minus 325-mesh powder loaded in the pressing tubes to a density of 7.8 to $8.2 \mathrm{~g}$ per $\mathrm{cm}^{3}$, the reduction in diameter under the 100,000-psi hydrostatic pressure was less than 5 per cent, and the powder would not hold together. The initial pressure increase was erratic as noted above for the minus $80-$ mesh powder, but in this case only up to 25,000 psi. Pressure increase and ram travel was smooth and uniform above this pressure.

Compaction by Vibration of the Powder. As indicated in the above section on hydrostatic pressing, minus 325-mesh powder will pack to a higher density than the minus 80-mesh powder. Some variations in loading techniques are less effective than others. For instance, considerably more powder can be loaded into a given tube if the powder is slowly poured into the tube while it is simultaneously vibrated than if the tube is filled and then vibrated. The highest densities obtained with minus 325 -mesh powder were 8.8 to $8.9 \mathrm{~g}$ per $\mathrm{cm}^{3}$.

Swaging. A cursory evaluation of the swaging of some short, green pressedpowder cores in metal tubes was made at room temperature, $480 \mathrm{C}$, and $980 \mathrm{C}$, with reductions in area up to 75 per cent. No data were obtained by which the effects of particle size, reduction in area, and swaging temperature could be clearly evaluated. The major difficulties experienced were cracking of welds, extruding of powder between the tubing and end plugs, and blowing of plugs, which would have necessitated development of better canning techniques for further investigation.

Figure 6 shows two metallographically polished sections of UN powder that had been reduced about 30 per cent in area by swaging at room temperature and $980 \mathrm{C}$. The starting density was $10.2 \mathrm{~g}$ per $\mathrm{cm}^{3}$.

Explosive Compaction. Only limited effort was given to evaluation of explosive compaction. Six 1/2-in.-OD, 20-gage-wall stainless steel tubes containing UN powder were compacted either in a 2-in. -ID housing with charge densities of $2-1 / 2,3$, and 3$1 / 2 \mathrm{~g}$ per in. 2 , or in a 5-in. -ID housing with a charge density of $3-1 / 2 \mathrm{~g}$ per in. 2 . The conditions bracketed what would seem to be optimum. Some of the compacts had center spikes. The pressure had not reached the center of others. The reduction in area ranged from 37 to 41 per cent and was uniform over the 2-1/2-in. length of powder.

Although areas of nearly full density were obtained, the bulk density was not high because of considerable cracking, as shown in Figure 7. The UN was extensively deformed, as also may be seen in Figure 7. The "flow lines" were radial in orientation. 


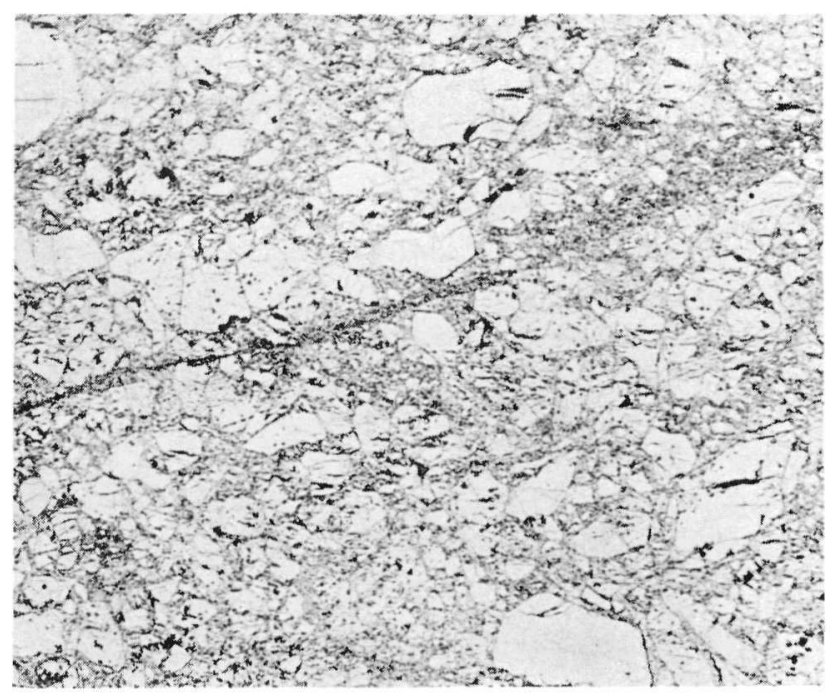

a. Swaged at Room Temperature (Longitudinal Section)

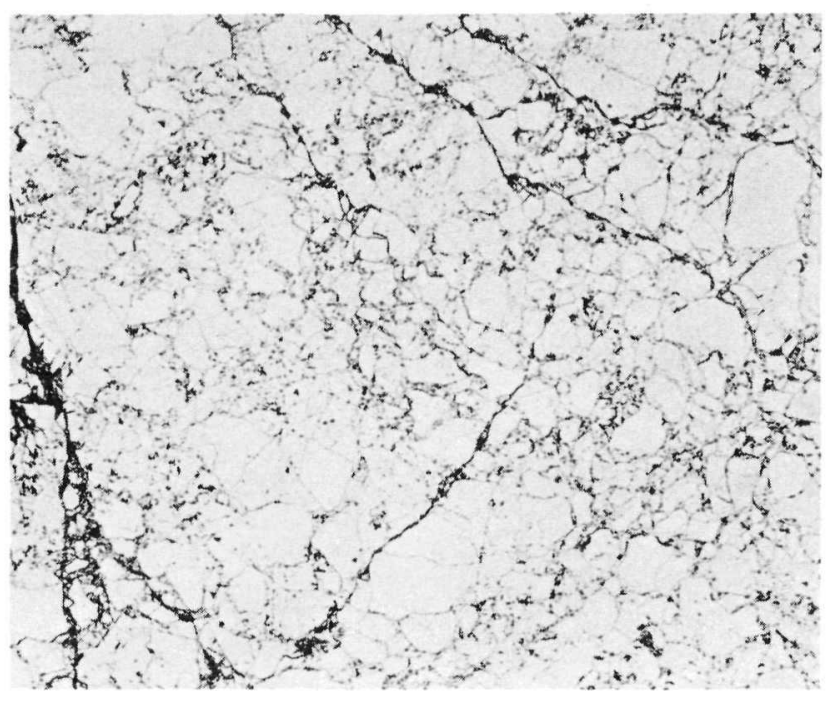

b. Swaged at $980 \mathrm{C}$ (Transverse Section)

FIGURE 6. SWAGED UN POWDER

Starting particle size of the powder was minus 60 plus 200 mesh. Reduction was about 30 per cent. As-polished sections are shown. 

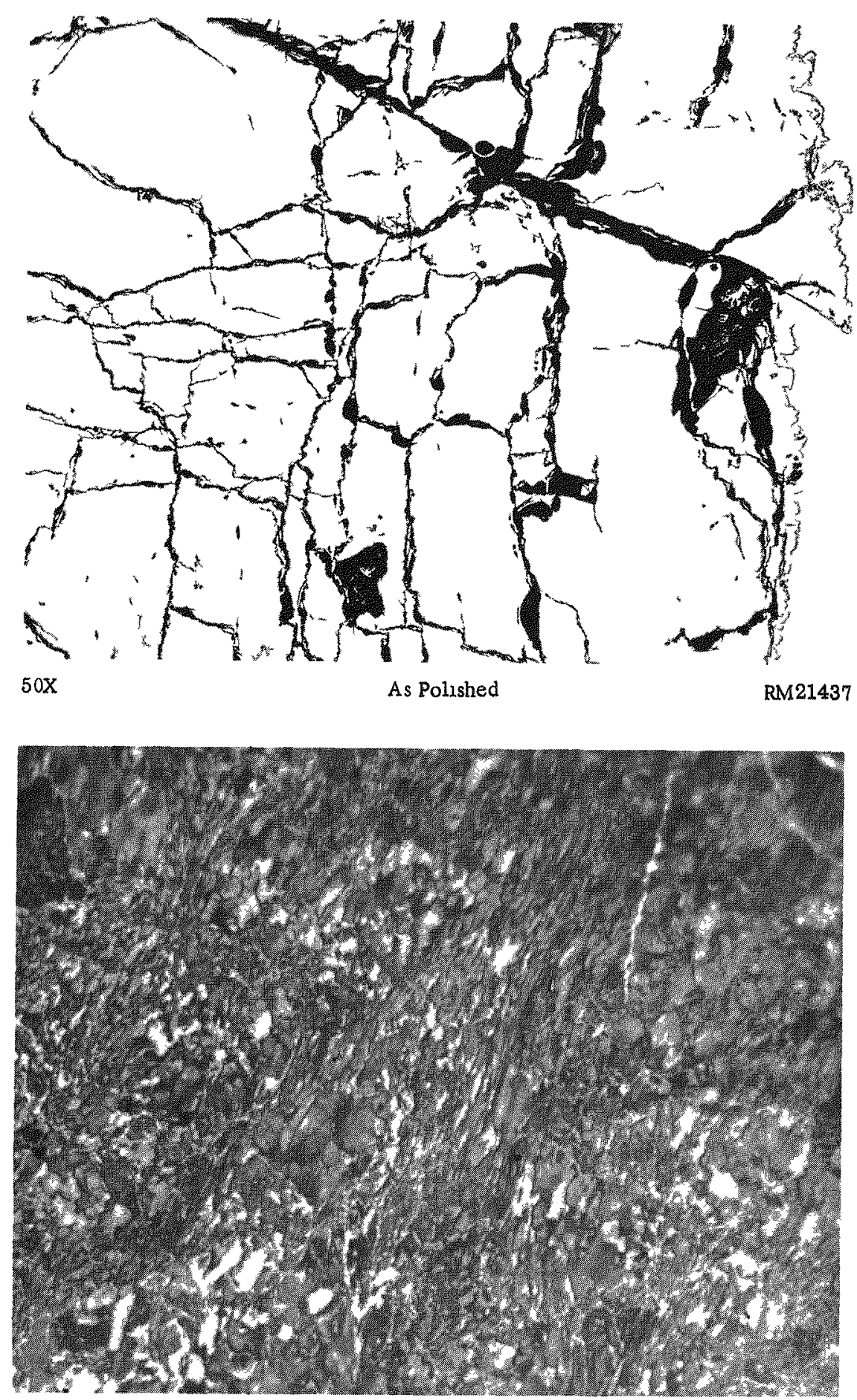

$750 \mathrm{X}$

Etched

RM21445

FIGURE 7. EXPLOSIVELY COMPACTED UN POWDER

This specimen was compacted in a $2-1$ ID housing with charge density of $3-1 / 2 \mathrm{~g}$ per in. ${ }^{2}$. The interface between the UN and the stanless steel tube is at the right in the as-polished specimen The etchant employed consisted of $30 \mathrm{~cm}^{3}$ lactic acid, $10 \mathrm{~cm}^{3} \mathrm{HNO}_{3}$, and 2 drops HF. 
Conclusions

This phase of the work showed that UN powder pellets having densities 70 to 75 per cent of theoretical can be pressed in steel dies. Size limitations are those normally associated with die pressing. Maximum densification is not obtained if the length-to-diameter ratio much exceeds one. Lubricating coarse powder (minus $80 \mathrm{mesh}$ ) is not necessary. Fine (minus $325 \mathrm{mesh}$ ) powder will not hold together unless it is lubricated with some type of binder. Pressures above 40 tsi do not significantly increase the pressed density, but do cause other problems, such as die galling and lamination cracking.

The most effective factor in obtaining strong, dense cold-pressed UN powder compacts is the particle size. Best results are obtained with coarser powder. This seems to be related to the crushability in situ during pressing of the coarser particles, which, as previously shown, are irregularly shaped agglomerates of finer particles. This was shown in hydrostatic pressing. Coarse powder once pressed could not be repressed. Fine powder could not be pressed satisfactorily with binder additions. The packing of the fine powder is only slightly increased by pressures up to 25,000 psi (12.5 tsi). Pressures up to 100,000 psi $(50 \mathrm{tsi})$ did not effectively stick the fine binderless particles together. With the coarse powder, however, pressures up to 75,000 psi (37. 5 tsi) were effective in increasing the density. The mechanism by which the particles are cold bonded together thus seems to be a mechanical interlocking enhanced by crushing in situ rather than deformation of the powder particles.

This same mechanism appeared to have a significant effect on the amount of densification that could be obtained by swaging. Thus, while long rods of UN powder could be swaged in metal tubes, a subsequent operation, such as isostatic hot pressing, would be required to obtain near theoretical densities and particle bonding.

High-energy-rate (explosive) compaction results in plastic deformation of the UN particles and bonding between particles. The mechanism of this method is not fully understood. However, high temperatures at contact points are apparently developed which results in particle bonding.

\section{Vacuum Sintering}

Required mechanical strength, final densification, and other desired properties can often be achieved by a thermal treatment of the consolidated powders.

\section{Procedures}

Cold-pressed powder pellets were heated in vacuum furnaces at several temperatures and for various times. A sintering furnace that would operate under nitrogen gas pressure was not available. 
$\mathrm{U}_{2} \mathrm{~N}_{3}$ powder and UN powder prepared by modified production techniques were also incorporated as starting materials.

$\underline{\text { Results }}$

At $1900 \mathrm{C}$ and above in vacuum, UN powder compacts rapidly decomposed. As shown in Figure 8 , liquid uranium ran down the sides of the compact. The liquid uranium was also continuous throughout the microstructure as shown by Figure 9 , which was a minus 100-mesh powder compact that was heated to $2000 \mathrm{C}$ and cooled with no holding time at temperature.

At $1800 \mathrm{C}$, the decomposition which started at the surface was less rapid as shown in Figure 10. This was a compact pressed from powder that passed a 400-mesh screen. Note that even though decomposition had started at the surface, there is very little evidence of particle rounding and neck growth to indicate that much sintering had taken place within the compact.

Pellets heated for $1 \mathrm{hr}$ at $1700 \mathrm{C}$ exhibited no detectable evidence of decomposition, but also no evidence of sintering, except for a possible slight strengthening of the compact indicative of some particle adhesion.

The decomposition was found to be time dependent. Figure 1 la shows the decomposed zone penetrating from the outside of a pellet heated $65 \mathrm{hr}$ at $1650 \mathrm{C}$. The diameter (0. 472 in.) decreased about 11 to 12 per cent during the heat treatment. The length decreased 9 to 10 per cent and the density increased from $10.2 \mathrm{~g} \mathrm{per} \mathrm{cm}^{3}$ to $14.0 \mathrm{~g} \mathrm{per} \mathrm{cm}^{3}$ with a 4.5 per cent loss in weight. The thickness of the uranium-UN zone was about $2.5 \mathrm{~mm}$ and was uniform both from the cylindrical surface and from the flat top of the specimen. Penetration from the bottom was slightly less. No decomposition was detected in the core of the specimen. Within this cylindrical core some grain growth, neck growth, and void rounding occurred as shown in Figure $11 \mathrm{~b}$.

Higher nitride powder, consolidated and decomposed in situ, reverted to UN during sintering, but then decomposed just as consolidated UN powder did. Very little increased sinterability was noted.

\section{Conclusions}

Some adhesion of UN powder particles can be effected by sintering in vacuum furnaces, but no densification can be achieved without decomposition of the UN and formation of liquid uranium.

To obtain temperatures required for densification without decomposition, a nitrogen atmosphere must be employed.

\section{Isostatic Hot Pressing}

The primary purpose of hot pressing is to obtain a higher density than would be possible by carrying out pressing and sintering separately. 


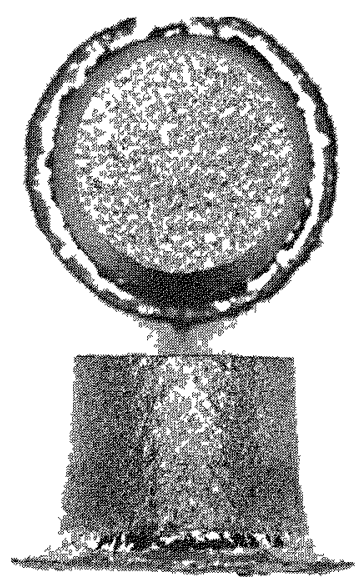

$3 \mathrm{X}$

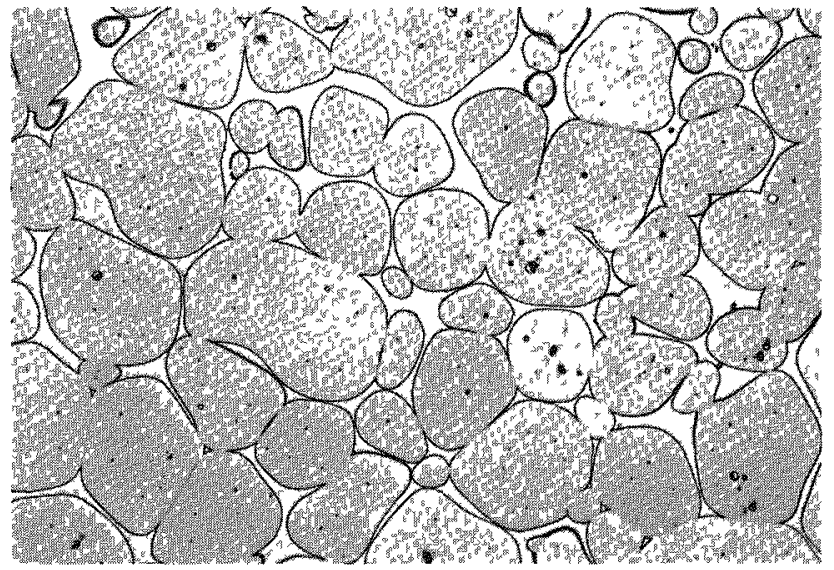

$250 \mathrm{X}$

As Polished

RM17380
FIGURE 8. UN POWDER COMPACT HEATED 1 HR AT 1900 C IN A VACUUM FURNACE

Liquid uranium ran down the sides of the compact.
FIGURE 9. URANIUM-UN CERMET THAT RESULTED WHEN A UN POWDER COMPACT WAS HEATED TO $2000 \mathrm{C}$ IN A VACUUM FURNACE

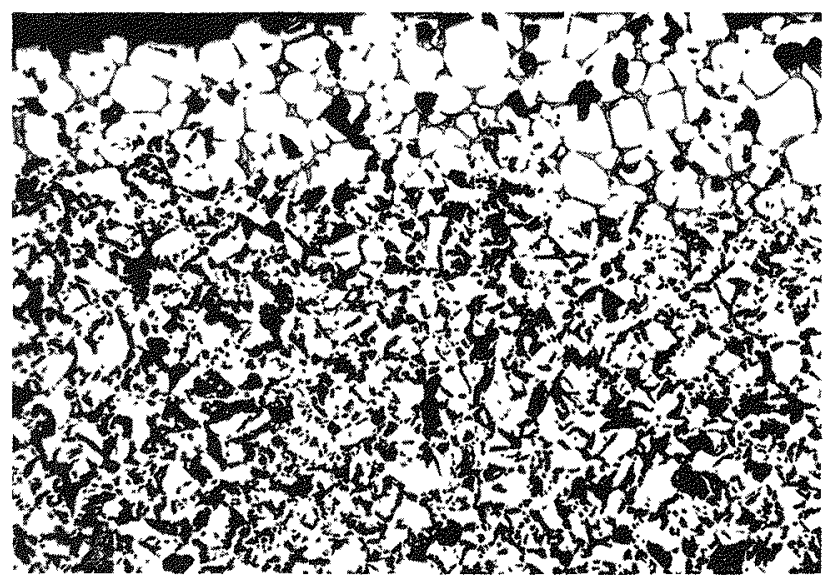

$100 \mathrm{X}$
RM17374
FIGURE 10. EDGE OF MINUS 400-MESH UN POWDER COMPACT THAT WAS HEATED 1 HR AT $1800 \mathrm{C}$

The general decomposition which took place at $2000 \mathrm{C}$ (Figure 9) occurred only near the surface in this specimen. Little evidence of sintering is visible within the compact. 


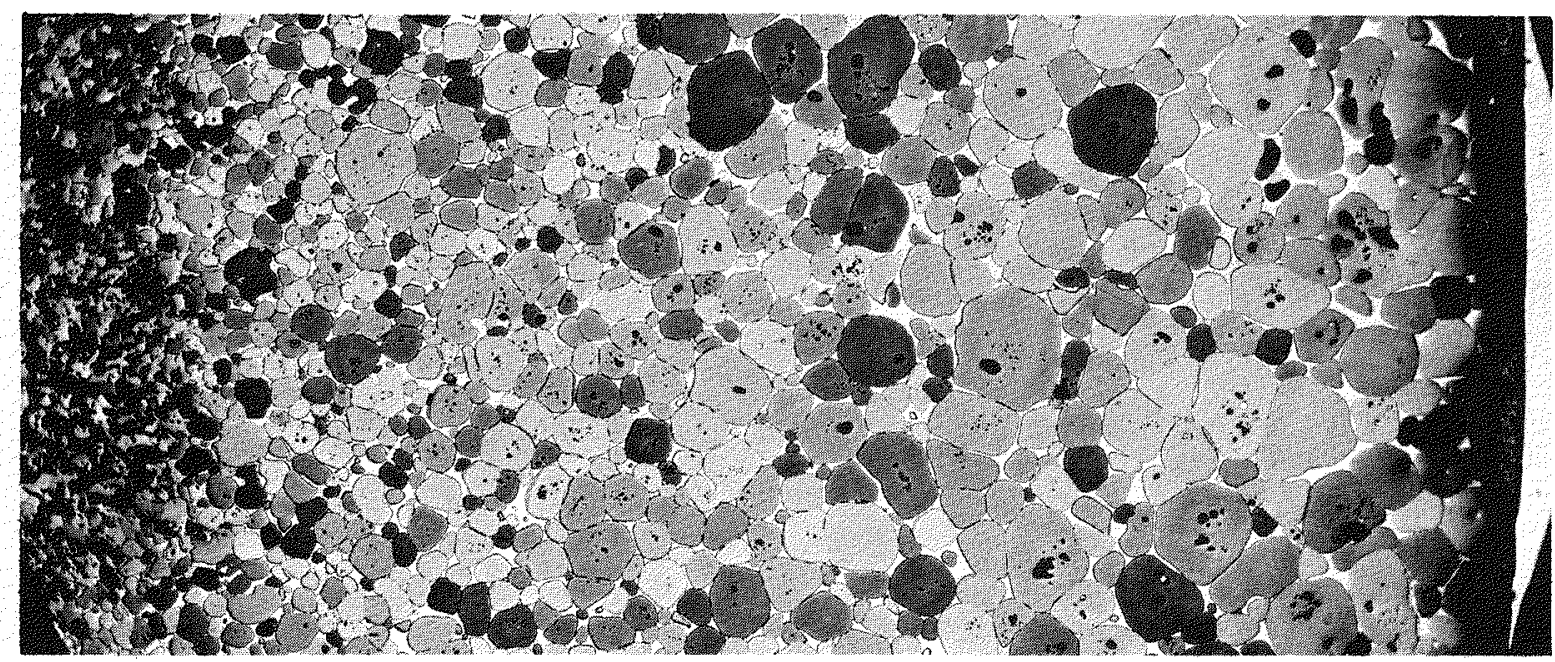

a. Outer Uranium-UN Zone of Pellet

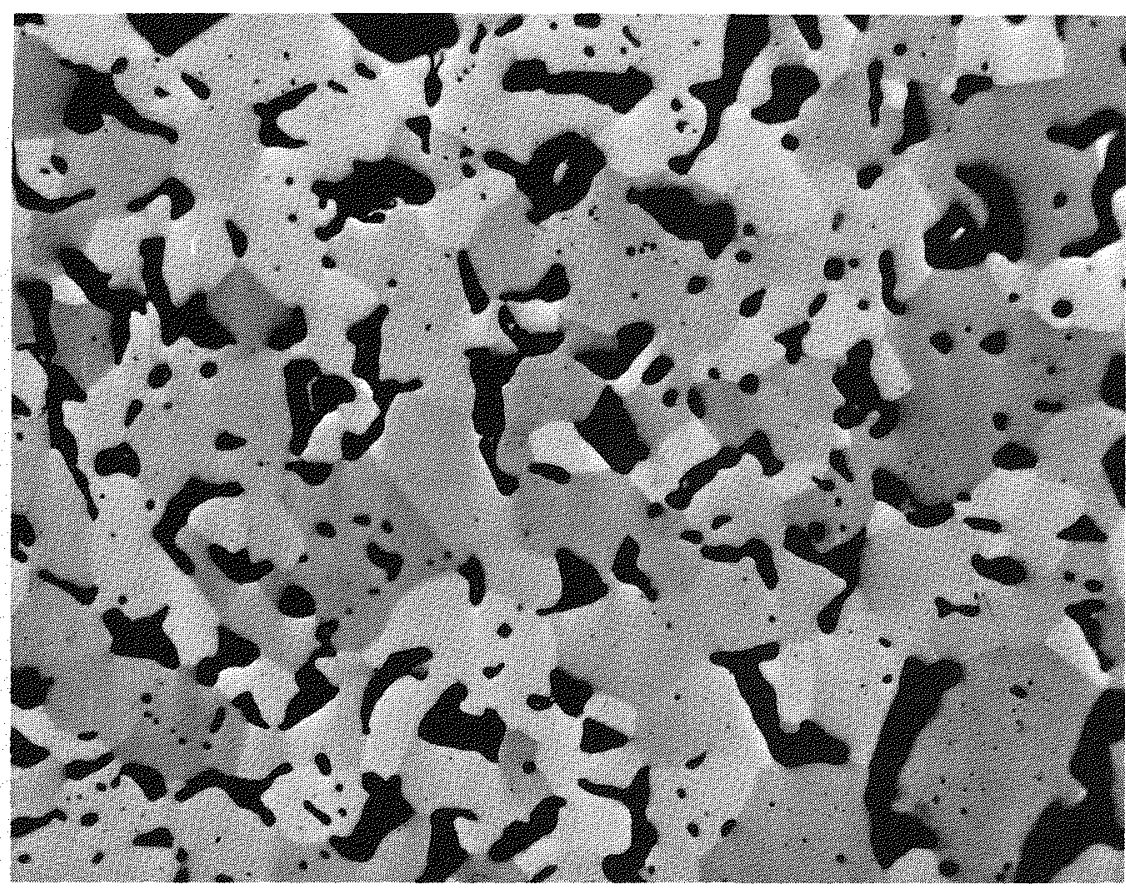

$500 \mathrm{X}$

Etchant: $30 \mathrm{~cm}^{3}$ lactic acid, $10 \mathrm{~cm}^{3} \mathrm{HNO}_{3}, 2$ drops $\mathrm{HF}$

RM21536

\section{b. Center of Pellet}

FIGURE 11. STRUCTURE OF UN PELLET VACUUM ANNEALED 65 HR AT $1650 \mathrm{C}$

Note decomposition proceeding from outer (right) edge of pellet in the top photomicrograph. No decomposition is evident in the core of the pellet shown in the bottom photomicrograph. 


\section{Procedures}

In the isostatic hot-pressing process, the UN powder was consolidated by one of the techniques discussed above and loaded into a tubular metal container. The container was sealed by electron-beam welding to produce a pressuretight, evacuated envelope. The assembly was then heated under inert-gas pressure in a high-temperature autoclave.

\section{Results}

At the working pressure of the autoclave, $10,000 \mathrm{psi}$, and for a normal $3 \mathrm{hr}$ at temperature, it was found that the maximum temperature of about $1540 \mathrm{C}$ would not completely densify the UN powder. Figure 12 shows a rough correlation between the temperature of pressing and the final density.

The data in Table 3 indicate that increased densification was not obtained by extending the pressing time beyond $3 \mathrm{hr}$. The hot-pressed UN was ground to rightcircular cylinders, from which the densities were measured.

TABLE 3. EFFECT OF PRESSING TIME ON THE DENSIT OF UN ISOSTATICALLY HOT PRESSED AT $1480 \mathrm{C}$ AND 10,000 PSI

\begin{tabular}{lc}
\hline Time & $\begin{array}{c}\text { Average Density(a), } \\
\text { g per cm }^{3}\end{array}$ \\
\hline 2 & 13.6 \\
3 & 13.9 \\
$4^{(a)}$ & 13.9 \\
\hline
\end{tabular}

(a) Average of at least two specimens for each time.

(b) Two 2-hr runs.

Several problems associated with the simultaneous densification and cladding of ceramic fuels by isostatic hot pressing have been previously enumerated. (19) These problems of indentation defects, wrinkling or pleating, warpage, cladding thickening, and dimensional control are similar for all materials and will not be discussed as problems observed as specific to UN.

The extensive transverse cracking in rod-type specimens that occurred when a strong bond was developed between the UN and the refractory-metal container was eliminated by inserting 0.015 to 0.030 -in. -thick cylindrical graphite sleeves between the UN powder and the refractory-metal can. The densified UN rod remained free to shrink away from the graphite during cooling and was thus easily removed as shown in Figure 13.

The depth of contamination of the UN by carbon appears metallographically no deeper than about $0.030 \mathrm{in}$. after a normal pressing cycle of $3 \mathrm{hr}$ at 10,000 psi and 1480 to $1540 \mathrm{C}$. A core was fractured, and two samples were analyzed. One sample contained only pieces having a surface exposed to the graphite; one sample was free of pieces with graphite-exposed surfaces. The sample exposed to graphite contained $4.76 \mathrm{w} / 0$ nitrogen and $1.17 \mathrm{w} / 0$ carbon. The "interior" sample had $5.46 \mathrm{w} / \mathrm{o}$ nitrogen and $0.075 \mathrm{w} / 0$ carbon. 


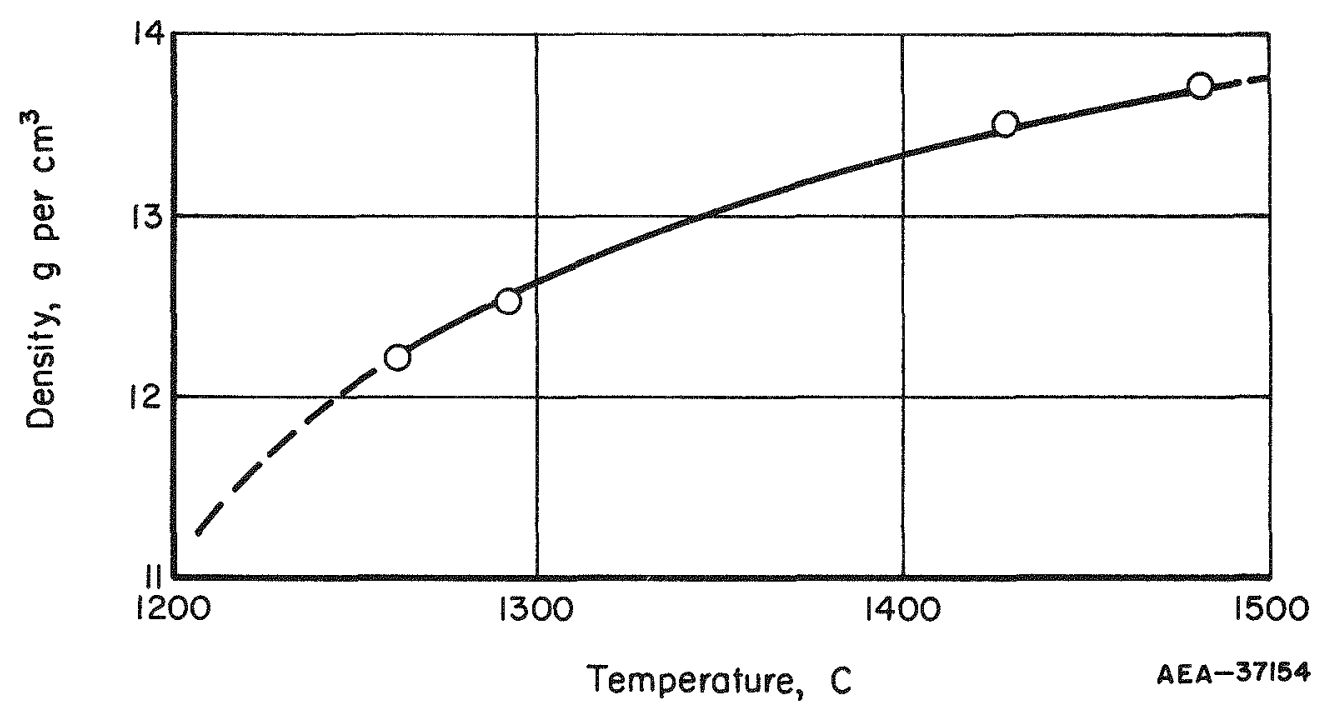

FIGURE 12. DENSITY OF UN VERSUS HOT-PRESSING TEMPERA TURE FOR MINUS 80-MESH POWDER
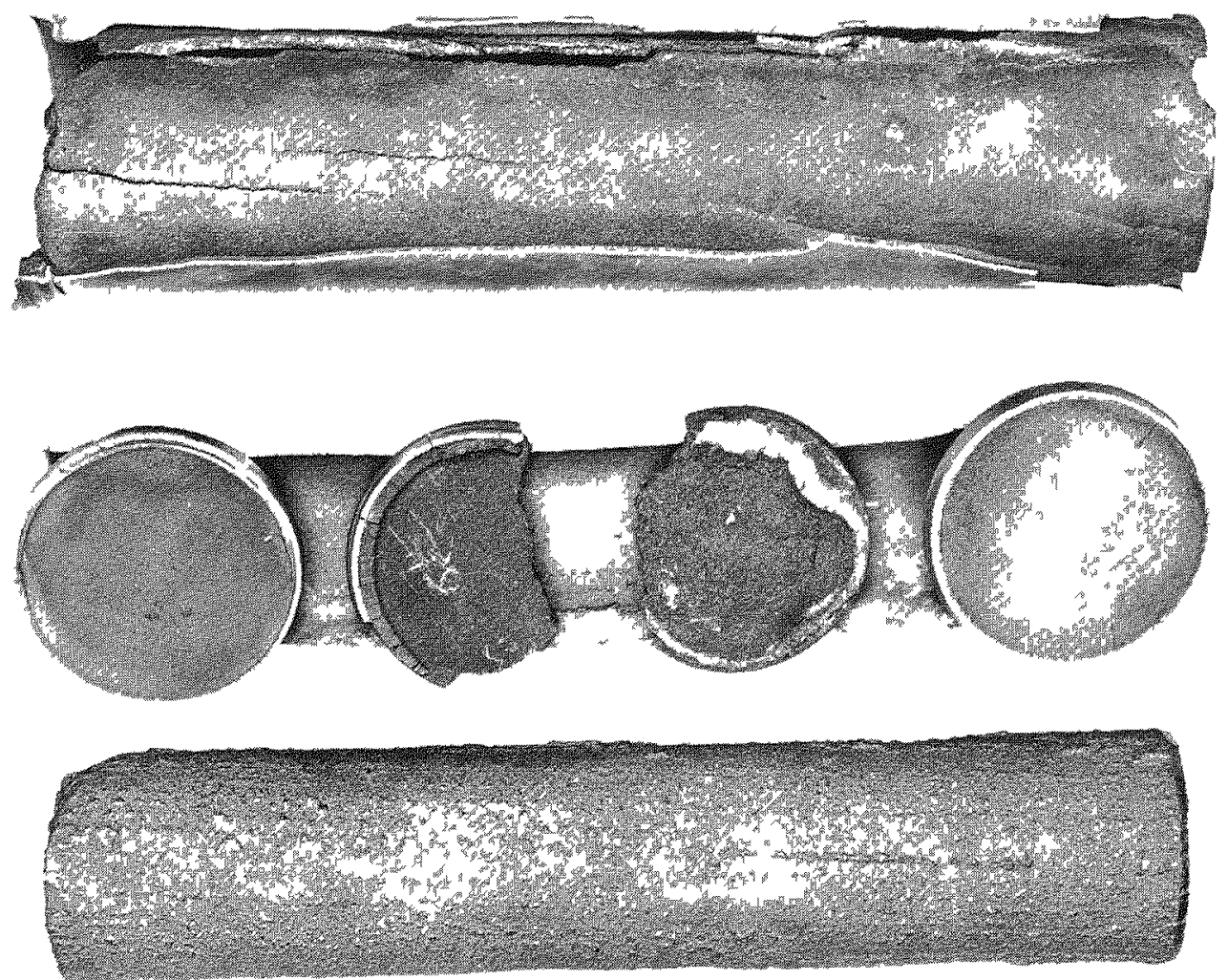

$1 \mathrm{X}$

FIGURE 13. ISOSTATICALLY HOT-PRESSED UN ROD AS REMOVED FROM THE HOT-PRESSING CONTAINER

Top: Graphite sleeve and tantalum can. The embrittled tantalum has been partially removed. Middle: Tantalum and graphite end plugs on part of the tantalum can. Bottom: UN rod, as removed. 
Carbon analyses as high as $0.07 \mathrm{w} / \mathrm{o}$ have been obtained on some UN samples even though pressed without the graphite sleeves.

Good control of the impurities in hot-pressed UN has not yet been established. The two major impurities are uranium oxide and a higher nitride, which normally appear interspersed throughout the UN matrix. Figure 14 shows these impurities. The relative amounts of the oxide and higher nitride can vary considerably. The amount of total oxide and higher nitride impurities can also vary considerably from specimen to specimen. Figure 15a shows hot-pressed UN virtually free of impurities while Figure 15b shows UN with a high concentration of impurities.

Identification of the oxide was based on its metallographic similarity to oxide films formed on UN rods, identified by X-ray diffraction. In the case of the higher nitride, it was possible to selectively etch out the oxide, leaving the higher nitride mechanically free. This was stripped out on adhesive, concentrated, and identified by $\mathrm{X}$-ray analysis as $\mathrm{U}_{2} \mathrm{~N}_{3}$.

\title{
Conclusions
}

The work showed that UN powder can be isostatically hot pressed to better than 95 per cent of the theoretical density. At temperatures of 1480 to $1540 \mathrm{C}$ under a pressure of $10,000 \mathrm{psi}$, the "end-point" density is practically achieved in $3 \mathrm{hr}$.

The major impurities in the hot-pressed product are uranium oxide and the higher nitride, $\mathrm{U}_{2} \mathrm{~N}_{3}$. Control over the amount of these impurities can probably be achieved with modifications in the handling and hot-pressing operations. Little difficulty has been encountered in preparing massive UN specimens by this technique. For example, samples $1 \mathrm{in}$. in diameter by $12 \mathrm{in}$, in length have been prepared with densities greater than 95 per cent of theoretical.

\section{PHYSICAL PROPERTIES OF UN}

\author{
Thermal Expansion
}

Expansion values are required for setting proper clearances in the mechanical assembly of a potential fuel element. The thermal-expansion test is also a widely used dynamic method for polymorphic-inversion investigations. Discontinuities in the linear expansion-temperature curves indicate changes in crystalline form. Therefore it was desirable to measure the thermal expansion of UN to the highest temperature allowed by available equipment.

\section{Procedures}

Apparatus and Methods. A sapphire assembly and a molybdenum-wound furnace were used to cover the temperature range from room to $1600 \mathrm{C}(2912 \mathrm{~F})$. The sapphire structure was calibrated with a molybdenum specimen which had been previously 

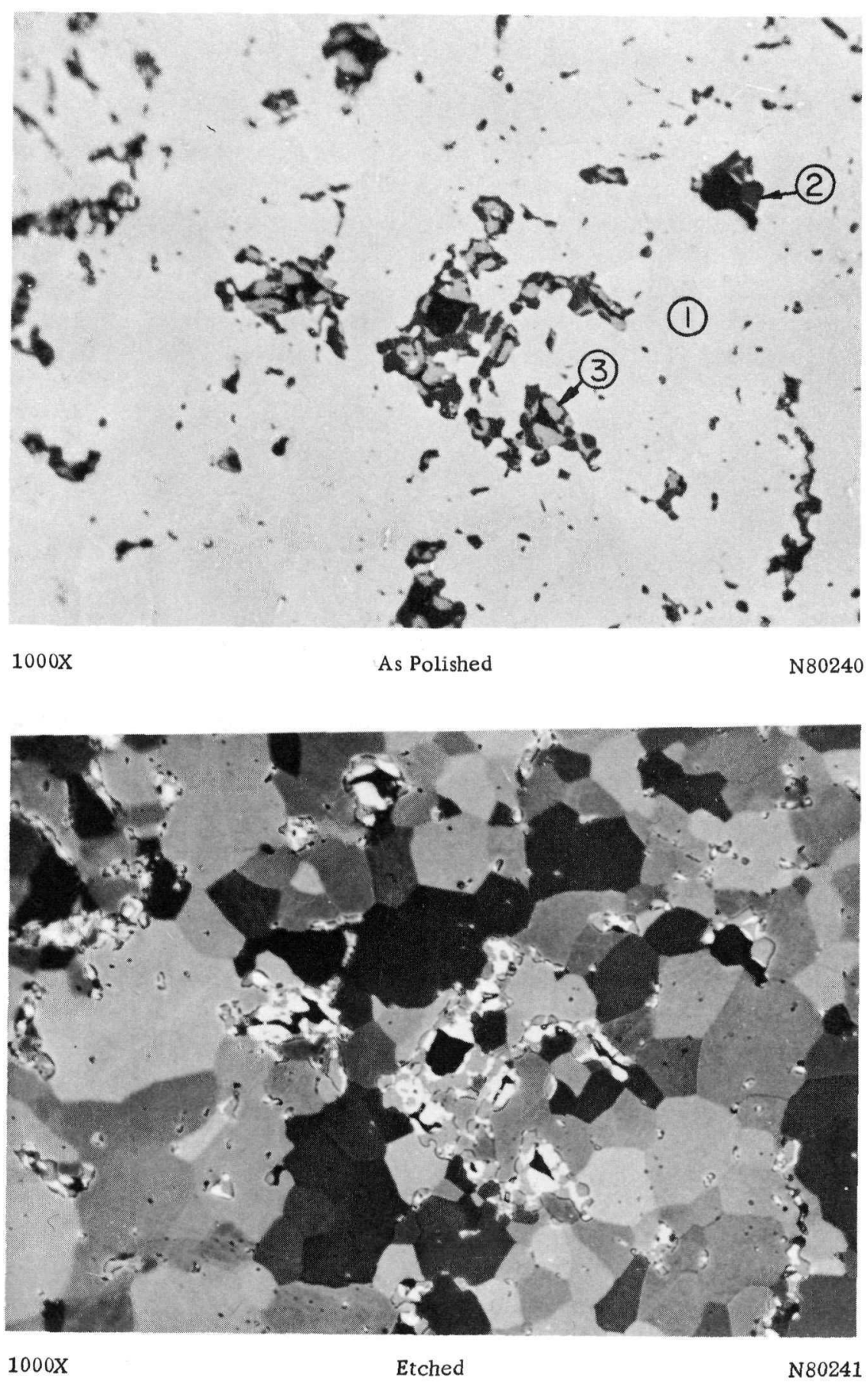

FIGURE 14. TY PICAL APPEARANCE OF OXIDE AND HIGHER NITRIDE IMPURITIES IN HOT -PRESSED URANIUM MONONITRIDE Both photomicrographs show the same field. UN (1), oxide (2), and $\mathrm{U}_{2} \mathrm{~N}_{3}(3)$ phases are visible. Etchant consisted of $30 \mathrm{~cm}^{3}$ of lactic acid, $10 \mathrm{~cm}^{3}$ of $\mathrm{HNO}_{3}$, and 2 drops of $\mathrm{HF}$. 


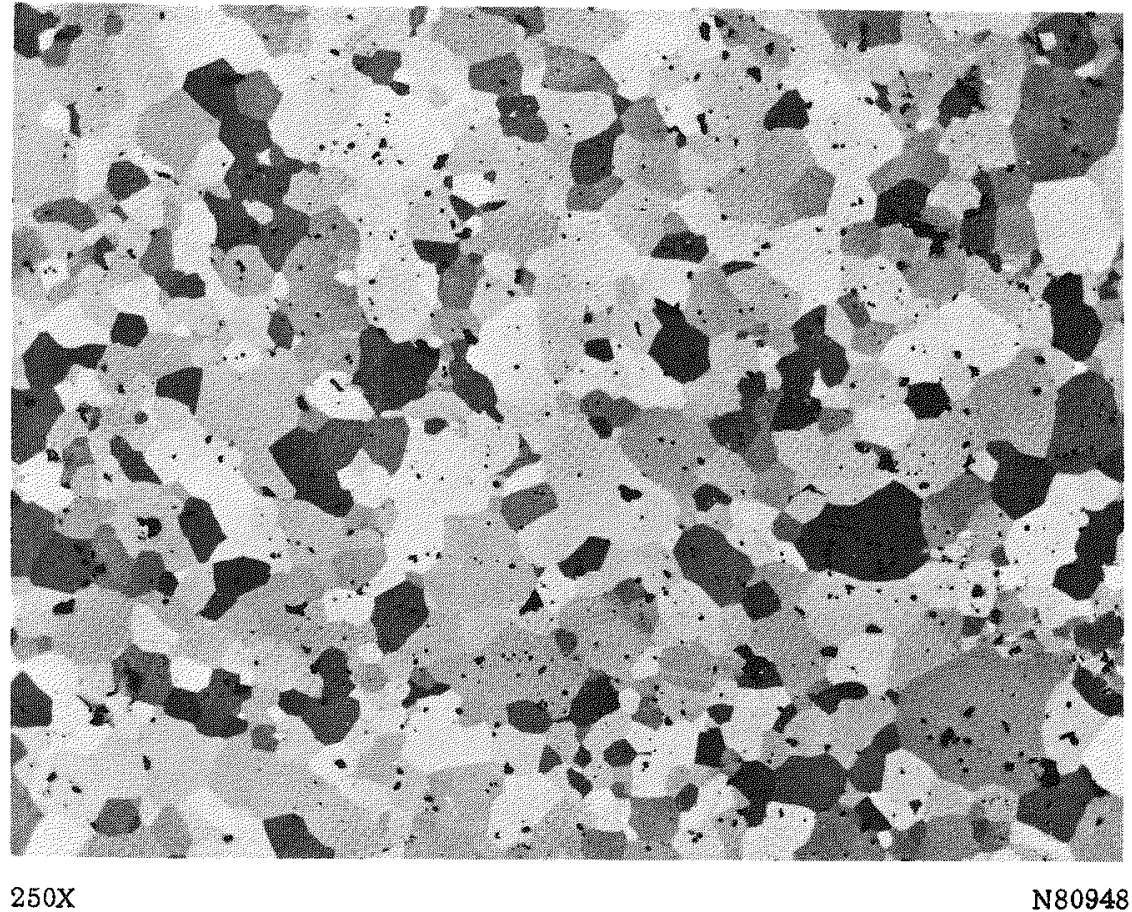

a. Microstructure of a Minimum of Visibly Detectable Impurities

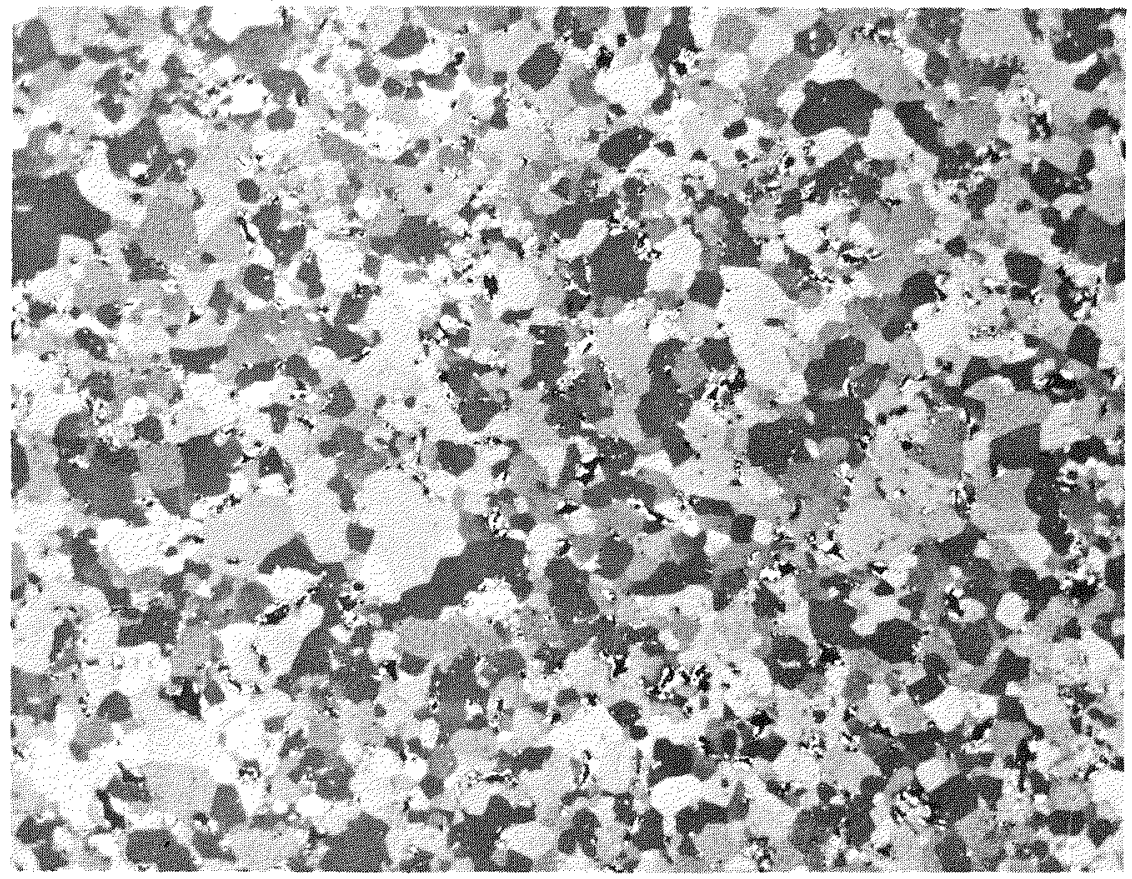

RM18650

b. Distribution of Oxide and Higher Nitride Impurities in UN With a High Percentage of These Impurities

FIGURE 15. VARIATION OF IMPURITY CONTENT IN HOT-PRESSED UN

Both specimens were etched with a mixture of $30 \mathrm{~cm}^{3}$

lactic acid, $10 \mathrm{~cm}^{3} \mathrm{HNO}_{3}$, and 2 drops $\mathrm{HF}$. 
measured in a quartz-tube dilatometer to $950 \mathrm{C}(1742 \mathrm{~F})$. Values from the calibrating run were also compared with literature values of molybdenum to $1650 \mathrm{C}$ (3002 F).

A recording dilatometer, which draws a dilation-yersus-temperature curve, measured the expansion. Mean coefficients of the linear expansion over selected temperature ranges were calculated from a curve of dilation per unit length versus temperature plotted after corrections for sapphire were made to the dilatometer curves.

Measurements were made both during heating and cooling to disclose any lack of reversibility of dilation characteristics. Heating and cooling rates were maintained within a maximum of $3 \mathrm{C}(5 \mathrm{~F})$ per min.

For temperature measurement a calibrated platinum-platinum $10 \mathrm{w} / \mathrm{o}$ rhodium thermocouple contained in morganite high-fired alumina two-hole tubing was employed. A pressure of $1 \times 10^{-4}$ torr was maintained within the system during the measurements.

From previous experience, the error of the thermal-expansion measurements is estimated to not exceed \pm 2 per cent.

Specimen. The UN rod specimen was fabricated by isostatic hot pressing of coldpressed-binderless UN powder pellets in a niobium container. The hot-pressing conditions were $3 \mathrm{hr}$ at $1480 \mathrm{C}$ under a 10,000-psi gas pressure. After removal of the container and grinding to size the rod was $0.343 \mathrm{in}$. in diameter by $2.211 \mathrm{in}$. long. With a weight of $46.845 \mathrm{~g}$, the bulk density of the rod was $14.0 \mathrm{~g}$ per $\mathrm{cm}^{3}$ or 97.6 per cent of the theoretical density of UN. Metallographic inspection of control material revealed that only very small amounts of impurity phases were present, concentrated in a few widely scattered small patches.

$\underline{\text { Results }}$

The specimen was given two thermal cycles from room temperature to $1600 \mathrm{C}$ (2912 F). The elongations measured are shown in Table 4 and plotted in Figure 16. An apparent growth of 0.098 per cent in the length of the specimen was measured.

As examined after the measurements, the specimen had a metallic gray surface except for about 1/4 in. at one end which had been inserted in a molybdenum holder. That end was dark gray to black and had not expanded to the 0.346-in. diameter measured on the rest of the specimen, an increase of 0.003 in. during the run. X-ray diffraction analysis indicated a $\mathrm{UO}_{2}$ layer on the specimen with a very thin film of molybdenum on the surface. The thickness of the oxide layer was measured on a metallographic sample as 0.004 to 0.005 in.

\section{Conclusions}

From the initial and final diameters and the oxide-layer thickness, the volume expansion which occurred in unit length of the cylindrical oxide shell was calculated to be between 34 and 44 per cent. The volume expansion of the solid according to the reaction $\mathrm{UN}+\mathrm{O}_{2} \longrightarrow \mathrm{UO}_{2}+1 / 2 \mathrm{~N}_{2}$ is approximately 40 per cent. Hence, the apparent growth of the specimen during thermal cycling appears to be a result of oxidation of the specimen rather than of a characteristic of the UN. 


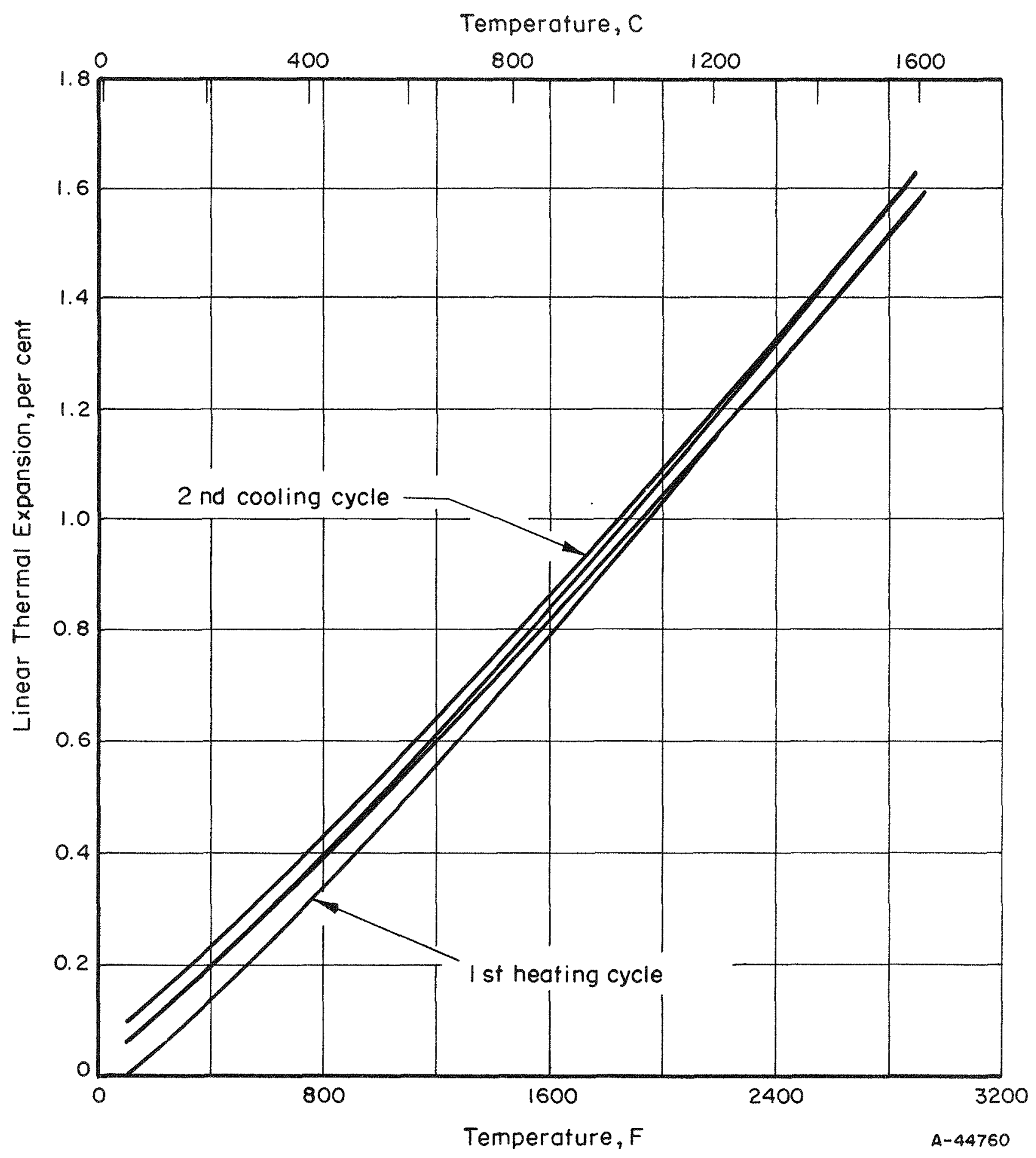

FIGURE 16. EFFECT OF TEMPERATURE ON LINEAR THERMAL EXPANSION OF URANIUM MONONITRIDE 
TABLE 4. LINEAR THERMAL-EXPANSION VALUES FOR UN

\begin{tabular}{|c|c|c|c|c|c|}
\hline \multirow{2}{*}{\multicolumn{2}{|c|}{ Temperature }} & \multicolumn{4}{|c|}{ Elongation, per cent } \\
\hline & & \multicolumn{2}{|c|}{ First Thermal Cycle } & \multicolumn{2}{|c|}{$\begin{array}{c}\begin{array}{c}\text { Second Thermal } \\
\text { Cycle }\end{array} \\
\end{array}$} \\
\hline $\mathrm{C}$ & $F$ & Heating & Cooling & Heating & $\overline{\text { Cooling }}$ \\
\hline 20 & 68 & $0.00_{0}$ & $0.06_{4}$ & $0.06_{4}$ & $0.09_{8}$ \\
\hline 100 & 212 & $0.06_{0}$ & $0.12_{2}$ & $0.12_{3}$ & $0.15_{6}$ \\
\hline 200 & 392 & $0.14_{1}$ & $0.20_{1}^{2}$ & $0.20_{2}$ & $0.23_{3}$ \\
\hline 300 & 572 & $0.22_{8}^{1}$ & $0.28_{4}$ & 0.288 & $0.31_{5}^{\circ}$ \\
\hline 400 & 752 & $0.32_{0}^{8}$ & $0.36_{2}^{4}$ & 0.377 & $0.40_{2}^{\circ}$ \\
\hline 500 & 932 & $0.41_{5}$ & $0.45_{2}$ & $0.47_{1}$ & $0.49_{4}$ \\
\hline 600 & 1112 & $0.51_{2}$ & 0.547 & $0.56_{8}$ & $0.59_{0}^{2}$ \\
\hline 700 & 1292 & $0.61_{2}$ & $0.64_{4}$ & $0.66_{8}$ & 0.689 \\
\hline 800 & 1472 & $0.71_{6}$ & $0.74_{4}$ & $0.77_{1}^{\circ}$ & $0.69_{1}^{\circ}$ \\
\hline 900 & 1652 & $0.82_{2}^{\circ}$ & $0.84_{6}^{4}$ & $0.87_{6}^{1}$ & $0.89_{5}^{1}$ \\
\hline 1000 & 1832 & $0.93_{0}$ & 0.949 & $0.97_{6}^{\circ}$ & 1.000 \\
\hline 1100 & 2012 & $1.03_{8}$ & $1.05_{5}$ & $1.09_{1}$ & $1.10_{6}$ \\
\hline 1200 & 2192 & 1.146 & $1.16_{2}$ & $1.20_{0}^{\circ}$ & $1.21_{3}$ \\
\hline 1300 & 2372 & $1.25_{5}^{\circ}$ & $1.27_{0}$ & $1.31_{0}$ & $1.32_{0}^{\circ}$ \\
\hline 1400 & 2552 & $1.36_{6}$ & $1.37_{8}$ & $1.42_{1}$ & $1.42_{8}$ \\
\hline 1500 & 2732 & $1.47 \mathrm{~g}$ & $1.48_{6}$ & $1.53_{2}$ & $1.53_{6}$ \\
\hline 1600 & 2912 & $1.59_{5}^{\circ}$ & $1.59_{5}^{\circ}$ & $1.64_{4}^{4}$ & $1.64_{4}$ \\
\hline
\end{tabular}

The calculated mean linear-thermal-expansion coefficients for each cycle are shown in Table 5. If it is as sumed that as much oxidation occurred on cooling as on heating, then the expansion coefficients measured during heating are high and those measured during cooling are low due to the over-all increase in the rod length as a result of $\mathrm{UO}_{2}$ formation on the ends of the specimen.

TABLE 5. MEAN LINEAR-THERMAL-EXPANSION COEFFICIENTS FOR UN

\begin{tabular}{|c|c|c|c|c|c|}
\hline \multirow{3}{*}{$\begin{array}{c}\text { Temperature } \\
\text { Range, } \\
\text { C }\end{array}$} & \multicolumn{5}{|c|}{$\begin{array}{c}\text { Mean Linear-Thermal-Expansion Coefficient Over } \\
\text { the Temperature Ranges Shown, } 10^{-6} \text { per } \mathrm{C}\end{array}$} \\
\hline & \multicolumn{2}{|c|}{ First Thermal Cycle } & \multicolumn{2}{|c|}{$\begin{array}{l}\text { Second Thermal } \\
\text { Cycle }\end{array}$} & \multirow[b]{2}{*}{ Average } \\
\hline & Heating & Cooling & Heating & $\overline{\text { Cooling }}$ & \\
\hline $20-100$ & 7.5 & 7.3 & 7.4 & 7.2 & 7.4 \\
\hline $20-200$ & 7.8 & 7.6 & 7.7 & 7.5 & 7.6 \\
\hline $20-300$ & 8.2 & 7.8 & 8.0 & 7.8 & 8.0 \\
\hline $20-400$ & 8.4 & 8.1 & 8.2 & 8.0 & 8.2 \\
\hline $20-500$ & 8.6 & 8.3 & 8.5 & 8.3 & 8.4 \\
\hline $20-600$ & 8.8 & 8.5 & 8.7 & 8.5 & 8.6 \\
\hline $20-700$ & 9.0 & 8.7 & 8.9 & 8.7 & 8.8 \\
\hline $20-800$ & 9.2 & 8.9 & 9.1 & 8.9 & 9.0 \\
\hline $20-900$ & 9.3 & 9.0 & 9.2 & 9.1 & 9.2 \\
\hline $20-1000$ & 9.5 & 9.1 & 9.3 & 9.2 & 9.3 \\
\hline $20-1100$ & 9.6 & 9.3 & 9.5 & 9.3 & 9.4 \\
\hline $20-1200$ & 9.7 & 9.4 & 9.6 & 9.5 & 9.5 \\
\hline $20-1300$ & 9.8 & 9.5 & 9.7 & 9.6 & 9.6 \\
\hline $20-1400$ & 9.9 & 9.6 & 9.8 & 9.6 & 9.7 \\
\hline $20-1500$ & 10.0 & 9.6 & 9.9 & 9.7 & 9.8 \\
\hline $20-1600$ & 10.1 & 9.7 & 10.0 & 9.8 & 9.9 \\
\hline
\end{tabular}


If one-half of the apparent permanent elongation of the first thermal cycle is subtracted from the 1.595 per cent measured during heating up to $1600 \mathrm{C}(2912 \mathrm{~F})$, then the mean expansion coefficient obtained is $9.89 \times 10^{-6}$ instead of $10.1 \times 10^{-6}$ per C. Further, the elongation at $1600 \mathrm{C}$ during the second thermal cycle is $1.644-0.064$ or 1.580 per

cent. Subtracting one-half of the apparent permanent elongation $\frac{0.098-0.064}{2}$ yields

1.563 per cent elongation or the same $9.89 \times 10^{-6}$ per $C$ mean expansion coefficient as calculated above for the first run. The average value of the four coefficients shown in Table 5 for the 20 to $1600 \mathrm{C}$ temperature range is $9.9 \times 10^{-6}$ per $\mathrm{C}$.

The average of the four values for each temperature range is plotted versus temperature in Figure 17. These average values should be within the \pm 2 per cent error of the measurements.

\section{Thermal Conductivity}

For a given heat flux, the thermal conductivity determines the temperature gradients which will be produced. It is also fundamental in fixing the resistance of a material to thermal stresses.

To evaluate the potential of UN as a nuclear fuel, it was thus desirable to measure its thermal conductivity to the temperature allowed by available equipment.

Procedures

Apparatus and Methods. The steady-heat-flow-type apparatus used for the thermalconductivity measurements was patterned after that described by Van Dusen and Shelton (20). Determinations were made by establishing a temperature gradient along the specimen and the Type 347 stainless steel reference standard which was fastened in good thermal contact to the cold end of the specimen. The temperature gradients were measured with 36-gage Chromel-Alumel thermocouples wedged in holes about 0.6 in. apart along the specimen; similar thermocouples were placed in the stainless steel standard. Heat flow was determined by the known thermal conductivity of the reference standard. Radial heat flow into, or away from, the specimen was minimized by bubbled alumina insulation and an encircling guard tube in which temperatures were adjusted, as nearly as possible, to match those in the specimen and standard at corresponding levels. The guard tube was evacuated to a pressure of about $2 \times 10^{-5}$ tor during the measurements. Experience with the apparatus has established that the relative error between the different runs does not exceed \pm 2 per cent. The chief uncertainty in the absolute error of the thermalconductivity values is the absolute thermal conductivity of the comparative standard. This is estimated to not exceed \pm 5 per cent.

Measurements were made in steps of decreasing as well as increasing temperatures to check on thermocouples and also to detect possible changes in the specimen. 


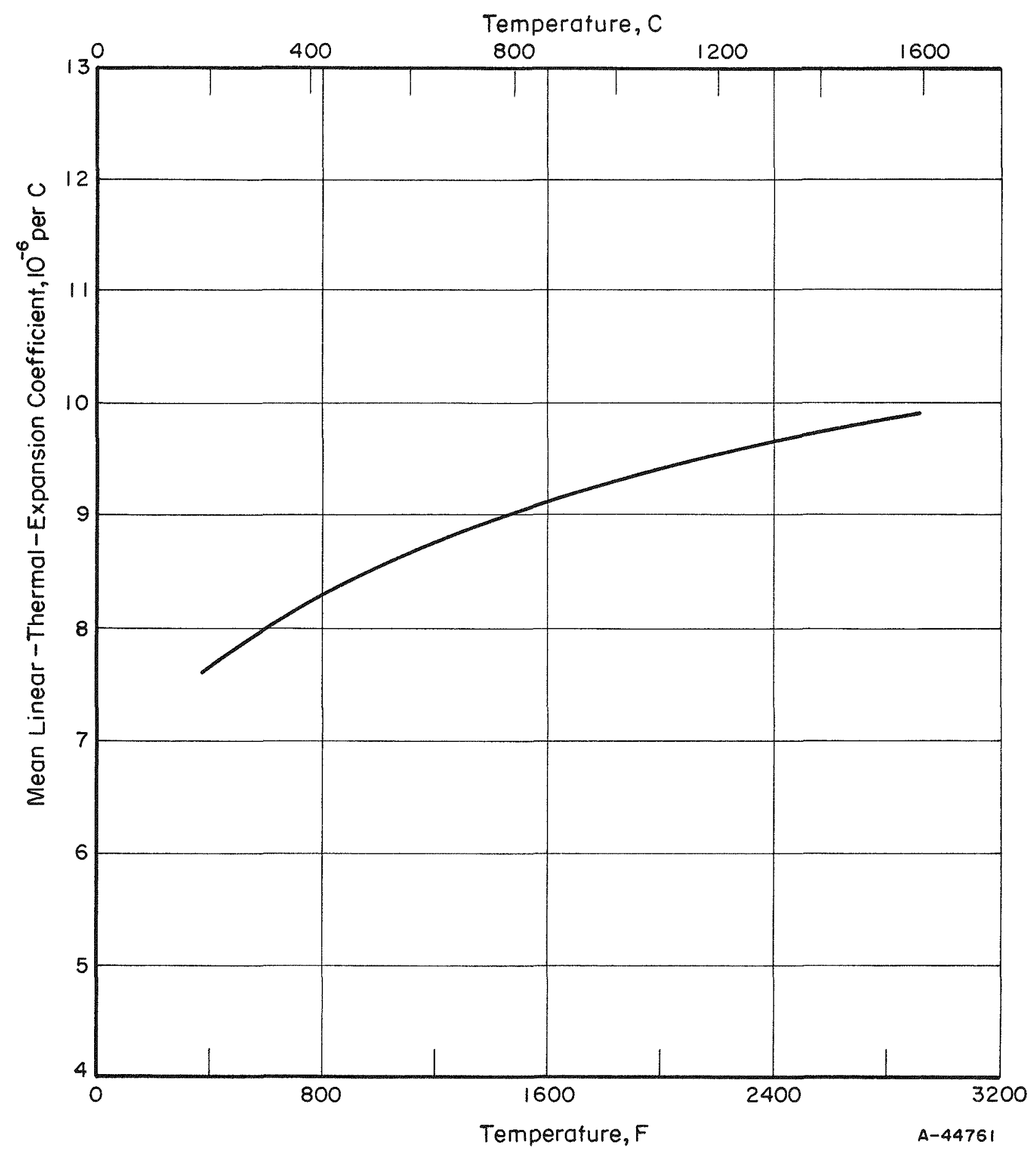

FIGURE 17. THERMAL-EXPANSION COEFFICIENT VERSUS TEMPERATURE FOR URANIUM MONONITRIDE 
Specimens. Measurements were made on two UN specimens. Powder pellets for Specimen TC-1-A were densified to about 87 per cent of the theoretical UN density by isostatic hot pressing in a stainless steel can for $3 \mathrm{hr}$ at $1290 \mathrm{C}(2350 \mathrm{~F})$ and 10,000 psi. This material was ground to remove the cladding, recanned in niobium, and isostatically hot pressed $3 \mathrm{hr}$ at $1480 \mathrm{C}(2700 \mathrm{~F})$ and $10,000 \mathrm{psi}$ to a bulk density of $14.0 \mathrm{~g} \mathrm{per} \mathrm{cm}^{3}$ ( 98 per cent of theoretical density).

In order to bond the specimen to the Type 347 stainless steel standard, the ends of the specimen were plated with nickel and copper and then tinned. The procedure for plating on uranium, which involves pickling in nitric acid, anodic etching in phosphorichydrochloric acid, pickling again in nitric acid followed by nickel plating, was used on the uranium nitride specimen. The nickel-plated specimen was copper-strike plated (cyanide bath) and tin plated (fluoborate bath).

The final specimen was approximately $0.83 \mathrm{in.}$ long and $0.58 \mathrm{in}$. in diameter.

Two approximately 0.030-in.-diameter thermocouple holes were ultrasonically drilled in the specimen. This permitted the calculation of only one thermal-conductivity value for each thermal equilibrium.

Specimen TC-177 was prepared by isostatically hot pressing UN powder pellets in a niobium can in two $2-\mathrm{hr}$ runs for a total of $4 \mathrm{hr}$ at $1480 \mathrm{C}(2700 \mathrm{~F})$ and 10,000 psi. After grinding to size the specimen was $0.360 \mathrm{in}$. in diameter and 2.50 in. long. The bulk density measured $13.9 \mathrm{~g}$ per $\mathrm{cm}^{3}$ or 97 per cent of theoretical UN density.

This specimen was bonded to the Type 347 stainless steel reference material by coating the ends of the specimen with soft solder with an ultrasonic soldering gun. This technique proved satisfactory.

Four thermocouple holes were ultrasonically drilled about 0.6 in. apart along the length of the specimen thus allowing three thermal-conductivity values to be calculated for each the rmal equilibrium.

$\underline{\text { Results }}$

The thermal-conductivity values as measured for Specimen TC-1-A are shown in Table 6 and for Specimen TC-177 in Table 7. These data are plotted as thermal

TABLE 6. EXPERIMENTAL THERMAL-CONDUCTIVITY VALUES FOR UN SPECIMEN TC-1-A

\begin{tabular}{|c|c|c|c|}
\hline \multirow{2}{*}{$\begin{array}{c}\text { Temperature, } \\
\text { C }\end{array}$} & \multicolumn{2}{|c|}{ Thermal Conductivity } & \multirow{2}{*}{$\begin{array}{c}\text { Sequence } \\
\text { of } \\
\text { Measurement }\end{array}$} \\
\hline & $W /(\mathrm{Cm})(\mathrm{C})$ & $\mathrm{Cal} /(\mathrm{Cm})(\mathrm{Sec})(\mathrm{C})$ & \\
\hline 198 & $0.15_{8}$ & 0.0378 & 1 \\
\hline 311 & $0.16_{5}$ & $0.039_{4}$ & 2 \\
\hline 381 & $0.17_{4}^{\circ}$ & $0.041_{6}$ & 3 \\
\hline 476 & 0.187 & 0.0447 & 7 \\
\hline 571 & $0.19_{4}$ & $0.046_{4}$ & 4 \\
\hline 672 & 0.199 & 0.0475 & 6 \\
\hline 747 & 0.200 & $0.047_{8}$ & 5 \\
\hline 800 & $0.20 \mathrm{~g}$ & $0.049_{9}$ & 8 \\
\hline
\end{tabular}


TABLE 7. EXPERIMENTAL THERMAL-CONDUCTIVITY VALUES FOR UN SPECIMEN TC -177

\begin{tabular}{|c|c|c|c|c|c|c|}
\hline \multirow{3}{*}{$\begin{array}{c}\text { Temperature, } \\
\text { C }\end{array}$} & \multicolumn{4}{|c|}{ Thermal Conductivity } & \multirow{2}{*}{\multicolumn{2}{|c|}{$\begin{array}{c}\text { Sequence of } \\
\text { Measurement }\end{array}$}} \\
\hline & \multicolumn{2}{|c|}{$\mathrm{W} /(\mathrm{Cm})(\mathrm{C})$} & \multicolumn{2}{|c|}{$\mathrm{Cal} /(\mathrm{Cm})(\mathrm{Sec})(\mathrm{C})$} & & \\
\hline & First Run & Second Run & First Run & Second Run & First Run & $\overline{\text { Second Run }}$ \\
\hline 181 & $0.17_{8}$ & -- & $0.042_{5}$ & -- & 1 & $-\infty$ \\
\hline 199 & $0.14_{6}$ & - & $0.034_{8}$ & - & 1 & $-\infty$ \\
\hline 210 & 0.172 & -- & $0.041_{1}$ & - & 7 & - \\
\hline 217 & $0.16_{0}^{2}$ & - & $0.038_{2}^{+}$ & - & 1 & -- \\
\hline 228 & 0.187 & - & $0.044_{6}$ & - & 7 & -- \\
\hline 248 & $0.15_{4}$ & -- & 0.0367 & -- & 7 & $-\infty$ \\
\hline 320 & $0.17_{3}$ & -- & $0.041_{3}$ & $\cdots$ & 6 & -- \\
\hline 350 & $0.16 \mathrm{~g}$ & - & $0.040_{3}$ & - & 2 & $-\infty$ \\
\hline 351 & $0.19_{2}$ & - & $0.045_{8}$ & -- & 6 & $-\infty$ \\
\hline 382 & $0.17_{0}$ & -- & $0.040_{6}$ & -- & 6 & -- \\
\hline 384 & $0.20_{9}$ & -- & $0.049_{8}$ & -- & 2 & $-\infty$ \\
\hline 415 & 0.197 & -- & $0.047_{0}$ & -- & 2 & -- \\
\hline 460 & 0.183 & $\cdots$ & $0.043_{6}$ & - & 5 & -- \\
\hline 505 & $0.18_{4}$ & $\cdots$ & 0.0439 & -- & 3 & -- \\
\hline 506 & $0.20_{6}$ & - & $0.049_{2}$ & -. & 5 & -- \\
\hline 526 & $\cdots$ & $0.19_{2}$ & -- & $0.045_{8}$ & -- & 1 \\
\hline 550 & $0.19_{0}$ & - & $0.045_{3}$ & - & 5 & -- \\
\hline 556 & $0.20_{5}$ & - & $0.048_{9}$ & -- & 3 & -- \\
\hline 558 & -- & $0.19_{8}$ & $-{ }^{y}$ & $0.047_{3}$ & $\ldots$ & 4 \\
\hline 580 & -- & 0.197 & - & $0.047_{1}$ & - & 1 \\
\hline 605 & $0.20_{0}$ & -- & 0.0477 & -- & 3 & -- \\
\hline 612 & -- & $0.20_{5}$ & -- & $0.048 \mathrm{~g}$ & - & 1 \\
\hline 631 & -- & $0.20_{8}$ & -- & 0.0497 & - & 1 \\
\hline 639 & $0.19_{2}$ & - & $0.045_{1}$ & .- & 4 & -- \\
\hline $672^{(a)}$ & -. & $0.159^{(a)}$ & $-{ }^{\perp}$ & - & - & 4 \\
\hline 705 & 0.212 & -- & $0.050_{6}$ & -- & 4 & $-\infty$ \\
\hline 769 & $0.19_{8}$ & -- & $0.047_{3}$ & - & 4 & $-\infty$ \\
\hline 824 & $-\infty$ & $0.22_{0}$ & -- & $0.052_{6}$ & $\cdots$ & 2 \\
\hline 882 & - & $0.24_{4}$ & $-\infty$ & $0.058_{3}$ & - & 3 \\
\hline 905 & - & $0.23_{5}$ & -- & $0.056_{1}$ & - & 2 \\
\hline 963 & -- & $0.25_{4}$ & - & $0.060_{7}^{2}$ & -- & 3 \\
\hline 985 & - & $0.22_{9}^{4}$ & $\cdots$ & $0.054_{6}$ & -. & 2 \\
\hline 1042 & $-\infty$ & $0.26_{3}$ & $-\infty$ & $0.062_{8}$ & -- & 3 \\
\hline
\end{tabular}

(a) Rejected value. The thermocouple had deteriorated after having been to about $1150 \mathrm{C}$. 
conductivity versus temperature in Figure 18 and 19, respectively. Neither of the curves has been adjusted to 100 per cent density.

As shown by the curves in Figures 18 and 19, the measured thermal conductivity for Specimen TC-1-A fell within the 10 per cent scatter observed in Specimen TC-177. While there seemed to be some real difference in the thermal conductivity of the two specimens, gross differences are not readily apparent. Typical microstructures of the specimens after the measuring process, which is a week-long heat treatment varying along the specimen length, are shown in Figure 20. Chemical and vacuum-fusion analyses of samples from the center of each specimen are tabulated below.

\begin{tabular}{|c|c|c|c|c|}
\hline \multirow[b]{2}{*}{ Specimen } & \multicolumn{4}{|c|}{ Analysis, w/o } \\
\hline & Uranium & Nitrogen & Carbon & Oxygen \\
\hline & 94.3 & 5.32 & 0.034 & 0.047 \\
\hline $\mathrm{TC}-177$ & 94.57 & 5.38 & 0.046 & -- \\
\hline
\end{tabular}

Sectioning of Specimen TC-1-A after the measurements revealed cracks near one bond, as shown in Figure 21. The measurements did not seem to be significantly affected by these cracks, possibly because they did not separate the thermocouple holes. Some of the reaction products noted at the UN-nickel interface were detected in the cracks, suggesting that the cracks were present during the measurement.

The surface of Specimen TC-177 was oxidized during the measuring process, but the depth of the affected zone was only about $0.004 \mathrm{in.}$ A transverse section is shown in Figure 22.

The temperature gradient along the specimens during the measurements was roughly $100 \mathrm{C}$ per in. The gradient could not be held constant at each thermal equilibrium. Only one thermal-conductivity value was obtained at each thermal equilibrium for Specimen TC-1-A, whereas three thermal-conductivity values at each thermal equilibrium were obtained for Specimen TC-177. It was noted that the thermal-conductivity values measured at the hotter end of the specimen at each thermal equilibrium were consistently lower than those measured at the middle of the specimen.

\section{Conclusions}

The measurements showed that UN exhibits metallic characteristics with respect to thermal conductivity. The thermal conductivity increases with temperature. An approximate empirical relation is

$$
\mathrm{K}=0.31 \times 10^{-4} \mathrm{~T}+0.029,
$$

where $\mathrm{K}$ is thermal conductivity in $\mathrm{cal} /(\mathrm{sec})(\mathrm{cm})(\mathrm{C})$ and $\mathrm{T}$ is temperature in $\mathrm{C}$. The extrapolated room-temperature value is about $0.030 \mathrm{cal} /(\mathrm{sec})(\mathrm{cm})(\mathrm{C})$. At $1000 \mathrm{C}$ the conductivity is about $0.060 \mathrm{cal} /(\mathrm{sec})(\mathrm{cm})(\mathrm{C})$.

While the theoretical Weidemann-Franz relation has been calculated for pure metals, applying this relationship to the measured thermal and electrical conductivities of UN suggests that about 50 to 60 per cent of the observed thermal conductivity in UN is due to electrons. About the same fraction has been observed for $\mathrm{Z}_{\mathrm{rC}}$. $^{(21)}$ The apparent electronic contributions are plotted in Figures 18 and 19 as the line $k_{e}$. 


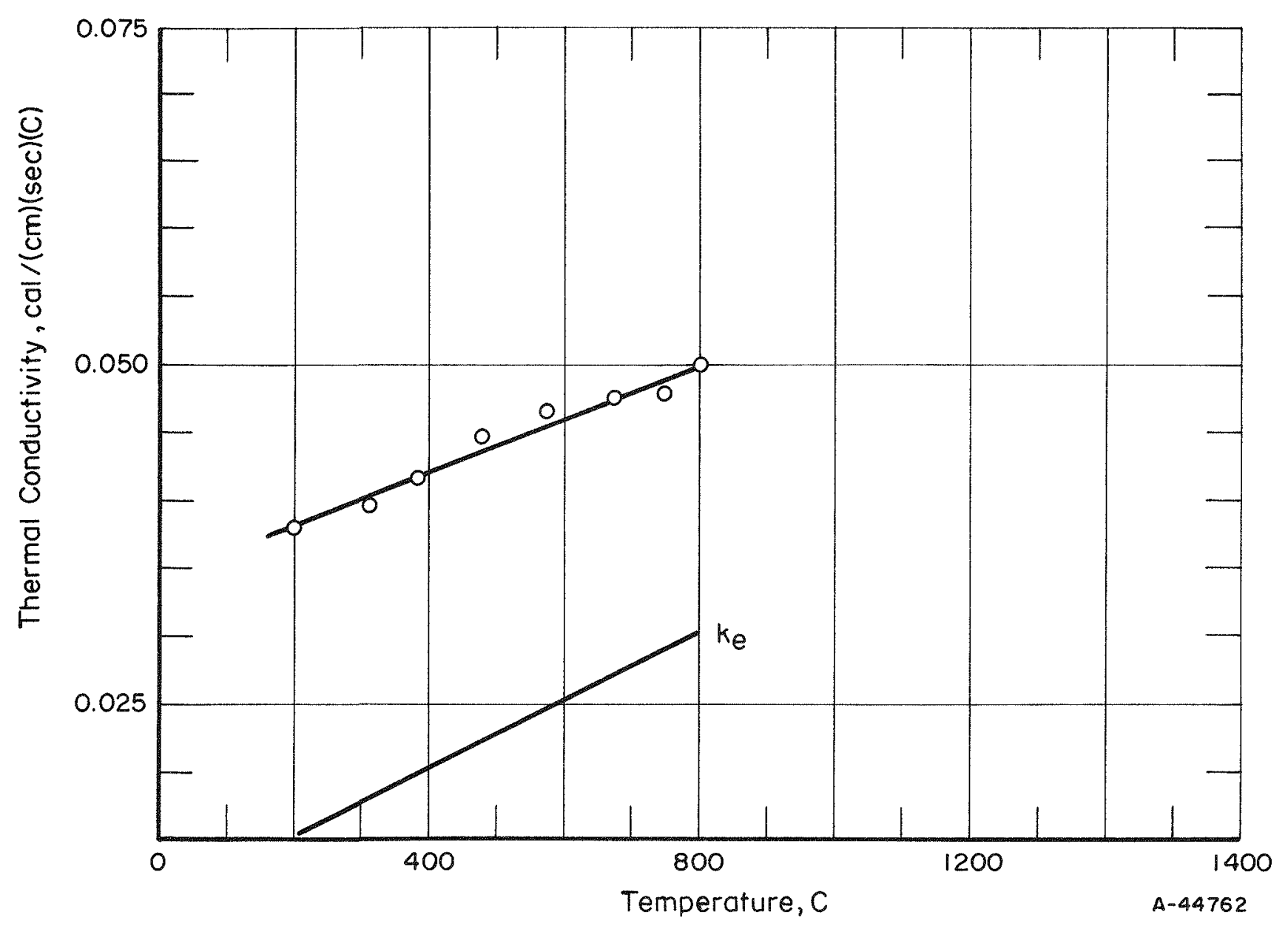

FIGURE 18. THERMAI CONDUCTIVITY OF URANIUM MONONITRIDE SPECIMEN TC-1-A. 


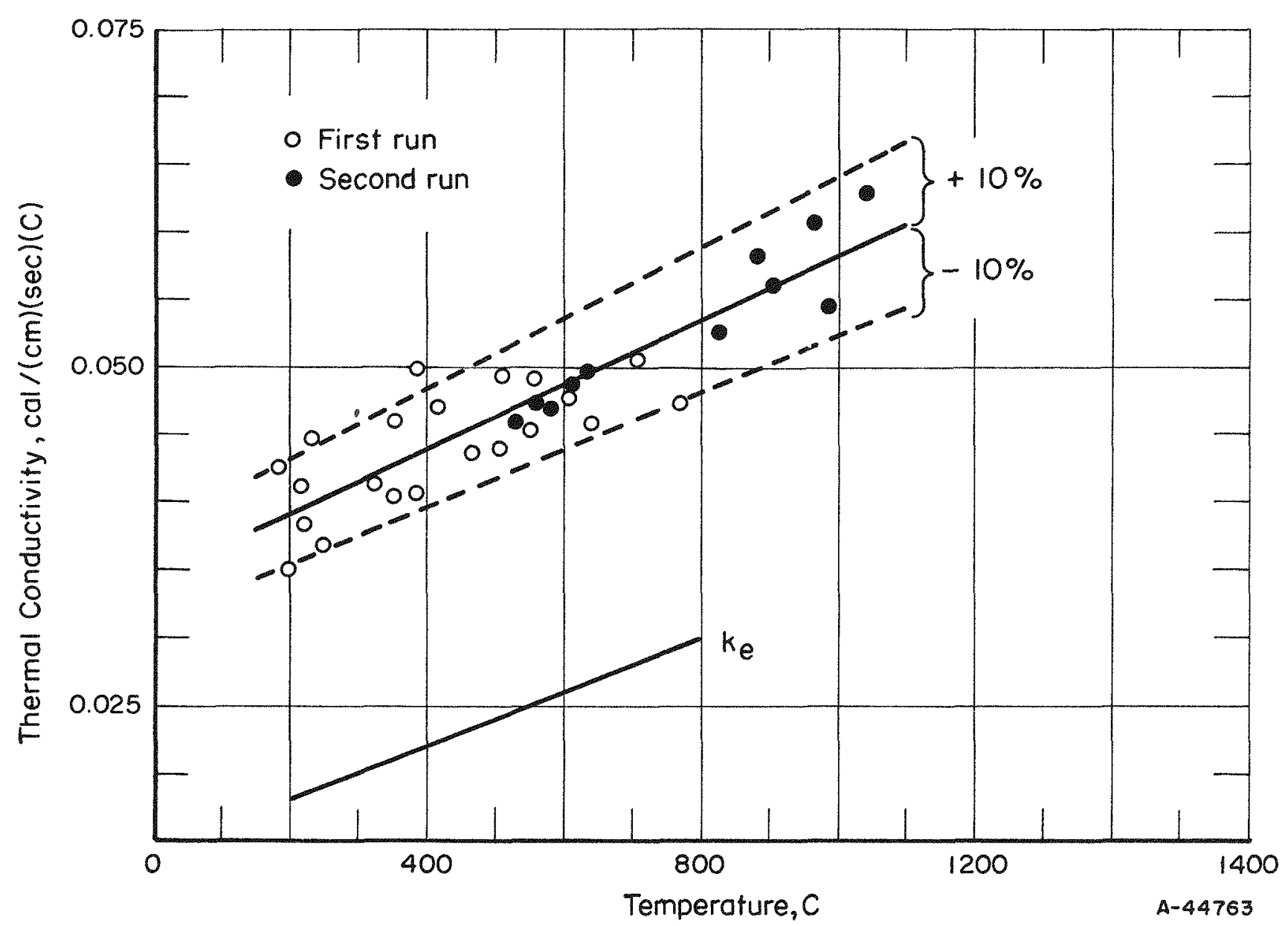

FIGURE 19. THERMAL CONDUCTIVITY OF URANIUM MONONITRIDE SPECIMEN TC-177 


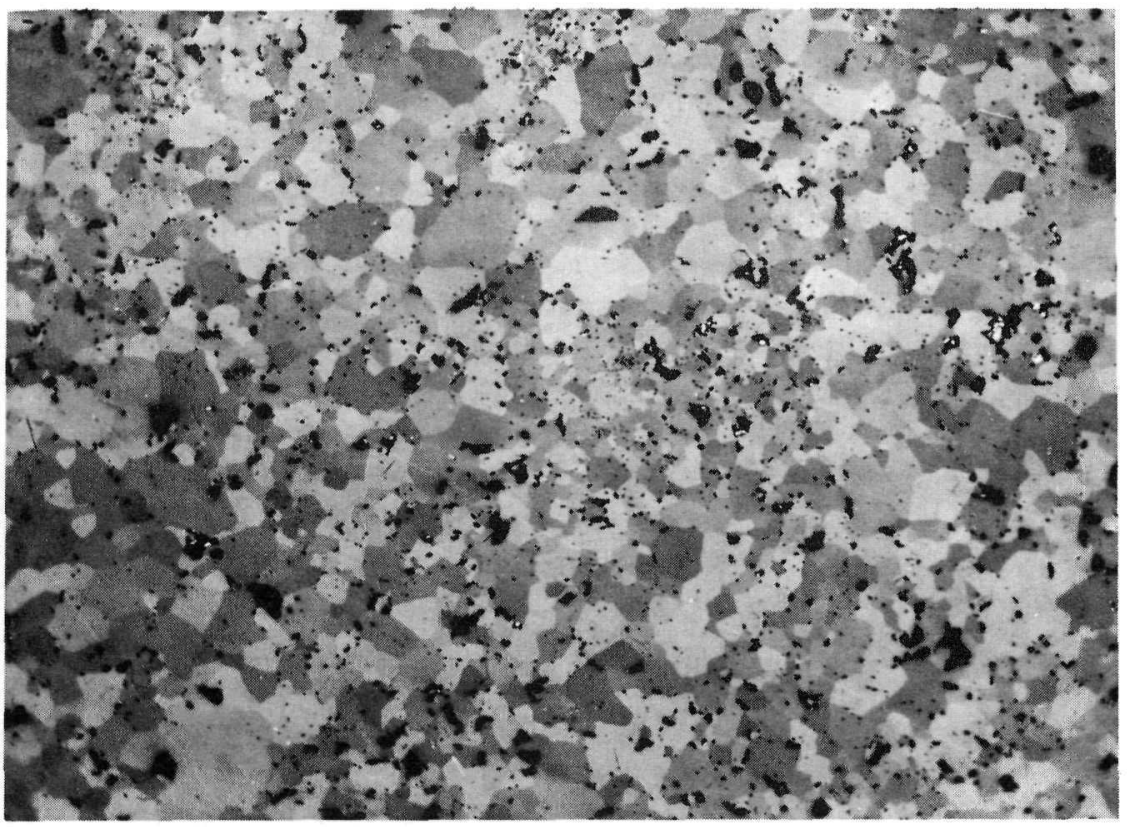

$250 \mathrm{X}$

N80947

Etchant: $30 \mathrm{~cm}^{3}$ lactic acid, $10 \mathrm{~cm}^{3} \mathrm{HNO}_{3}, 2$ drops $\mathrm{HF}$

a. Specimen TC-1-A

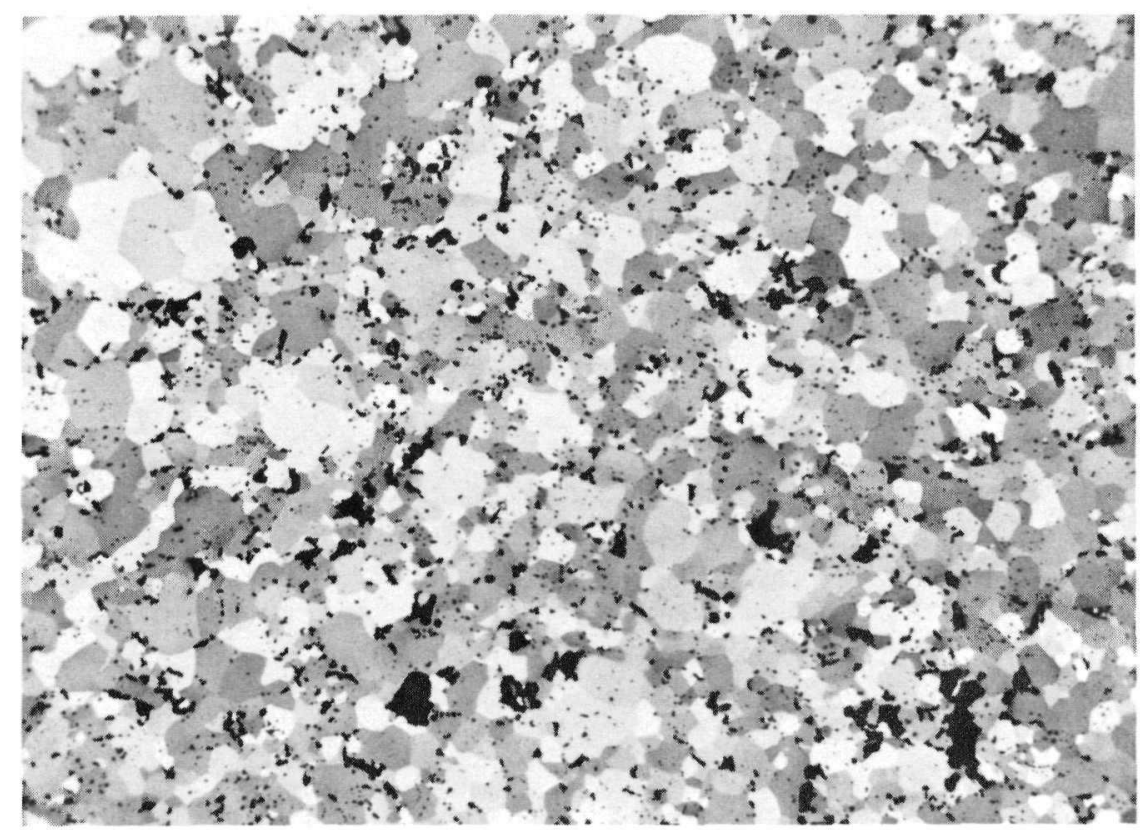

$250 \mathrm{X}$

Etchant: $50 \mathrm{~cm}^{3}$ lactic acid, $30 \mathrm{~cm}^{3} \mathrm{HNO}_{3}, 3$ drops $\mathrm{HF}$

RM22753

b. Specimen TC -177

FIGURE 20. MICROSTRUCTURES OF UN THERMAL-CONDUCTIVITY SPECIMENS AFTER THE MEASURING PROCESS

Darks areas are voids. Light-etching inclusions are probably $\mathrm{UO}_{2}$, some of which may have been removed during etching. 


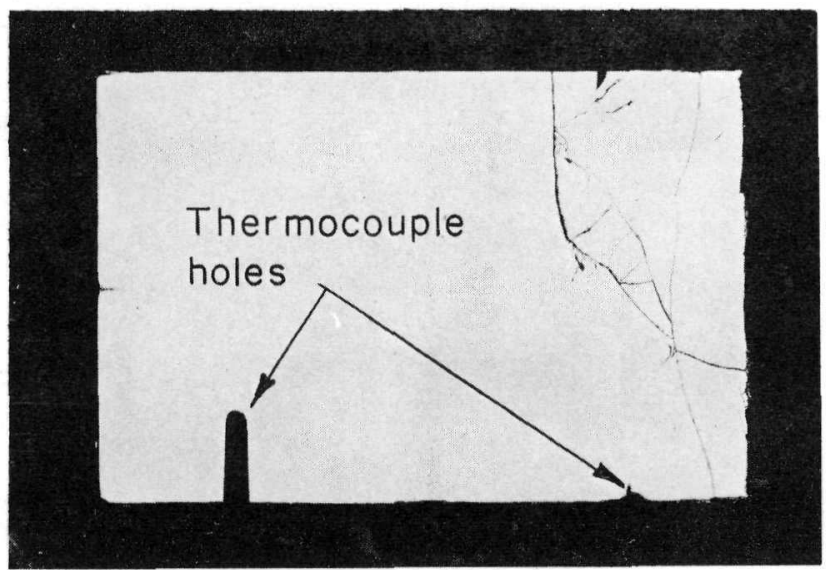

$3 \mathrm{X}$

As Polished

N80975

FIGURE 21. LONGITUDINAL SECTION OF UN THERMAL-CONDUCTIVITY SPECIMEN TC-1-A AFTER THE MEASURING PROCESS

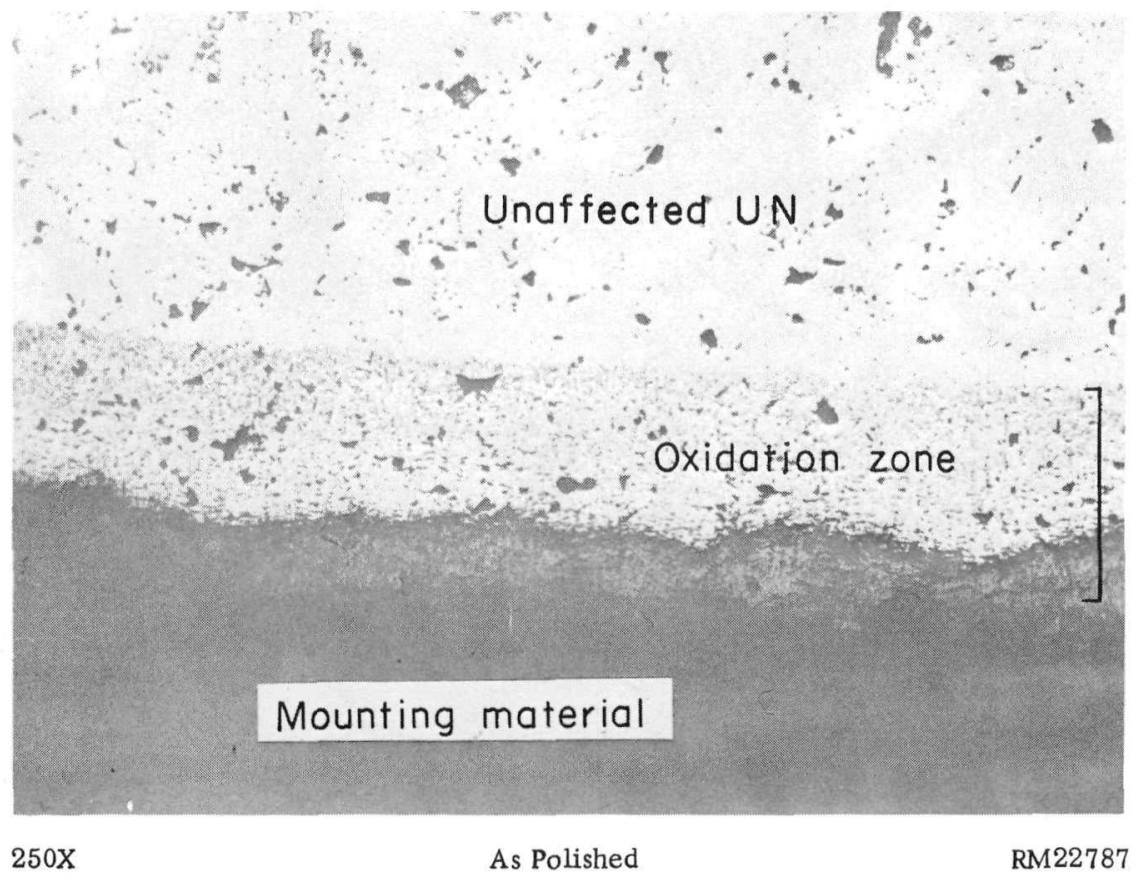

FIGURE 22. OXIDATION OF THE SURFACE OF SPECIMEN TC-177 WHICH OCCURRED DURING THE THERMAL-CONDUCTIVITY MEASURING PROCESS 
Perhaps the best qualitative over-all measure of the heat-transfer characteristic of a potential reactor fuel material is that of the integrated thermal conductivity, proposed by Lewis. (22) It has been used by Canadian workers $(23,24)$ in evaluating fuel performance, and has been extended by Robertson (25), who showed its applicability for inpile use. The integrated thermal conductivity may be looked upon simply as a measure of the thermal conductivity weighted over the whole temperature range.

Estimates of the integrated thermal conductivity of $\mathrm{UO}_{2}$ and $\mathrm{UN}$ are tabulated below.

\begin{tabular}{|c|c|c|}
\hline \multicolumn{3}{|c|}{$C^{T_{m}}$} \\
\hline Material & $\mathrm{T}_{\mathrm{s}}(275 \mathrm{C})$ & Ratio \\
\hline $\mathrm{UO}_{2}$ & 70 & 1 \\
\hline $\begin{array}{l}\text { UN (Specimen } \\
\text { TC-1-A) }\end{array}$ & 498 & 7 \\
\hline $\begin{array}{l}\text { UN (Specimen } \\
\text { TC-177) }\end{array}$ & 580 & 8. 4 \\
\hline
\end{tabular}

The lower limit of the integral is taken at $275 \mathrm{C}$, a reasonable reactor coolant temperature. The upper limit is the melting point of the material, but because of the uncertainty in extrapolating the data to the melting point, a constant conductivity was as sumed for UN above $800 \mathrm{C}$ in the case of Specimen TC-1-A and above $1200 \mathrm{C}$ in the case of Specimen TC-177.

It thus appears that UN is about seven to eight times more effective than $\mathrm{UO}_{2}$ in transferring heat.

\section{$\underline{\text { Specific Heat }}$}

The specific heat and the closely related enthalpy are essentially a measure of the internal energy of a material. They give directly the energies involved in phase changes if they occur. Specific-heat values are required for many thermodynamic and other calculations. Consequently, it was desirable to measure the specific heat of UN to as high a temperature as possible, consistent with available apparatus and compatibility with canning materials.

$\underline{\text { Procedures }}$

Apparatus and Method. Enthalpy measurements were made in an ice calorimeter similar to that described by Ginnings and Corruccini. (26) In the ice calorimeter, heat from the specimen melts ice that is in equilibrium with water in a closed system. The resulting volume change is determined by means of mercury which makes up the volume change. The ratio of heat input to the mass of mercury making up the volume change is a constant which is used as a calibration factor to obtain heat inputs to the calorimeter. 
There is no temperature change in the calorimeter since all heat transfer occurs at the ice point.

The specimen was dropped at a number of temperatures over the range $0 \mathrm{C}(32 \mathrm{~F})$ and $1140 \mathrm{C}(2090 \mathrm{~F})$. The enthalpy [total heat content per gram between the specified temperature and $0 \mathrm{C}(32 \mathrm{~F})]$ was determined. Error in the measured values was estimated not to exceed \pm 2 per cent.

Two methods were used to determine the specific heat. In one, the enthalpyversus-temperature curve was plotted and slopes of this curve, determined at interpolated temperatures, gave instantaneous specific heats at these temperatures.

The other method, which avoids drawing tangents to the curve and which provides a more conveniently usable relationship in calculations involving the specific heat, consisted of fitting the enthalpy data to an equation of the general form.

$$
\mathrm{H}_{\mathrm{T}}-\mathrm{H}_{273}=\mathrm{aT}+\mathrm{bT}^{2}+\mathrm{cT}^{-1}+\mathrm{d}
$$

by multiple regression correlation on a digital computer program. Differentiation of this equation then gave the specific heat as a function of temperature in the general form

$$
C_{p}=a+b T+c T^{-2}
$$

over the range 0 to $1150 \mathrm{C}(273$ to $1423 \mathrm{~K})$.

Specimen. The specimen consisted of a few dense pieces of UN which were broken from a rod that had been isostatically hot pressed $2 \mathrm{hr}$ at $1540 \mathrm{C}(2800 \mathrm{~F})$ and 10,000 psi in a tantalum can. Chemical analysis of this material indicated a substoichiometric nitrogen content ( $5.24 \mathrm{w} / \mathrm{o}$ nitrogen), but metallographic examination of the material revealed only single-phase UN with a small amount of widely scattered $\mathrm{UO}_{2}$ impurity. The UN pieces were encapsulated in Type 304 stainless steel tubing $1 / 2$ in. in OD with a $0.020-i n$. wall. End plugs were sealed by electron-beam welding, thus sealing the specimen in a partial vacuum.

$\underline{\text { Results }}$

The experimentally determined enthalpy values are shown in Table 8 . The multiple regression correlation of the data gave the equation:

$$
\mathrm{H}_{\mathrm{T}}-\mathrm{H}_{273}=13.3211 \mathrm{~T}+5.9302 \times 10^{-4} \mathrm{~T}^{2}+2.1025 \times 10^{5} \mathrm{~T}^{-1}-4437.23 .
$$

A comparison of the experimental enthalpy values with those calculated by the equation is shown in Table 9.

Differentiation of the above enthalpy equation gave the following $C_{p}$ equation for $\mathrm{UN}(\mathrm{c})$ in cal per $\mathrm{g}$ mole:

$$
C_{p}=13.32+1.19 \times 10^{-3} \mathrm{~T}-2.10 \times 10^{5} \mathrm{~T}^{-2}(273 \text { to } 1423 \mathrm{~K}) .
$$

Specific-heat values calculated from this equation are compared with the interpolated values obtained by the method of tangents in Table 10. These values are also compared in Figure 23, which is a plot of the instantaneous specific heat versus temperature. 
TABLE 8. EXPERIMENTAL ENTHALPY VALUES FOR A UN SPECIMEN

\begin{tabular}{rrrr}
\hline \hline & Temperature & K & $\begin{array}{r}\text { Enthalpy, } \mathrm{H}_{\mathrm{T}}^{\circ} \\
\text { Btu per } \mathrm{lb}\end{array}$ \\
\hline & $\mathrm{C}$ & & \\
32 & 0 & 273 & 0 \\
183 & 84 & 357 & 7.13 \\
190 & 88 & 381 & 7.44 \\
359 & 182 & 455 & 15.82 \\
717 & 381 & 654 & 34.44 \\
1050 & 566 & 839 & 52.69 \\
1414 & 768 & 1041 & 73.70 \\
1418 & 770 & 1043 & 73.41 \\
1776 & 969 & 1242 & 94.50 \\
2089 & 1143 & 1416 & 112.4 \\
\hline \hline
\end{tabular}

TABLE 9. ENTHALPY OF UN(c) ABOVE $273 \mathrm{~K}$

\begin{tabular}{cccc}
\hline & Enthalpy, $\mathrm{H}_{\mathrm{T}}-\mathrm{H}_{273}$, cal per g mole \\
\cline { 2 - 4 } $\begin{array}{c}\text { Temperature, } \\
\mathrm{K}\end{array}$ & $\begin{array}{c}\text { Experimental } \\
\text { Value }\end{array}$ & $\begin{array}{c}\text { Calculated } \\
\text { From Derived } \\
\text { Equation }\end{array}$ & $\begin{array}{c}\text { Deviation } \\
\text { (Calculated } \\
\text { minus } \\
\text { Experimental) }\end{array}$ \\
\hline & 0 & 14 & +14 \\
273 & 998 & 983 & -15 \\
357 & 1,042 & 1,029 & -13 \\
381 & 2,216 & 2,205 & -11 \\
455 & 4,823 & 4,845 & +22 \\
654 & 7,378 & 7,402 & +24 \\
839 & 10,320 & 10,272 & -48 \\
1041 & 10,280 & 10,305 & +25 \\
1043 & 13,220 & 13,190 & -30 \\
1242 & 15,740 & 15,760 & +20 \\
1416 & & & $\Sigma=-12$ \\
& & & \\
\hline \hline
\end{tabular}

TABLE 10. INSTANTANEOUS SPECIFIC HEAT OF UN

\begin{tabular}{|c|c|c|c|c|c|}
\hline \multirow{2}{*}{\multicolumn{3}{|c|}{ Temperature }} & \multicolumn{3}{|c|}{ Specific Heat } \\
\hline & & & \multirow{2}{*}{$\begin{array}{c}\text { Interpolated, } \\
\text { cal } /(\mathrm{g})(\mathrm{C}) \\
\end{array}$} & \multirow{2}{*}{$\begin{array}{l}\text { Calculated, } \\
\text { cal } /(\mathrm{g})(\mathrm{C})\end{array}$} & \multirow{2}{*}{$\begin{array}{c}\text { Calculated, } \\
\text { cal } /(\mathrm{g} \text { mole })(\mathrm{C})\end{array}$} \\
\hline$F$ & C & $\mathrm{K}$ & & & \\
\hline 32 & 0 & 273 & 0.045 & 0.0430 & 10.83 \\
\hline 300 & 149 & 422 & 0.050 & 0.0502 & 12.64 \\
\hline 600 & 316 & 589 & 0.053 & 0.0533 & 13.42 \\
\hline 900 & 482 & 755 & 0.055 & 0.0550 & 13.85 \\
\hline 1200 & 649 & 922 & 0.055 & 0.0562 & 14.17 \\
\hline 1500 & 816 & 1089 & 0.056 & 0.0573 & 14.44 \\
\hline 1800 & 982 & 1255 & 0.058 & 0.0582 & 14.68 \\
\hline 2100 & 1149 & 1422 & 0.059 & 0.0592 & 14.91 \\
\hline
\end{tabular}




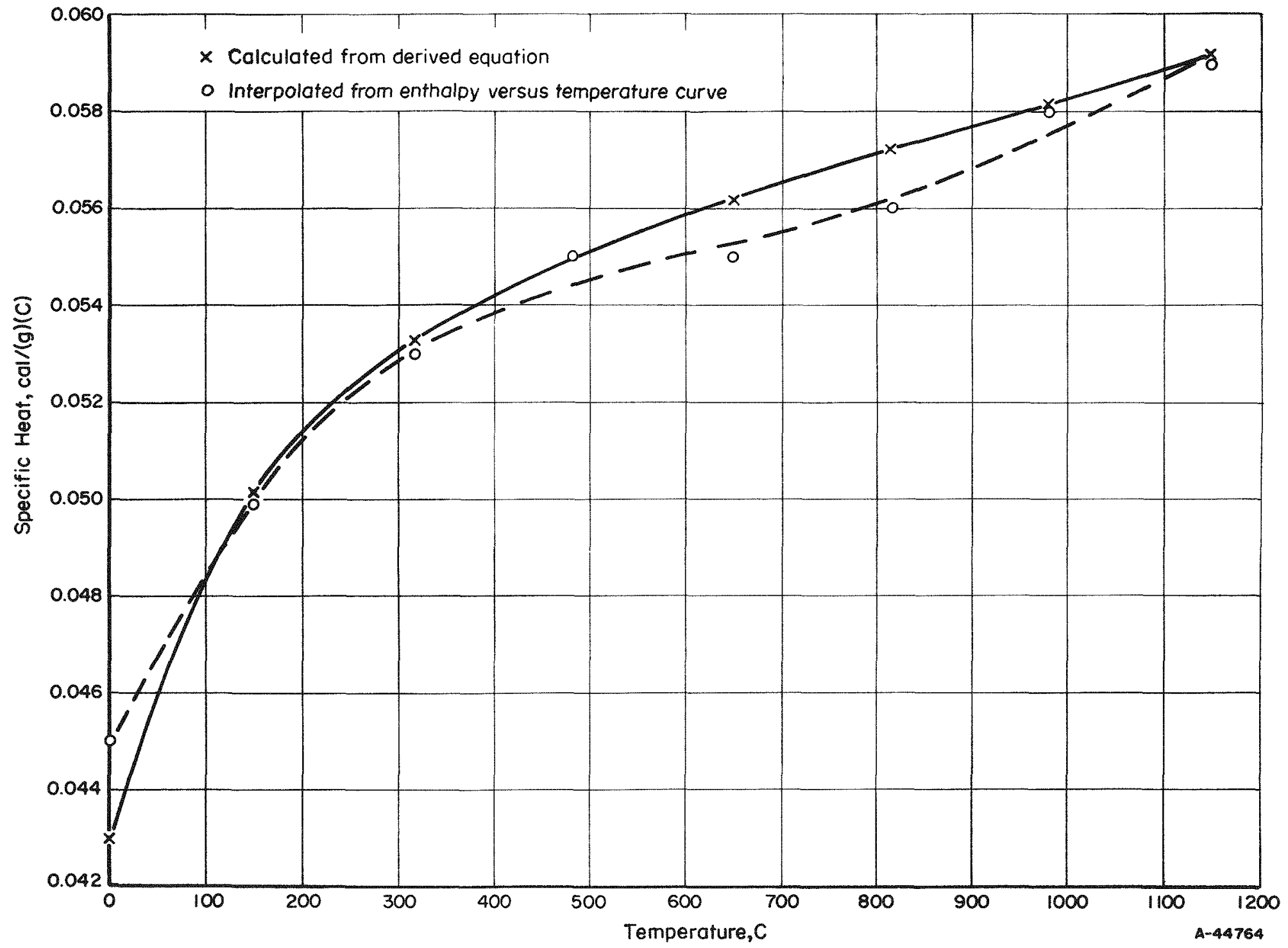

FIGURE 23. INSTANTANEOUS SPECIFIC HEAT OF UN VERSUS TEMPERATURE 


\section{Conclusions}

The derived curve for the specific heat of UN as a function of temperature shows the specific heat falling more rapidly near $0 \mathrm{C}$ than indicated by the method of tangents. It also smooths out an S-shaped portion of the curve between 500 and $1000 \mathrm{C}$ that is indicated by the method of tangents.

The method of tangents can allow the investigator to more fully weigh each experimental data point to prevent forcing the data to a standard curve, especially in the lowtemperature sharply breaking portion. However, the relatively few experimental enthalpy measurements increase the difficulty in accurately plotting the enthalpy-versustemperature curve as well as determining the actual slopes.

The S-shaped portion in the specific heat-temperature curve between 500 and $1000 \mathrm{C}$ as shown by the method of tangents could be an indication that an electronic contribution to the specific heat of UN starts at about 700 to $800 \mathrm{C}$. Because of the meager amount of data, this is very speculative. The derived equation which shows the specific heat of UN as a function of temperature according to the relationship

$$
C_{p}=13.32+1.19 \times 10^{-3} \mathrm{~T}-2.10 \times 10^{5} \mathrm{~T}^{-2}(273 \text { to } 1423 \mathrm{~K})
$$

appears to be a good practical representation of the available data over the temperature range indicated. Some very recent results at Battelle indicate that the specific heat of UN may be increasing with temperature somewhat faster than indicated by the equation, being as much as 6.5 to 7 per cent higher than the calculated value at $1650 \mathrm{C} \mathrm{(3000} \mathrm{F).}$

\section{Electrical Conductivity}

The electrical conductivity of solids at elevated temperatures is dependent not only on the temperature, but also on the chemical and physical composition. The electrical conductivity is a readily measurable property which can give some insight into the nature of a material.

Procedures

Apparatus and Methods. Electrical-resistivity measurements were made concurrently with the thermal-conductivity measurements by a voltage-drop method in which a direct current was passed through the specimen and a series-connected standard resistance. One leg of each of the Chromel-Alumel thermocouples served as a potential probe. The electrical resistivity was calculated from the voltage drop along a measured length of the specimen, the voltage drop across the standard resistor, and the specimen dimensions. The electrical conductivity is thus obtained as the reciprocal of electrical resistivity.

Although the components of the electrical-resistivity measuring system are of high accuracy, several factors can introduce errors up to \pm 5 per cent (estimated). The temperature gradient in the specimen and apparatus as well as the probe contact resistance cause the major uncertainties. 
Specimens. The specimens on which the electrical resistivity was measured were the same specimens on which the thermal conductivity was measured, TC-1-A and TC- 177 .

Results

The experimentally measured values of electrical resistivity for both UN specimens are shown in Table 11 and plotted as a function of temperature in Figures 2.4 and 25.

TABLE 11. EXPERIMENTAL ELECTRICAL-RESISTIVITY VALUES FOR URANIUM MONONITRIDE

\begin{tabular}{|c|c|c|c|}
\hline \multirow{2}{*}{$\begin{array}{c}\text { Temperature, } \\
\text { C }\end{array}$} & \multicolumn{2}{|c|}{ Electrical Resistivity, $10^{6} \mathrm{ohm}-\mathrm{cm}$} & \multirow{2}{*}{$\begin{array}{c}\text { Sequence of } \\
\text { Measurement }\end{array}$} \\
\hline & Specimen TC-1-A & Specimen TC-177 & \\
\hline 198 & 176 & $-\infty$ & 1 \\
\hline 199 & -- & 161 & 1 (b) \\
\hline 217 & - & 157 & $1(b)$ \\
\hline 248 & - & 162 & $7(b)$ \\
\hline 311 & 184 & -- & 2 \\
\hline 381 & 189 & $m$ & 3 \\
\hline 382 & -- & 170 & $6^{(b)}$ \\
\hline 460 & -- & 186 & $5(b)$ \\
\hline 476 & 197 & -- & 7 \\
\hline 505 & $-\infty$ & 185 & $3(b)$ \\
\hline 506 & -- & 187 & $5(b)$ \\
\hline 526 & -- & $172(c)$ & $1(c)$ \\
\hline 550 & -- & 184 & $5(b)$ \\
\hline 556 & -- & 187 & $3(b)$ \\
\hline 571 & 199 & $\cdots$ & 4 \\
\hline 580 & -- & $168(c)$ & $1(c)$ \\
\hline 605 & -. & 184 & $3^{(b)}$ \\
\hline 631 & $\ldots$ & 166 (c) & $1(\mathrm{c})$ \\
\hline 639 & $-\infty$ & 204 & $4(b)$ \\
\hline 672 & 204 & -- & 6 \\
\hline 705 & -- & 205 & ${ }_{4}^{(b)}$ \\
\hline 747 & 207 & -- & \\
\hline 769 & -. & 204 & ${ }_{4}(b)$ \\
\hline 800 & 208 & - & 8 \\
\hline 824 & - & $190(c)$ & $2(c)$ \\
\hline 905 & - & $180^{(c)}$ & $2(c)$ \\
\hline 985 & -- & $182^{(c)}$ & ${ }_{2}(c)$ \\
\hline
\end{tabular}

(a) Corresponds to the same equilibrium at which thermal-conductivity values were obtained.

(b) From the first run on Specimen TC-177.

(c) From the second run on Specimen TC-177.

The values obtained in a second run on Specimen TC-177 are shown in Figure 25 but are rejected as having a high probability of error because of loss of probe contact. As discussed in the thermal-conductivity results, Specimen TC-177 was oxidized to a depth of about $0.004 \mathrm{in}$. some time during the measuring process. Because the probes (thermocouples) for the second-run measurements were reinserted into the thermocouple holes drilled prior to the first run, it is highly probable that an oxide film of different conducting properties separated the probes and the UN surface. The values measured in the first run fall within a \pm 5 per cent range as shown in Figure 25. 


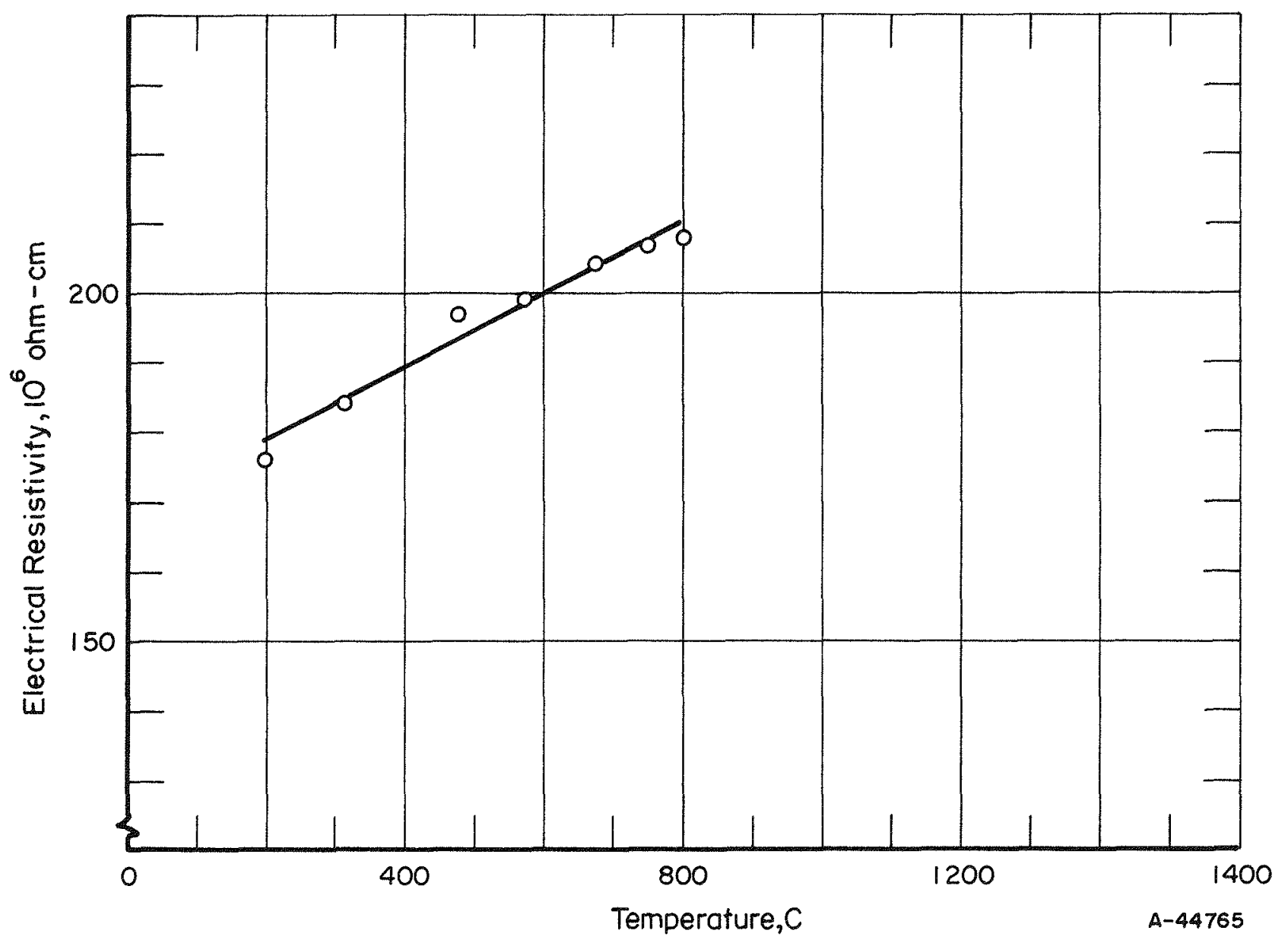

FIGURE 24. ELECTRICAL RESISTIVITY OF URANIUM MONONITRIDE SPECIMEN TC-1-A 


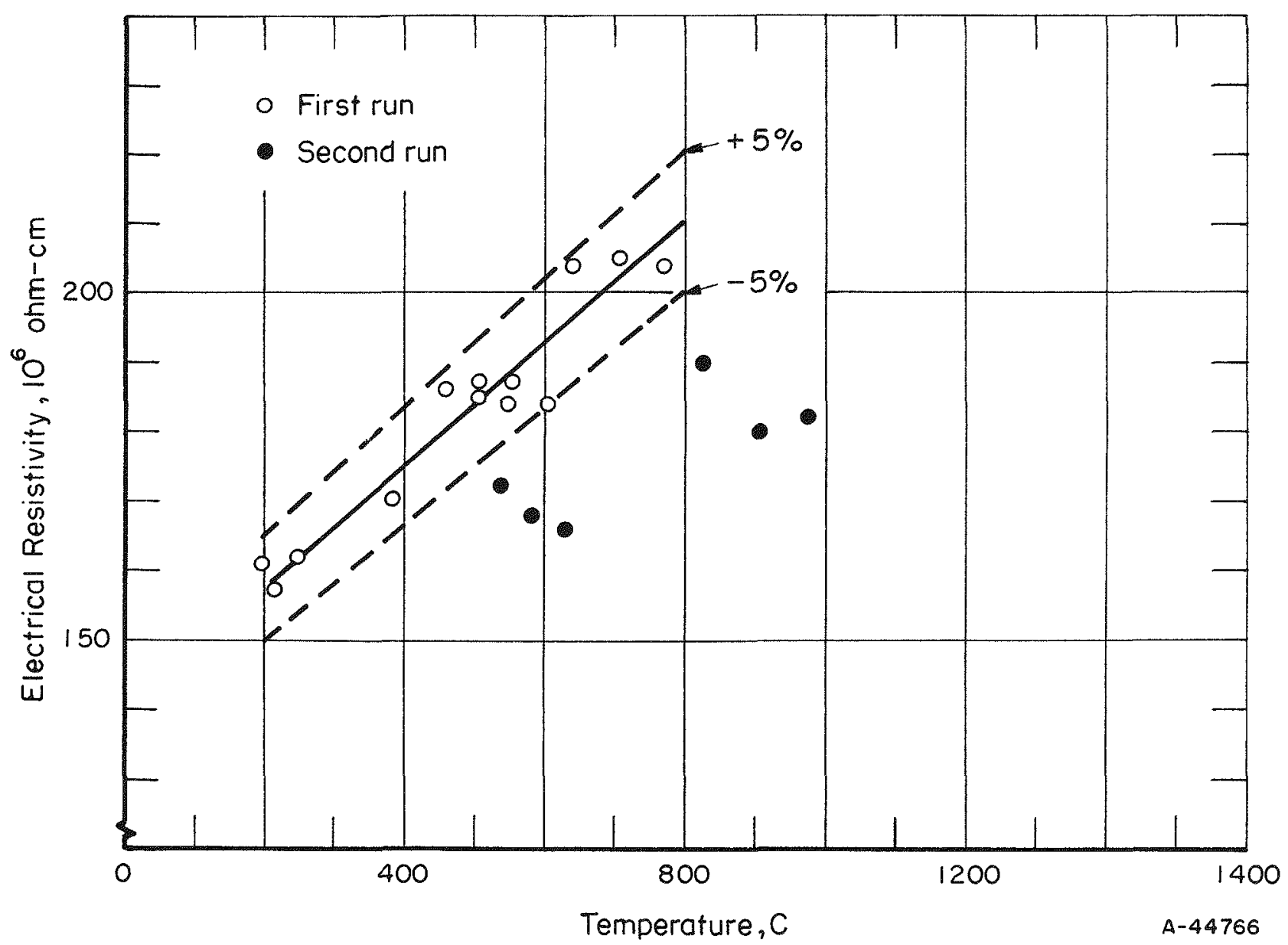

FIGURE 25. ELECTRICAL RESISTIVITY OF URANIUM MONONITRIDE SPECIMEN TC- 177 
Empirical relations describing the electrical resistivity of the two UN specimens were derived from least-squares analyses and are as follows:

$$
\begin{aligned}
& \text { For TC-1-A: } \rho=0.053 t+168.1 . \\
& \text { For TC-177: } \rho=0.070 t+148.6 .
\end{aligned}
$$

where $\rho$ is electrical resistivity in microhm $-\mathrm{cm}$ and $t$ is temperature in C. The electrical conductivities calculated from these relations are shown in Table 12.

TABLE 12. ELECTRICAL CONDUCTIVITY OF TWO HOT-PRESSED

\begin{tabular}{|c|c|c|}
\hline \multirow{2}{*}{$\begin{array}{l}\text { Temperature, } \\
\text { C }\end{array}$} & \multicolumn{2}{|c|}{$\begin{array}{l}\text { Electrical Conductivity, } \sigma \\
\qquad 10^{-3} \mathrm{ohm}^{-1} \mathrm{~cm}^{-1}\end{array}$} \\
\hline & Specimen TC-1-A & Specimen TC-177 \\
\hline 25 & 5.92 & 6.66 \\
\hline 100 & 5.78 & 6.43 \\
\hline 200 & 5.59 & 6.15 \\
\hline 300 & 5.43 & 5.90 \\
\hline 400 & 5.29 & 5.66 \\
\hline 500 & 5.15 & 5.45 \\
\hline 600 & 5.00 & 5.35 \\
\hline 700 & 4.88 & 5.06 \\
\hline 800 & 4.76 & 4.89 \\
\hline
\end{tabular}
URANIUM MONONITRIDE SPECIMENS

\section{Conclusions}

A characteristic distinction between metals and ceramics is the variation of electral conductivity with temperature. The electrical conductivity of UN decreases with increased temperature, a metallic characteristic.

Because measurements were made on both UN specimens in steps of decreasing as well as increasing temperatures, the differences in measured electrical conductivity seem to be real differences in the specimens rather than effects of thermal treatment or reaction within the environment. These differences could be reflections of structuresensitive defects owing to small amounts of impurities or to variations in stoichiometry.

\section{MECHANICAL PROPERTIES OF UN}

\section{Elastic Properties}

Three constants that are definite properties of a material and fundamental to any consideration of stresses in the material are the elastic modulus or Young's modulus (E), the shearing modulus of elasticity or modulus of rigidity $(G)$, and Poisson's ratio $(\mu)$. These quantities are not independent of one another. If any two are determined experimentally, the third may be computed from the relationship:

$$
\mathrm{G}=\frac{\mathrm{E}}{2(1+\mu)} \text {. }
$$


Procedures

Apparatus and Methods. Modulus determinations were made on two UN samples of simple geometric shape by a sonic-vibration method. A rod specimen was suspended at the nodal points by two adjustable cross wires. Mechanical vibration was transmitted to the sample from a piezoelectric transducer by means of a fine coupling wire. A crystal pickup detected the vibrations which were shown on a cathode-ray oscilloscope. The oscillator frequency was then adjusted to the resonant frequency of the specimen. This adjusted frequency was measured with an electronic events-per-unit-time counter. The modulus was calculated from the resonant frequency, dimensions, and density of the sample.

The sample can be excited to vibrate in the torsional, longitudinal, or flexural mode to obtain the desired modulus. The frequency range of the instrument is 200 to $25,000 \mathrm{cps}$. The estimated error in the modulus determinations from the ability of the apparatus to distinguish differences in frequency is les than 1 per cent.

Specimens. Two UN rod specimens isostatically hot pressed to 96 per cent of the theoretical $\mathrm{X}$-ray density were ground to the sizes tabulated below.

$\begin{array}{cccc}\text { Specimen } & \frac{\text { Average Diameter, in. Average Length, in. }}{\mathrm{E}-2} & \frac{\text { Bulk Density, g per } \mathrm{cm}^{3}}{2.5015} & \frac{13.89}{\mathrm{E}-3} \\ 0.3745 & 0.3590 & 2.4226 & 13.88\end{array}$

The rods were relatively short for this type of measurement but represented the maximum length obtainable at the time of measurement. Although essentially singlephase UN, some scattered minute impurities, primarily $\mathrm{UO}_{2}$, could be detected by metallog raphy.

\section{Results}

The measured fundamental frequencies in flexure ("free-free" or floating beam method) were 8226 and $8438 \mathrm{cps}$, yielding calculated moduli of elasticity of $30.9 \times 10^{6}$ and $31.1 \times 10^{6}$ psi for Specimens $E-2$ and $E-3$, respectively.

The torsional frequencies were 20,914 and $21,443 \mathrm{cps}$ for $E-2$ and $E-3$, respectively. The calculated shear moduli were $14.3 \times 10^{6}$ and $14.0 \times 10^{6}$ psi.

These values give a calculated Poisson's ratio of about 0.1 , which is lower than recent preliminary values obtained in compression tests.

\section{Hardness}

In general terms, hardness is the resistance to permanent indentation by an indenter of fixed size and shape under a known load. Not being a fundamental property of a material, hardness is dependent upon several basic properties. 
Procedures

No systematic study of the hardness of UN as a function of other properties was made. Several room-temperature hardness values were obtained in conjunction with attempts to identify impurities in the UN. These are reported in this section. Readings were obtained on a Tukon tester.

$\underline{\text { Results }}$

Table 13 gives the results in summary.

TABLE 13. HARDNESS VALUES FOR VARIOUS UN MATERIALS

\begin{tabular}{|c|c|c|c|c|}
\hline \multirow{2}{*}{$\begin{array}{c}\text { Load, } \\
\mathrm{g}\end{array}$} & \multicolumn{2}{|c|}{ Average Hardness } & \multirow{2}{*}{$\begin{array}{l}\text { Number of } \\
\text { Readings }\end{array}$} & \multirow{2}{*}{$\begin{array}{l}\text { Average } \\
\text { Error(a) }\end{array}$} \\
\hline & $\mathrm{KHN}$ & DPH & & \\
\hline 10 & 660 & - & 3 & \pm 70 \\
\hline 25 & 610 & -- & 29 & \pm 80 \\
\hline 100 & 580 & -- & 15 & \pm 50 \\
\hline 500 & -- & 610 & 16 & \pm 30 \\
\hline 1,000 & -- & 500 & 1 & - \\
\hline 10,000 & -- & 560 & 2 & - \\
\hline
\end{tabular}

(a) Average error: $\pm \frac{\Sigma(d)}{n}$, where $d$ is the deviation (without sign) from the mean value and $n$ is the number of observations.

\section{Conclusions}

The increase in hardness value with decrease in load for loads smaller than $500 \mathrm{~g}$ is observed in practically all microhardness testing and is probably due primarily to visual and other systematic errors in the testing apparatus. At $500 \mathrm{~g}$ and above, the impressions from which the hardness values were read overlapped particles, impurities, and voids.

The Knoop hardness values were obtained on a variety of UN specimens ranging from powder to hot-pressed materials. Since the values were obtained by a number of operators, no attempt was made to correlate the hardness with chemical composition.

\section{Hot Hardness}

Hardness measurements at elevated temperatures may be of particular value in indicating the maximum useful temperature of UN. The hot hardness can also be a guide for fabrication practices such as hot pressing.

\section{Procedures}

Apparatus and Methods. For testing, the specimen was heated first to the lower recorded temperatures and held until thermal equilibrium was reached. Subsequent 
measurements were made in steps of increasing temperature. Five indentations were made at each temperature and the hardness values computed from microscopic measurements made after the complete run.

The tests were made in a vacuum chamber with a measured residual air pressure below $5 \times 10^{-3}$ torr throughout the run. Two tests were made. In the first, a deadweight load of $730 \mathrm{~g}$ was applied to a standard 136-deg square-based pyramid indenter tip made of sapphire. Temperature was measured with a thermocouple. In the second, a $1-\mathrm{kg}$ load was applied to a tungsten carbide tip. Temperature was measured with a disappearing-filament optical pyrometer.

Specimens. Specimens were ground to flat plates from isostatically hot-pressed materials. The tested face of the specimens were metallographically polished before testing. The first specimen was $1 / 8 \mathrm{in}$. thick; the second, $1 / 4 \mathrm{in}$. thick.

By chemical analysis, the nitrogen content of the second specimen was low (5. $24 \mathrm{w} / \mathrm{o}$ nitrogen). But metallographically, the specimen was single-phase UN except for a few isolated particles of $\mathrm{UO}_{2}$ which, because of their location, would be expected to have no effect on the hardness values obtained. There was no visible free uranium.

\section{Results}

The values obtained in the first test are shown in Table 14. This specimen was darkened during the test by surface oxidation.

TABLE 14. HARDNESS OF UN VERSUS TEMPERATURE

\begin{tabular}{|c|c|c|c|}
\hline \multicolumn{2}{|c|}{ Temperature, } & \multicolumn{2}{|c|}{$\begin{array}{c}\text { Hardness, } \mathrm{DPH}(\mathrm{b}) \\
\mathrm{kg} \text { per } \mathrm{mm}^{2}\end{array}$} \\
\hline $\mathrm{C}$ & $\mathrm{F}$ & First Test & Second Test \\
\hline 25 & 77 & $-\infty$ & $499(a)$ \\
\hline 650 & 1200 & 275 & $-\infty$ \\
\hline 760 & 1400 & 224 & - \\
\hline 800 & 1470 & $\cdots$ & 169 \\
\hline 870 & 1600 & 164 & -- \\
\hline 900 & 1650 & $\cdots$ & 143 \\
\hline 980 & 1800 & 130 & -. \\
\hline 1000 & 1830 & -. & 123 \\
\hline 1090 & 2000 & 116 & -- \\
\hline 1100 & 2010 & $\cdots$ & 107 \\
\hline 1200 & 2190 & $-\infty$ & 81 \\
\hline 1300 & 2370 & - & 64 \\
\hline 1400 & 2550 & $=-$ & 53 \\
\hline
\end{tabular}

(a) Single room-temperature value obtained on a Vicker's hardness tester.

(b) Average values. 
The values from the second test are also shown in Table 14 and plotted as $\log \mathrm{DPH}$ versus temperature in Figure 26. Testing was not attempted above $1400 \mathrm{C}(2550 \mathrm{~F})$ because of a slight tendency for the indenter to stick to the specimen at this temperature. This did not affect the visual quality of the indentations as is shown in Figure 27. There was no metallographic evidence of decomposition and only very slight surface oxidation of the specimen, which also shows in Figure 27 as a "thermal etch".

\section{Conclusions}

Hot hardness is not easy to measure with precision. The biggest problem is obtaining reliable and reproducible results which are relatively free from external influences.

The values from the first test are thought to be unreliable because of the specimen oxidation which occurred. The volume expansion accompanying the oxidation would tend to fill in the indenter impressions, particularly those made at the lower temperatures early in the run, causing high hardness readings. The higher temperature values obtained between 870 and $1090 \mathrm{C}$ do fall within 10 per cent of values at those temperatures as determined from the curve of Figure 26 for the second test.

The second test indicates that the moderate hardness of UN at room temperature drops slightly with increasing temperature to $1100 \mathrm{C}$, where it falls more abruptly. The curve extrapolates back quite well to the room-temperature hardness.

Although hardness may not be unequivocally interpreted as a measure of mechanical strength, the retention by UN of about 80 per cent of its room-temperature hardness at $1100 \mathrm{C}(2012 \mathrm{~F})$ suggests that a large percentage of its mechanical strength will also be retained at that temperature.

Schwab (27) noted that plots of the log of the hardness number versus the reciprocal of the absolute temperature for several pure metals gave two straight lines, one with low slope at low temperature and one with higher slope in the higher temperature range. He suggested that the hardness as a function of temperature could be described by an equation of the general form

$$
\mathrm{H}=\frac{1}{A e^{-E_{1} / R T}+B e^{-E_{2} / R T}},
$$

where $H$ is the hardness at temperature, $K$, and $E_{1}$ and $E_{2}$ are activation energies.

This same behavior is noted for UN as shown in Figure 28. For UN, however, extrapolation of this curve to room temperature gives an unreasonable value for the room-temperature hardness.

\section{CHEMICAL PROPER TIES OF UN}

\section{Solubility of Hydrogen}

To aid in evaluating the effects of the $\mathrm{N}^{14}(\mathrm{n}, \mathrm{p}) \mathrm{C}^{14}$ reaction on the integrity of UN during irradiation, it was desirable to determine how hydrogen affected UN out-of-pile. 


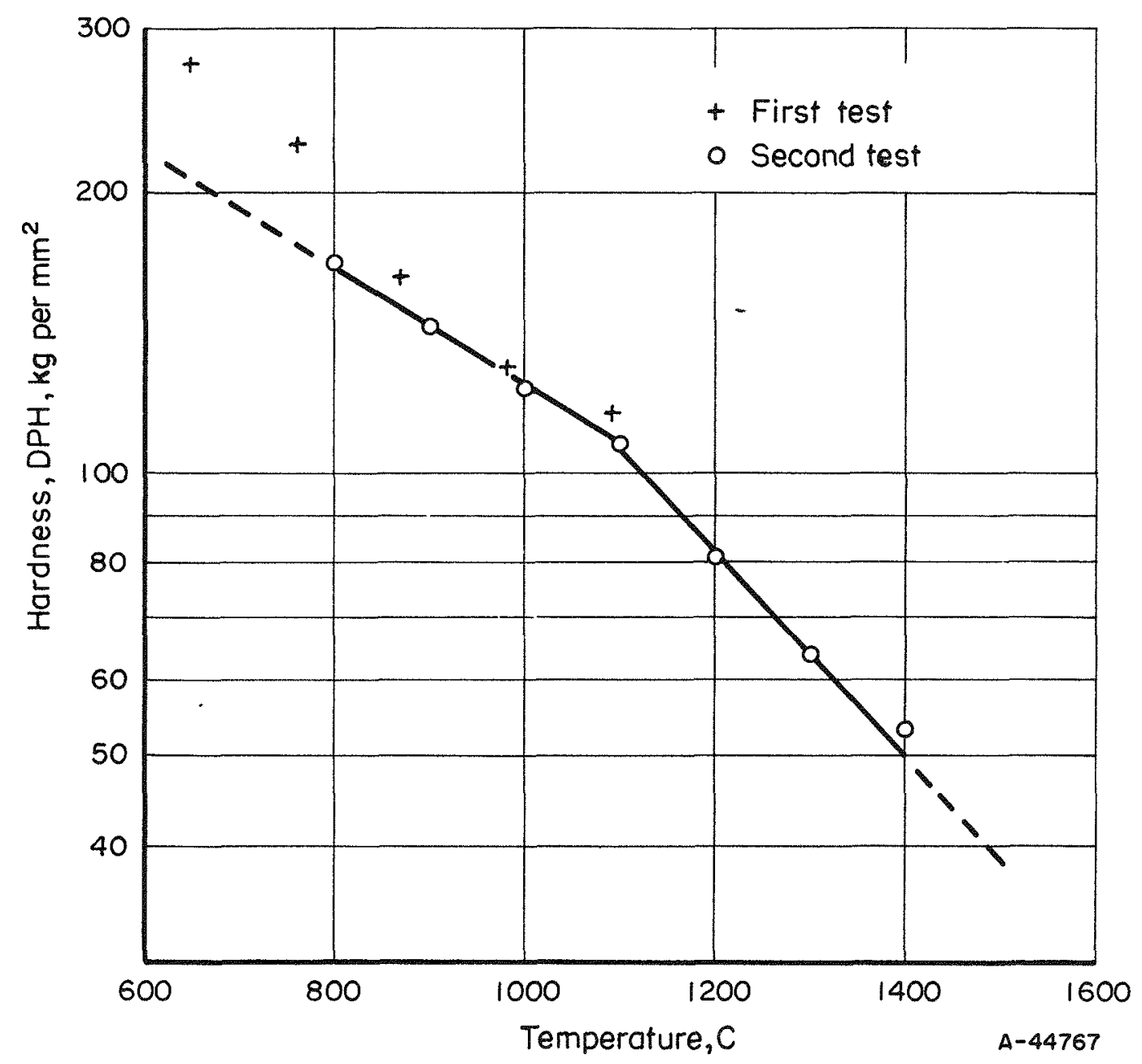

FIGURE 26. EFFECT OF TEMPERATURE ON HARDNESS OF UN 


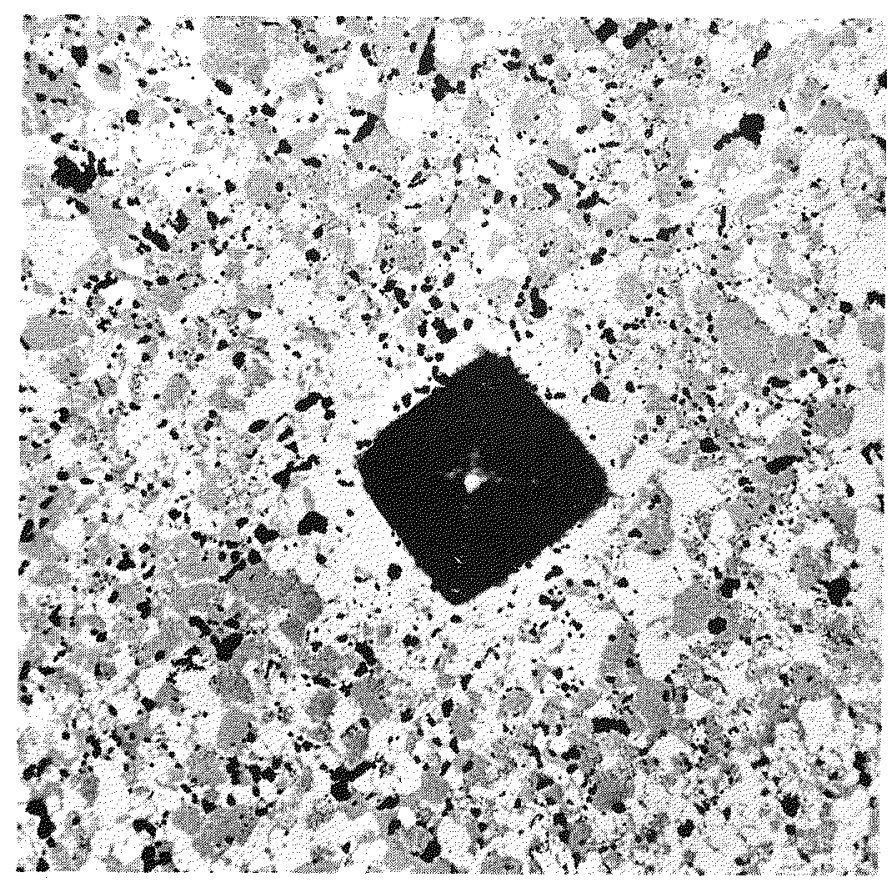

$250 \mathrm{X}$

RM21147

a. At $800 \mathrm{C}$

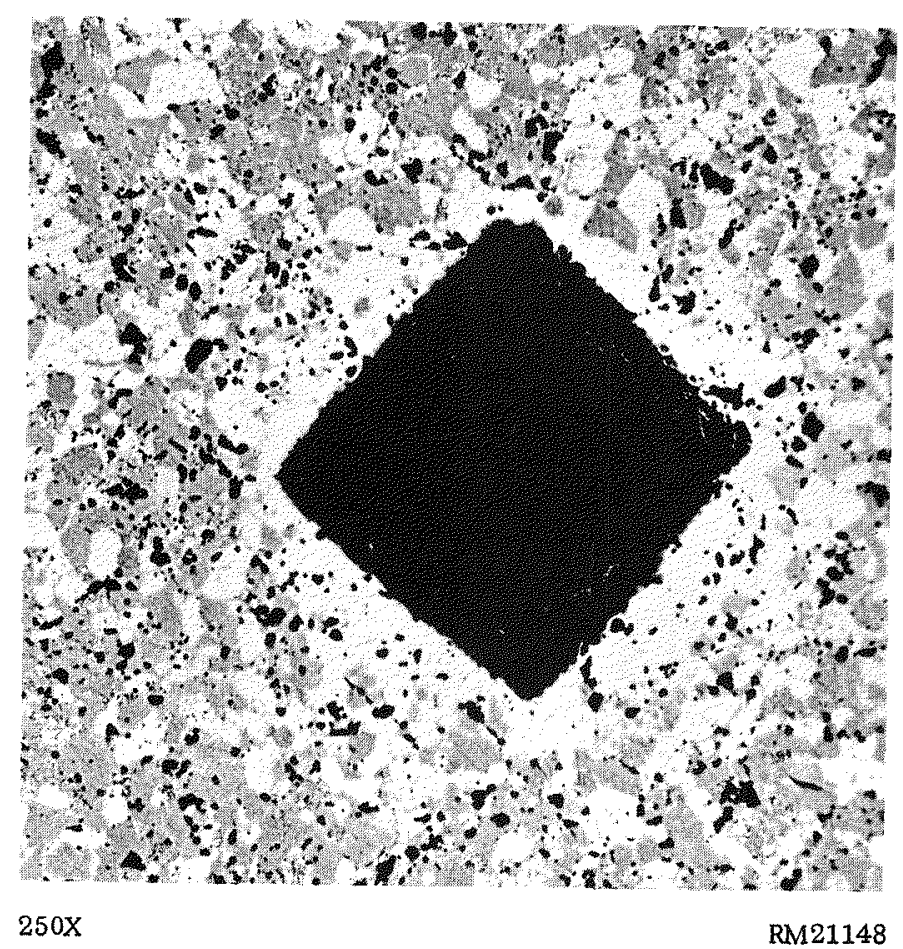

b. At $1400 \mathrm{C}$

FIGURE 27. TYPICAL HOT-HARDNESS IMPRESSIONS IN UN Slight oxidation during the test gives the etched appearance. 


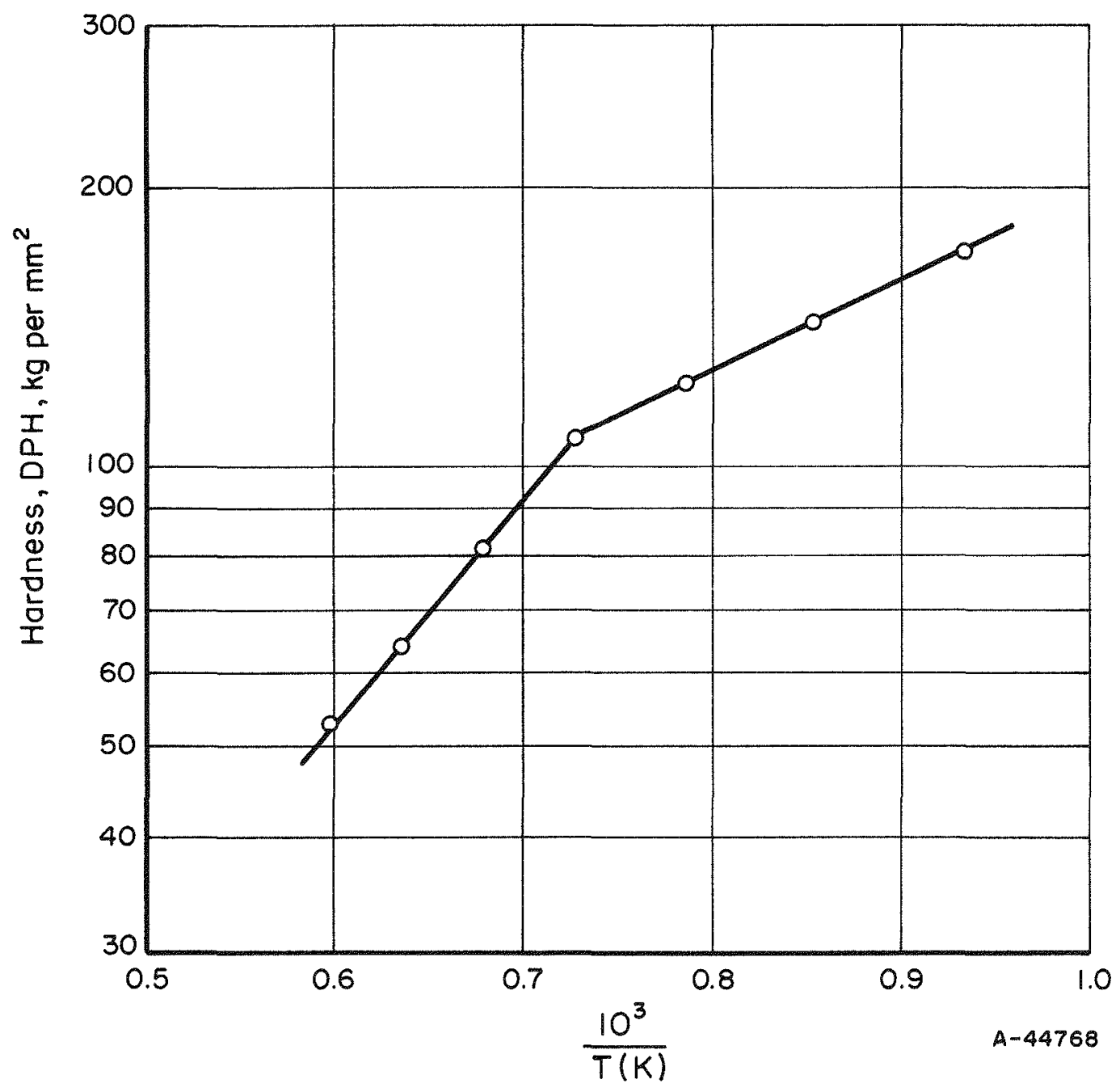

FIGURE 28. VARIATION OF HARDNESS WITH TEMPERATURE FOR UN 


\section{Procedures}

Apparatus and Methods. The solubility of hydrogen in UN was determined by two independent methods. In the first, samples were placed in a double-walled reaction tube. When hydrogen was contained in the apparatus, an independent hydrogen atmosphere was maintained in the tube jacket at close to the experimental pressure to eliminate the diffusion gradient across the tube wall and thus minimize diffusion losses from the vacuumtight reaction system. The volumes were calibrated so that both the hot and cold sections of the total volume were known over the experimental temperature range. Thus volume corrections for variations in temperature of both furnace and ambient-temperature parts of the system could be made. The sample was heated by a resistance-wound furnace with careful temperature control. Temperatures and pressures were read as the sample passed through the exact desired temperature during its normal control cycling. Readings were always taken on the heating part of the cycle. The hydrogen was metered into the system from a gas microburet and the solubility determined by the difference between the volume of added gas and the volume remaining in the system after equilibration.

In the second method, samples were equilibrated with $1 \mathrm{~atm}$ of hydrogen at 500 and $800 \mathrm{C}$ for several times. The hydrogen gas was from $\mathrm{UH}_{3}$. The samples were then analyzed for hydrogen by vacuum fusion.

Specimens. Three types of UN specimens were used: pellets cold pressed and vacuum sintered $1 \mathrm{hr}$ at $1600 \mathrm{C}$, high-density isostatically hot pressed fragments, and vacuum-sintered pellets containing free uranium.

Results. With a sample consisting of three pellets vacuum sintered $1 \mathrm{hr}$ at $1600 \mathrm{C}$, the results shown in Table 15 were obtained in the micro-Sieverts apparatus. The total weight of the three pellets was $4.4 \mathrm{~g}$. Equilibrium was not reached after 7 days at $300 \mathrm{C}$. About $20 \mathrm{hr}$ at $400 \mathrm{C}$ and $2 \mathrm{hr}$ at $500 \mathrm{C}$ was needed to reach equilibrium. The measured density was about 74 per cent of the theoretical $X$-ray density of UN. At the end of the experiment, the pellets were allowed to absorb $14 \pm 3$ ppm hydrogen as measured by the micro-Sieverts apparatus. Vacuum-fusion analysis of the three pellets showed 12, 14, and $16 \mathrm{ppm}$ hydrogen, confirming the apparatus measurements.

Fragments of high (96 per cent of theoretical X-ray density) density UN roughly $1 / 8$ in. in major dimension were equilibrated with 1 atm of hydrogen at 500 and $800 \mathrm{C}$ for the times and with the results shown in Table 16.

A dense sample was cycled through the normal uranium hydriding temperature range with no visually observable effects and no apparent change in the microstructure.

The free-uranium content of a dense sample which had partially decomposed during high-temperature vacuum sintering was measured by hydrogen absorption in the microSieverts apparatus. The absorption was practically complete after $30 \mathrm{~min}$ at $280 \mathrm{C}$ and at $1 \mathrm{~atm}$ of hydrogen pressure. The sample was converted to powder. The sample 
TABLE 15. SOLUBILITY OF HYDROGEN IN UN ${ }^{(a)}$ AS MEASURED IN A MICRO-SIEVERTS APPARATUS

\begin{tabular}{cc}
\hline Temperature, $\mathrm{C}$ & Solubility ${ }^{(\mathrm{b})}, \mathrm{ppm}$ \\
\hline $300^{(\mathrm{c})}$ & $15^{(\mathrm{c})}$ \\
350 & 20 \\
400 & $20^{(\mathrm{d})}$ \\
450 & 18 \\
500 & $16^{(\mathrm{e})}$ \\
800 & 9
\end{tabular}

(a) Samples having a density 74 per cent of theoretical were exposed in a hydrogen pressure of 1 atm.

(b) Estimated accuracy is $\pm 3 \mathrm{ppm}$.

(c) Equilibrium was not reached after 7 days.

(d) Equilibrium reached in about $20 \mathrm{hr}$.

(e) Equilibrium reached in about $2 \mathrm{hr}$.

TABLE 16. SOLUBILITIES OF HYDROGEN IN UN BY EQUILIBRATION AND ANALYSIS(a)

\begin{tabular}{ccccc}
\hline & \multicolumn{2}{c}{ Equilibrium Data } & & \\
\cline { 2 - 4 } Sample & $\begin{array}{c}\text { Temperature, } \\
\mathrm{C}\end{array}$ & $\begin{array}{c}\text { Time, } \\
\mathrm{hr}\end{array}$ & $\begin{array}{c}\text { Analysis, } \\
\mathrm{ppm}\end{array}$ & Remarks \\
\hline 1 & 500 & 3 & Nil & $<0.5 \pm 0.5 \mathrm{ppm}$ (b) \\
2 & 500 & 3 & Nil & $<0.5 \pm 0.5 \mathrm{ppm}$ (b) \\
4 & 500 & 16 & Nil & $<0.5 \pm 0.5 \mathrm{ppm}$ (b) \\
5 & 500 & 16 & Nil & $<0.5 \pm 0.5 \mathrm{ppm}$ (b) \\
$6,7,8$ & 500 & 65 & $0.3 \pm 0.3$ (c) & Corrected for 0.05 -ppm blank \\
9 & 800 & 24 & Nil & $1.1 \pm 0.5 \mathrm{ppm}$ (d) \\
10 & 800 & 24 & Nil & $1.3 \pm 0.5 \mathrm{ppm}$ (d) \\
11 & 800 & 24 & Nil & $<0.5 \pm 0.5 \mathrm{ppm}$ (b) \\
\hline \hline
\end{tabular}

(a) Samples having a density 96 per cent of theoretical were exposed in hydrogen at 1 atm.

(b) Uncorrected for blank which was actually greater than this.

(c) Analysis by hot vacuum extraction at $1200 \mathrm{C}$ from solid sample. All other analyses made by vacuum fusion in an iron bath at $1650 \mathrm{C}$.

(d) Uncorrected for blank and equal to blank. 
weighed $0.585 \mathrm{~g}$ and absorbed $18.96 \mathrm{ml}$ of hydrogen (STP). Chemical analysis of a similar sample which was crushed prior to analysis showed $4.2 \pm 0.02 \mathrm{w} / 0$ nitrogen in the fine-powder fraction and $3.8 \pm 0.02 \mathrm{w} / \mathrm{o}$ nitrogen in the coarse-powder fraction. More free UN particles would be expected in the finer powder sample.

\section{Conclusions}

Since $1 \mathrm{ml}$ of hydrogen at STP is $8.99 \times 10^{-2} \mathrm{mg}$ and as $1 \mathrm{mg}$ of hydrogen represents $79.3 \mathrm{mg}$ of uranium, the sample which contained the free uranium had $135 \mathrm{mg}$ of free uranium according to the hydrogen absorption. This would be $23.1 \mathrm{w} / \mathrm{o}$ of free uranium or $76.9 \mathrm{w} / \mathrm{o}$ of UN assuming no absorption by the UN. If the UN not decomposed was stoichiometric (5.56 w/o nitrogen) then the over-all sample should have contained about $4.3 \mathrm{w} / 0$ nitrogen. The mean chemical analysis, showing about $4.0 \mathrm{w} / \mathrm{o}$ nitrogen, is in fairly good agreement. These results along with the lack of any observable change in the dense UN sample cycled in hydrogen indicate that UN is probably not adversely affected by hydrogen unless free uranium is present.

The difference in sample types could account for the discrepancy between the hydrogen solubility in UN as determined by the equilibration and analysis method showing no $(<1 \mathrm{ppm})$ solubility and the micro-Sieverts apparatus method showing decreasing solubility with increasing temperature.

The decrease in solubility with increasing temperature is contradictory to the predicted trend if hydrogen solution were an endothermic reaction. The results indicate either an exothermic reaction or an adsorption phenomenon associated with the pore system of the samples (74 per cent of the theoretical density). The latter seems more likely.

Mallett and Trzeciak ${ }^{(28)}$ found an adsorption process acting to give a decrease in hydrogen retained by uranium powder with increasing temperature.

\section{Corrosion by Water}

Because UN was so much more resistant to attack by atmospheric moisture than UC, a natural curiosity was aroused as to its resistance to attack by water at or near the operating temperatures of pressurized-water reactors.

\section{Procedures}

Apparatus and Methods. UN specimens were suspended in a Chromel A wire basket attached to a Type 316 stainless steel holder which in turn was in contact with a Type 316 stainless steel autoclave. No provision was made to electrically insulate the specimens from the autoclave, but no galvanic effects have been noted in other tests with this type of system. 
Specimens. With one exception, all tests were made on isostatically hot-pressed UN. Fragments of arc-melted UN were included in one test.

$\underline{\text { Results }}$

The first test was in $260 \mathrm{C}(500 \mathrm{~F})$ deionized and degassed water at saturated steam pressure on a fragment of isostatically hot-pressed UN. The microstructure of this impure material was typical of that shown in Figure 29. After $24 \mathrm{hr}$ of exposure, it broke into six pieces of various sizes with other cracks visible in all pieces. The pieces were coated with some loose powder dark gray to black in color.

The second test was at the same temperature on a cylindrical specimen with much less impurities, as shown by the microstructure in Figure 30. The bulk density was $14.0 \mathrm{~g}$ per $\mathrm{cm}^{3}$ or 98 per cent of the theoretical UN density calculated from X-ray lattice parameters.

The deionized and degassed water at the start of testing normally shows a specific resistivity greater than $1 \times 10^{6} \mathrm{ohm}-\mathrm{cm}$ and a $\mathrm{pH}$ between 6.5 and 6.8 . The following conditions were measured during the test:

\begin{tabular}{|c|c|c|c|}
\hline $\begin{array}{c}\text { Time on Test, } \\
\text { hr }\end{array}$ & $\begin{array}{c}\text { Total Time, } \\
\text { hr } \\
\end{array}$ & $\mathrm{pH}$ & $\begin{array}{c}\text { Specific Resistivity, } \\
\mathrm{ohm}-\mathrm{cm}\end{array}$ \\
\hline 24 & 24 & 6.27 & 200,000 \\
\hline 48 & 72 & 6.35 & 325,000 \\
\hline 96 & 168 & 7.02 & 80,000 \\
\hline
\end{tabular}

After each test period the specimen was heated in air $5 \mathrm{~min}$ at about $140 \mathrm{~F}$ to dry it and the loose black powdery chemical corrosion products were brushed off prior to weighing. A dark, tightly adhering film remained after brushing. The measured weight losses are shown below:

\begin{tabular}{|c|c|c|c|}
\hline $\begin{array}{c}\text { Time on Test, } \\
\text { hr }\end{array}$ & $\begin{array}{c}\text { Total Time, } \\
\text { hr }\end{array}$ & $\begin{array}{l}\text { Weight Loss, } \\
\text { mg per } \mathrm{cm}^{2}\end{array}$ & $\begin{array}{c}\text { Total Weight Loss, } \\
\mathrm{mg} \text { per } \mathrm{cm}^{2}\end{array}$ \\
\hline 24 & 24 & 1.8 & 1.8 \\
\hline 48 & 72 & 2.0 & 3.8 \\
\hline 96 & 168 & $\ldots$ & $\ldots$ \\
\hline
\end{tabular}

Photomacrographs of the specimen before testing and after $24 \mathrm{hr}$ of exposure are shown in Figure 31.

During the $96-\mathrm{hr}$ test, or sometime prior to $168 \mathrm{hr}$ of total exposure, the specimen fractured at one end as shown in Figure 32. Some pitting of the cylindrical surface and of the other end was also observed.

No change in the microstructure was detected. Scattered evidence of corrosion was observed at the surface as shown in Figure 33.

The fractured end of this specimen was cut off, and the shortened length was again exposed to fresh $260 \mathrm{C}$ deionized and degassed water along with specimens from two different powder batches. The density of these new specimens measured 96 per cent of the theoretical UN density. 


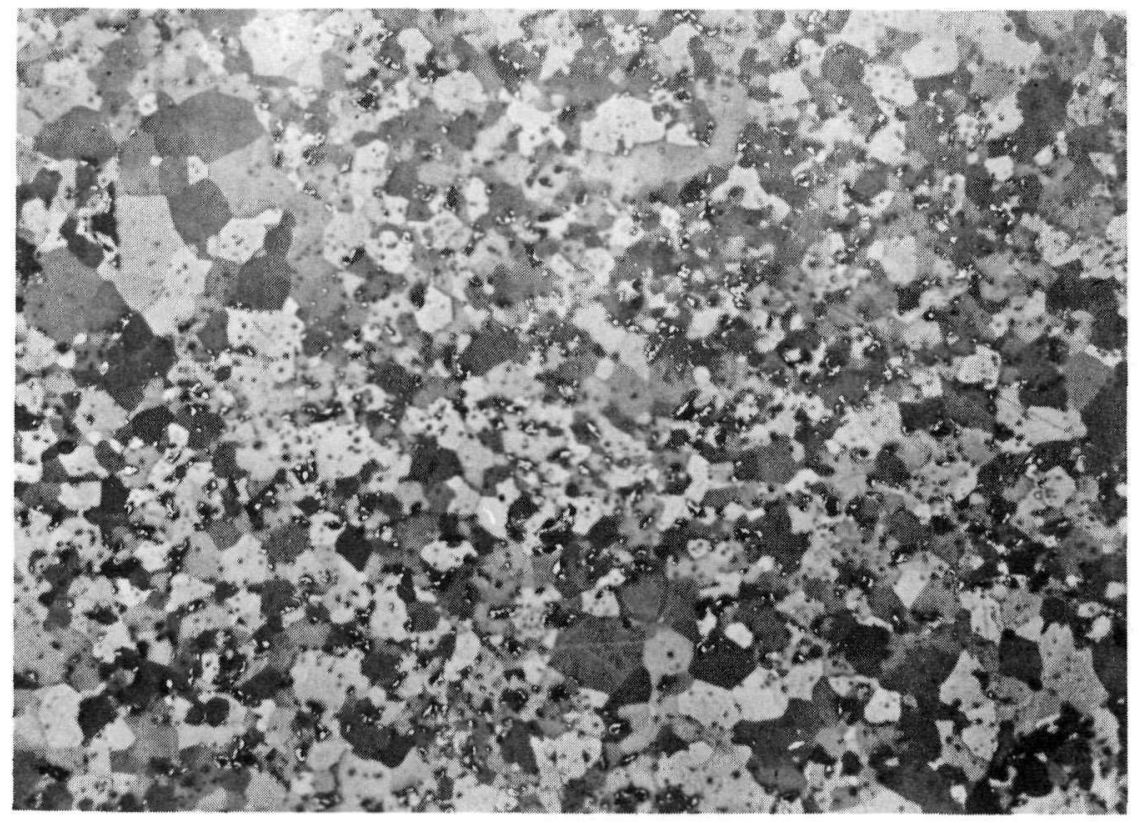

250X

Etchant: $30 \mathrm{~cm}^{3}$ lactic acid, $10 \mathrm{~cm}^{3} \mathrm{HNO}_{3}, 2$ drops $\mathrm{HF}$

RM18642

FIGURE 29. MICROSTRUCTURE OF UN WHICH FRAGMENTED DURING 24-HR EXPOSURE TO 260 C DEIONIZED AND DEGASSED WATER

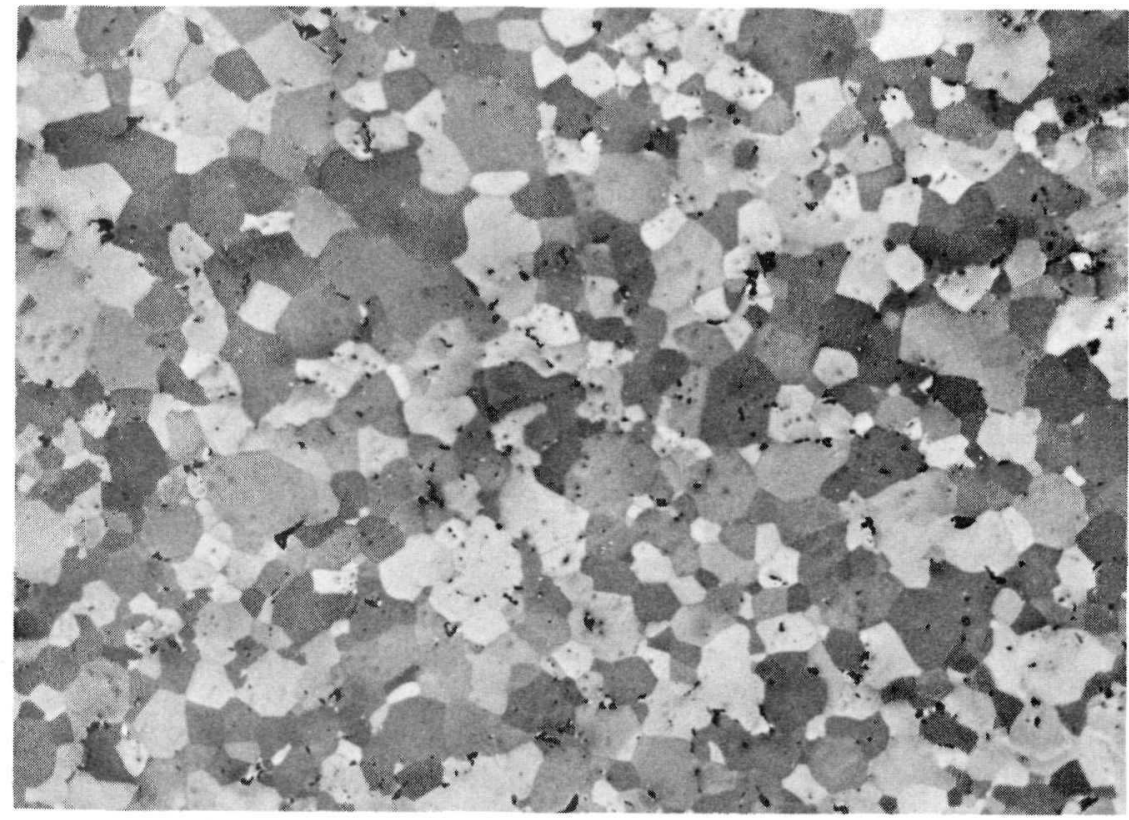

$250 \mathrm{X}$

Etchant: $30 \mathrm{~cm}^{3}$ lactic acid, $10 \mathrm{~cm}^{3} \mathrm{HNO}_{3}, 2$ drops $\mathrm{HF}$

$\mathrm{RM} 18664$

FIGURE 30. MICROSTRUCTURE OF UN WHICH SHOWED EXCELLENT RESISTANCE TO CORROSION BY 260 C DEIONIZED AND DEGASSED WATER

Impurity content is much lower than that of the specimen shown in Figure 29. 


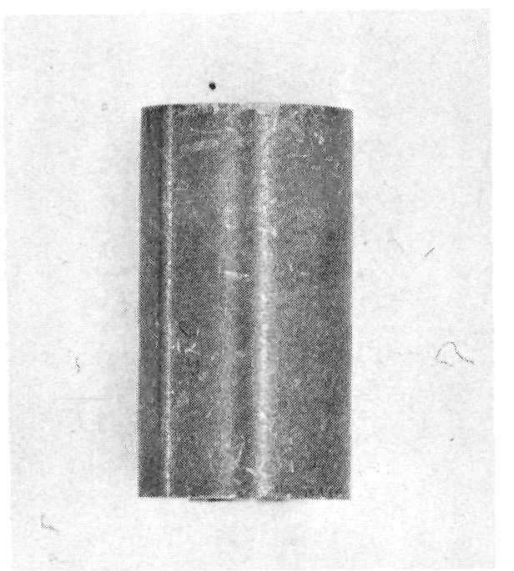

$3 \mathrm{X}$
RM18958

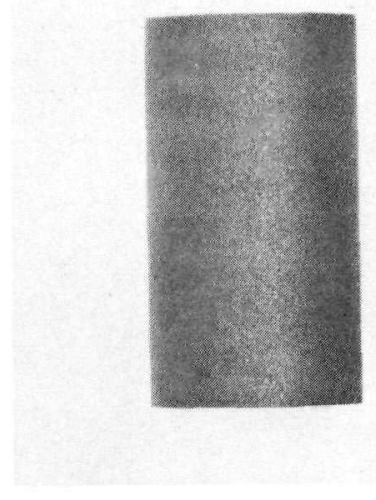

$3 \mathrm{X}$

RM18970

a. Before Exposure

FIGURE 31. APPEARANCE OF UN SPECIMEN BEFORE AND AFTER 24-HR EXPOSURE TO 260 C DEIONIZED AND DEGASSED WATER
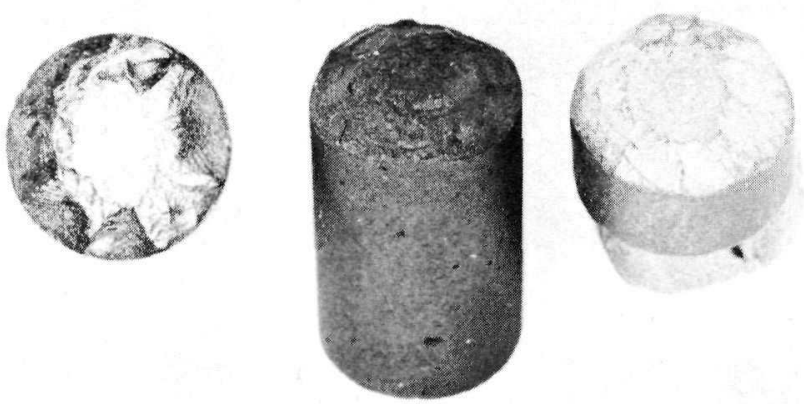

$3 \mathrm{X}$

RM19024

FIGURE 32. PHOTOGRAPH OF A UN SPECIMEN (CENTER) SHOWING THE CRACKING WHICH OCCURRED AT ONE END DURING 168-HR EXPOSURE TO $260 \mathrm{C}$ DEIONIZED AND DEGASSED WATER

The specimen is flanked by other specimen ends which were in contact with the sheathing end plugs during isostatic hot pressing. Note the similarity between the end cracking which occurs during hot pressing and that which occurred during corrosion testing. 


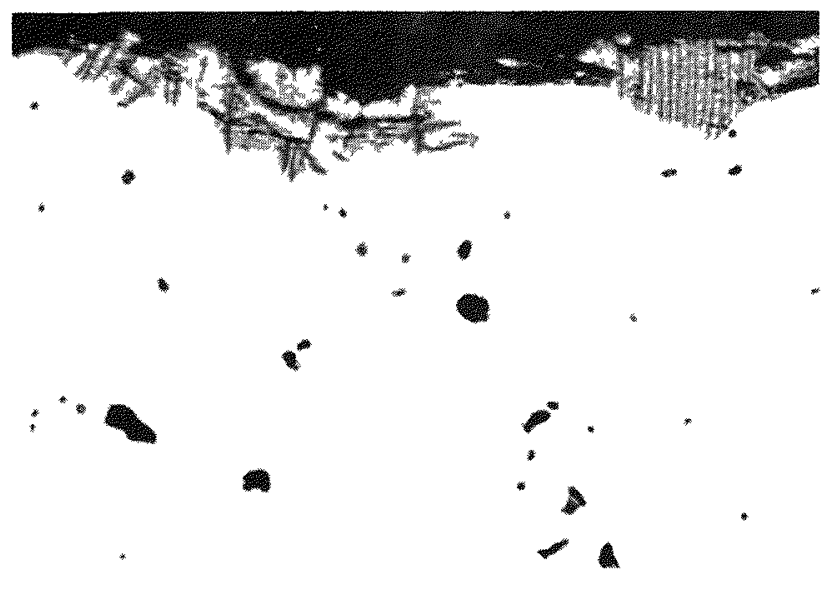

FIGURE 33. EDGE OF UN SPECIMEN EXPOSED TO 260 C DEIONIZED AND DEGASSED WATER FOR 168 HR

This is the same specimen shown in Figure 32. Some evidence of surface corrosion is visible. The dark area at the top is not part of the specimen.

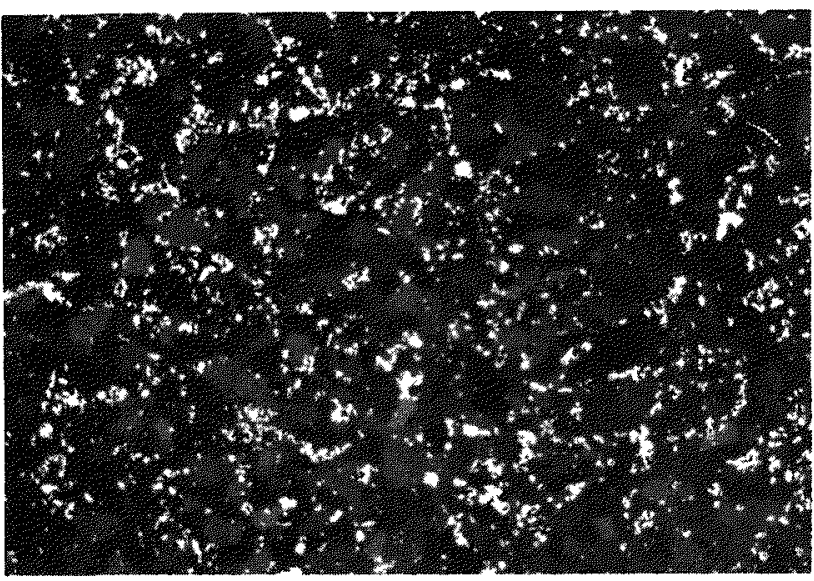

$250 \mathrm{X}$

Etchant: $30 \mathrm{~cm}^{3}$ lactic acid, $10 \mathrm{~cm}^{3} \mathrm{HNO}_{3}, 2$ drops $\mathrm{HF}$ superposed over Murakamis etch

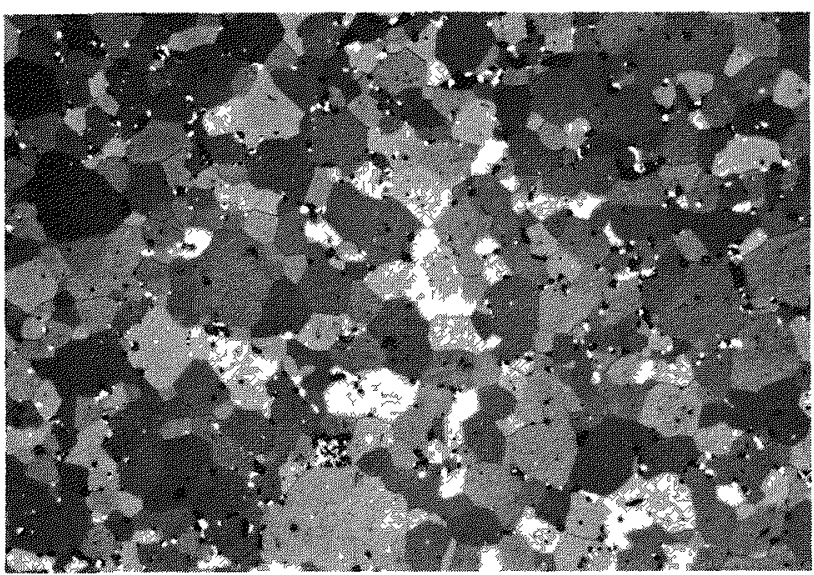

$250 \mathrm{X}$

N91797

Etchant $30 \mathrm{~cm}^{3}$ lactic acid, $10 \mathrm{~cm}^{3} \mathrm{HNO}_{3}, 2$ drops $\mathrm{HF}$
FIGURE 34. MICROSTRUCTURE LIKE THAT OF THE UN MATERIAL WHICH WAS CONVERTED TO POWDER WITHIN 24 HR IN $260 \mathrm{C}$ PURE WATER

This material was hot pressed in a graphite sleeve. A considerable content of impurities is evident.
FIGURE 35. UN SPECIMEN AFTER 66-HR VACUUM ANNEAL AT $1500 \mathrm{C}$

This material was prepared in the same manner as that shown in Figure 34 . The annealing resulted in noticeable reduction in the visible impurity content. Corrosion behavior, how ever, was not improved. The material turned to powder within $24 \mathrm{hr}$ in $260 \mathrm{C}$ pure water. 
The water characteristics changed during this run as follows:

\begin{tabular}{|c|c|c|c|}
\hline $\begin{array}{c}\text { Time on Test, } \\
\mathrm{hr}\end{array}$ & $\begin{array}{l}\text { Total Time, } \\
\mathrm{hr} \\
\end{array}$ & $\mathrm{pH}$ & $\begin{array}{c}\text { Specific Resistivity, } \\
\text { ohm-cm }\end{array}$ \\
\hline 24 & 24 & 6.42 & 340,000 \\
\hline 48 & 72 & 6.63 & 265,000 \\
\hline 96 & 168 & 9.42 & 80,000 \\
\hline
\end{tabular}

The corrosion damage to the specimens was very similar to that which occurred in the previous run. Weight losses were:

\begin{tabular}{|c|c|c|c|}
\hline \multirow[b]{2}{*}{ Specimen } & \multicolumn{3}{|c|}{$\begin{array}{l}\text { Total Weight Loss After Total } \\
\text { Exposure Shown. mg per } \mathrm{cm}^{2}\end{array}$} \\
\hline & $24 \mathrm{Hr}$ & $75 \mathrm{Hr}$ & $186 \mathrm{Hr}$ \\
\hline A & 2.3 & 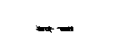 & Unobtainable \\
\hline B & 1.3 & 5.3 & Unobtainable \\
\hline C & 1.4 & 6.5 & Unobtainable \\
\hline
\end{tabular}

Specimen $A$ is the shortened specimen that had received the prior 168-hr exposure. The weight loss shown after the 24-hr additional exposure includes some possible material loss when the specimen was unfortunately dropped and cracked into two pieces during the weighing. At the end of the test, a total of $336 \mathrm{hr}$ of exposure for this material, these two pieces were still macroscopically sound, but significant weight-loss data were unobtainable.

The two new specimens, B and C, fractured at the ends during the 96-hr segment of the test. At $20 \mathrm{X}$ magnification, numerous cracks associated with these breaks could be seen. All surfaces were pitted.

UN specimens prepared by a modified isostatic hot pressing technique in which a graphite sleeve was interposed between the UN powder and niobium sheath did not show similar behavior. Although the diameters of these specimens were ground to remove all metallographically detectable evidence of a UN-graphite reaction zone, these specimens were converted to powder within $24 \mathrm{hr}$ in $260 \mathrm{C}$ deionized and degassed water, in $290 \mathrm{C}$ neutral water (evacuated but not degassed), and in $290 \mathrm{C}$ water to which LiOH and $42 \mathrm{~cm}^{3}$ of hydrogen (in a 1-liter autoclave) had been added to increase the starting $\mathrm{pH}$ to 10.5.

The differences in these specimens prior to testing as determined by chemical analyses were:

\begin{tabular}{|c|c|c|}
\hline \multirow[b]{2}{*}{ Specimen } & \multicolumn{2}{|c|}{ Analysis, w/o } \\
\hline & Nitrogen & Carbon \\
\hline A & 5. 47 & 0.03 \\
\hline B & 5.54 & 0.04 \\
\hline C & 5.53 & 0.01 \\
\hline D & 5.46 & 0.07 \\
\hline
\end{tabular}

Specimens A, B, and C are the same as discussed above. Specimen D was the material hot pressed in the graphite sleeves. The latter material, shown in Figure 34 , contained considerably more metallographically detectable impurity phases than the UN in Specimens A, B, and C. 
This impurity seemed to be considerably reduced by a 66-hr vacuum anneal at $1500 \mathrm{C}$ as shown by a comparison of Figures 34 and 35 . However, a pellet of this annealed material was also converted to powder within $24 \mathrm{hr}$ in $260 \mathrm{C}$ deionized and degassed water.

Three irregularly shaped fragments of arc-cast UN were included in the $290 \mathrm{C}$ neutral water test. Before the test, these fragments appeared macroscopically to be a single-crystal, a double-crystal, and a polycrystalline piece. In $24 \mathrm{hr}$ the single crystal had a 6.7 per cent weight loss, the double crystal fractured into two pieces with a total 7.5 per cent weight loss, and the polycrystalline piece fractured into numerous smaller particles.

\section{Conclusions}

The factors responsible for the observed excellent corrosion resistance of UN to pure water in the early cursory experiments are not readily discernible from the limited data. For those specimens with good corrosion resistance, the reaction seemed to occur only at the surface with the specimens fracturing at residual microcracks in the hotpressed material as illustrated in Figure 32. The behavior of the arc-melted material and of those specimens reduced to powder suggest a grain-boundary attack.

Whereas the carbon content of the hot-pressed material would seem to be a factor, this is not supported by the results of the arc-melted material, the carbon content of which does not normally exceed $0.04 \mathrm{w} / \mathrm{o}$.

Hot-pressed material with a high degree of metallographically observable impurities seems less resistant to attack, although these impurities appear to be agglomerated and dispersed rather than distributed continuously along the grain boundaries.

That a surface coating of some kind contributed to the good resistance of some specimens is somewhat discounted by the fact that the one specimen continued to show good corrosion resistance in a second 7-day test period even though one end had been cut off and a fresh surface exposed.

These results show that UN, in some as yet undetermined state of purity or composition, can be highly resistant to corrosion by water.

\section{Corrosion by $\mathrm{NaK}$}

Because unclad UN was to be irradiated in NaK, it was necessary to determine if UN would be attacked by the $\mathrm{NaK}$ to such an extent that irradiation results would be masked. 
$\underline{\text { Procedures }}$

Two UN specimens were encapsulated in each of two stainless steel cans filled with NaK-56. The specimens were suspended in aluminum baskets. One capsule was heated for $1000 \mathrm{hr}$ at $260 \mathrm{C}(500 \mathrm{~F})$ and one for $1500 \mathrm{hr}$ at $480 \mathrm{C}(900 \mathrm{~F})$.

At the time the tests were initiated, the UN available for specimens had been isostatically hot pressed in stainless steel cans at 1260 to $1280 \mathrm{C}(2300$ to $2350 \mathrm{~F})$ to bulk densities of about 75 to 85 per cent of the theoretical UN X-ray density. The specimens after being ground to remove the hot-pressing sheaths were irregular, as shown in Figure 36.

\section{Results}

Dimensional data for the specimens before and after the exposure are shown in Table 17. Photomicrographs of two of the specimens before and after testing are shown in Figures 36 and 37 and an end view of one sample before and after testing is shown in Figure 38.

TABLE 17. DIMENSIONAL DATA FOR UN SPECIMENS EXPOSED TO NAK AT ELEVATED TEMPERATURES

\begin{tabular}{|c|c|c|c|c|c|c|c|c|c|}
\hline \multirow[b]{3}{*}{ Capsule } & \multicolumn{2}{|c|}{ Exposure Conditions } & \multirow[b]{3}{*}{ Specimen } & \multirow{2}{*}{\multicolumn{2}{|c|}{ Weight, $\mathrm{g}$}} & \multirow{2}{*}{\multicolumn{2}{|c|}{ Diameter, in. }} & \multirow{2}{*}{\multicolumn{2}{|c|}{ Length, in. }} \\
\hline & \multirow{2}{*}{$\begin{array}{c}\text { Temperature, } \\
\mathrm{C}\end{array}$} & \multirow{2}{*}{$\begin{array}{c}\text { Time, } \\
\text { hr }\end{array}$} & & & & & & & \\
\hline & & & & Before & After & Before & After & Before & After \\
\hline \multirow[t]{2}{*}{1} & 260 & 1000 & 18 & 9.973 & 9.995 & 0.496 & 0.495 & 0.260 & 0.263 \\
\hline & & & 19 & 12.612 & 12.638 & 0.494 & 0.493 & 0.329 & 0.338 \\
\hline \multirow[t]{2}{*}{2} & 480 & 1500 & $20(a)$ & 8.101 & - & 0.492 & - & 0.256 & -- \\
\hline & & & $22^{(a)}$ & 14.288 & - & 0.495 & $-\cdots$ & 0.419 & $-\infty$ \\
\hline
\end{tabular}

(a) Oxidized during cleaning operations following exposure before measurements were obtained.

\section{Conclusions}

As examined visually after both tests, the specimens were darker but not grossly affected. Specimens 18 and 19 , run at $260 \mathrm{C}(500 \mathrm{~F})$ for $1000 \mathrm{hr}$, showed about a 0.2 per cent increase in weight. The uncertainty in the physical dimensions prevented determining any slight changes in dimensions. No gross changes occurred. There was no apparent gross change in the UN microstructure after the test at $260 \mathrm{C}(500 \mathrm{~F})$.

NaK was cleaned from Specimens 18 and 19 with butyl alcohol, water, and acetone in that order after the tests. Since the weight gain appeared to be due to the incomplete removal of $\mathrm{NaK}$ entrapped in the surface irregularities of Specimens 18 and 19, Specimens 20 and 22 were boiled in water in an attempt to remove all the NaK. Unfortunately, the container cracked, allowing the water to escape, and Specimens 20 and 22 were oxidized to powder before the container failure was noted.

Spectrographic analyses of the capsule residues following both tests showed some aluminum in Capsule 2 , but no trace of UN in either capsule.

It was concluded that $\mathrm{NaK}$ does not severely attack UN at temperatures up to $480 \mathrm{C}(900 \mathrm{~F})$ and times up to $1500 \mathrm{hr}$. 


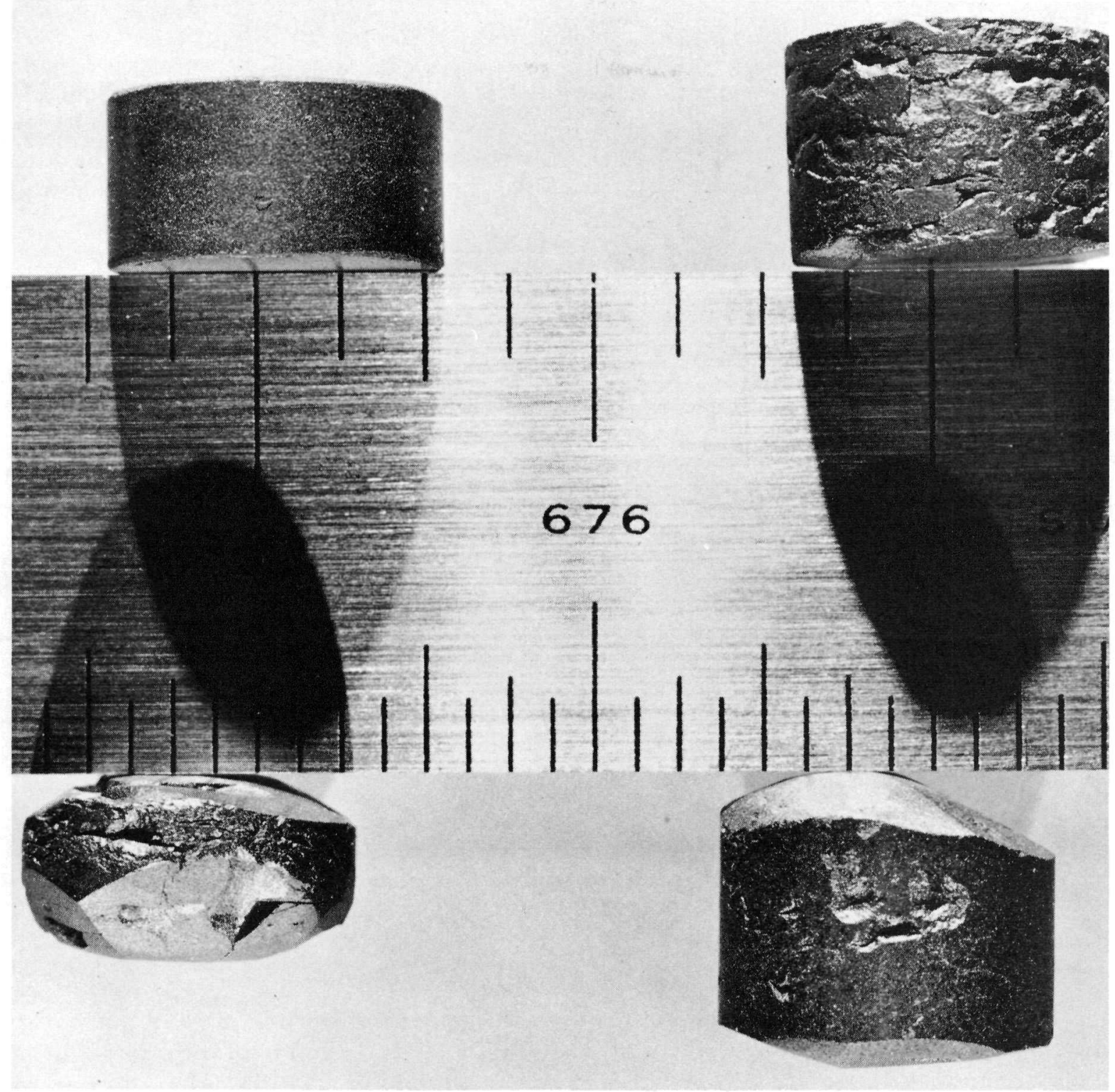

FIGURE 36. UN SPECIMENS BEFORE EXPOSURE TO NaK

Upper left - Specimen 19

Upper right - Specimen 18

Lower left - Specimen 22

Lower right - Specimen 20 
(13) Austin, A. E., and Gerds, A. F. , "The Uranium-Nitrogen-Carbon System", BMI- 1272 (1958).

(14) Sheinhartz, I. , and Zambrow, J. L. , "Dispersion Type Materials for Fuel Elements, Part I, Uranium Mononitride and Uranium Silicide Dispersion Materials", SCNC-266 (1958).

(15) Paprocki, S. J., Keller, D. L., and Cunningham, G. W., "Fabrication of Dispersed Uranium Fuel Elements Using Powder-Metallurgy Techniques", BMI-1184 (1957).

(16) Dayton, R. W. , and Tipton, C. R. , Jr., "Progress Relating to Civilian Applications During February, 1959", BMI-1324 (1959), p 37.

(17) Dayton, R. W. , and Tipton, C. R. , Jr., "Progress Relating to Civilian Applications During March, 1959 ", BMI-1330 (1959), p 46.

(18) Williams, J., and Sambell, R. A.J., "The Uranium Monocarbide-Uranium Mononitride System", J. Less Common Metals $\underline{1}$ (3), 217-226 (1959).

(19) Paprocki, S. J., Editor, "Progress on the Use of Gas-Pressure Bonding for Fabricating Low-Cost Ceramic, Cermet, and Dispersion Fuels, Phase II Report on AEC Fuel-Cycle Program", BMI-14.75 (November 7, 1960), pp 52-56.

(20) Van Dusen, M. S., and Shelton, S. M. , "Apparatus for Measuring The rmal Conductivity of Metals Up to $600 \mathrm{C}$ ", J. Research, Nat'1. Bur. Standards, 12, 429-440 (1934).

(21) Taylor, R. E., "Thermal Conductivity of Zirconium Carbide at High Temperatures", J. Am. Ceram. Soc., 45, 7, 353 (July, 1962).

(22) Lewis, W. B., "The Significance of Developing a High Performance Uranium Oxide Fuel", DM-44, AECL-478 (April 27, 1957).

(23) Runnells, O. J. C. , "Uranium Dioxide Fuel Elements", CRL-55, AECL-754 (January 28, 1959).

(24) Robertson, J. A. L., Bain, A. S., Allison, G. M., and Stevens, W. H., "Irradiation Behavior of $\mathrm{UO}_{2}$ Fuel Elements", AECL-890 (1959).

(25) Robertson, J. A. L., "Integral kd $\theta$ in Fuel Irradiations", CRFD-835, AECL-807 (April, 1959).

(26) Ginnings, D. C. , and Corruccini, R. J., "An Improved Ice Calorimeter - The Determination of its Calibration Factor and Density of Ice at $0^{\circ} \mathrm{C} "$, J. Research Nat'1. Bur. Standards, 38, 583-591 (1947).

(27) Schwab, G. M., "The Electronic Factor in Mechanical Strength", in Mechanical Properties of Intermetallic Compounds, Edited by J. H. Westbrook, John Wiley and Sons, Inc., New York (1960), p 71 .

(28) Mallett, M. W. , and Trzeciak, M. J., "Hydrogen-Uranium Relationships", Trans. ASM, 50 (1958), pp 981-989.

EOS:DLK/mln 
-

- 

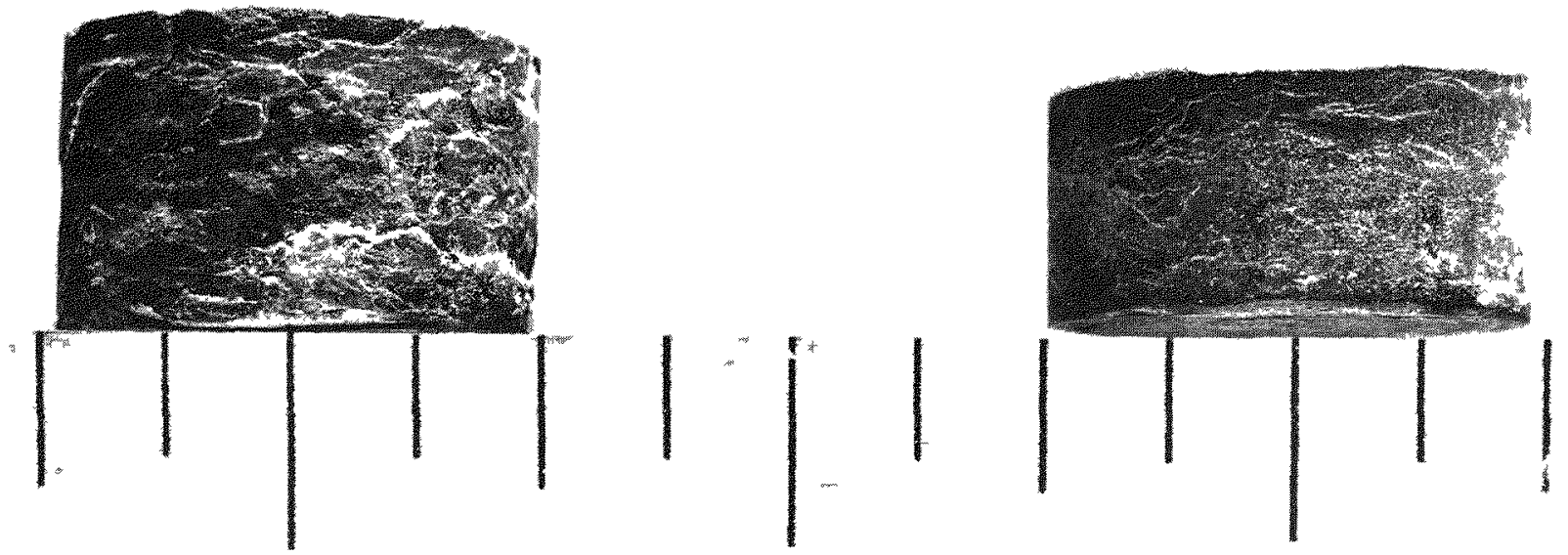

$4 \mathrm{X}$

FIGURE 37. UN SPECIMENS AFTER EXPOSURE TO $260 \mathrm{C}$ NaK EOR $1000 \mathrm{HR}$

$$
\begin{aligned}
& \text { Left - Specimen } 18 \\
& \text { Right - Specimen } 19
\end{aligned}
$$

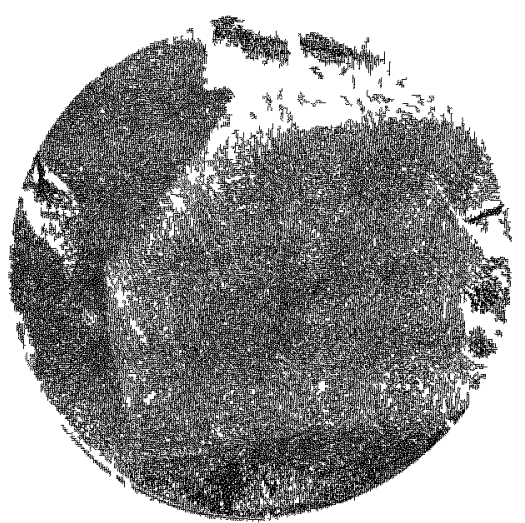

$4 X$

N75756

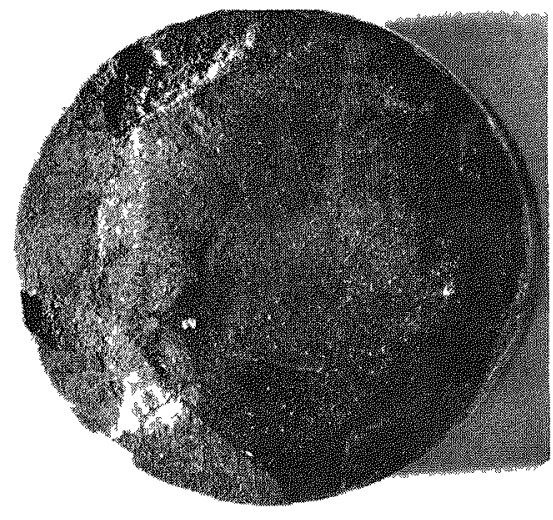

$4 \mathrm{X}$

N77459

a. Before Exposure

b. After Exposure

FIGURE 38. END VIEWS OF UN SPECIMEN 19 BEFORE AND AFTER EXPOSURE TO $260 \mathrm{C}$ NaK FOR $1000 \mathrm{HR}$ 


\section{ACKNOWLEDGMENT}

The authors wish to acknowledge the contributions of several Battelle staff members who aided in evaluating the properties of UN. Messrs. J. R. Matolich, Jr., E. A. Eldridge, A. R. Noe, E. L. Sanford, and H. W. Deem measured the physical properties of UN, Mr. E. G. Bodine obtained the elastic constants and Mr. D. P Moak measured the hot hardness. The reactions with hydrogen were determined by Mr. H. J. Stocker (Euratom Scientist) and Mr. M. W. Mallett.

\section{REFERENCES}

(1) Rundle, R. E. , Baenziger, N. C., Wilson, A. S., and McDonald, R. A., "The Structures of the Carbides, Nitrides, and Oxides of Uranium", J. Am. Chem. Soc., 70, 99-105 (1948).

(2) Katz, J. J. , and Rabinowitch, E., The Chemistry of Uranium, Part I, Mc-GrawHill Book Company, New York (1951), pp 232-241.

(3) Kempter, C. P., McGuire, J. C., and Nadler, M. R. , "Uranium Mononitride", Anal. Chem., 31 (1), 156-157 (1959).

(4) Mueller, M. E., and Knott, H. W., "The Crystal Structure of Uranium Mononitride by Neutron Diffraction", Acta, Cryst, 11, 751-752 (October, 1958).

(5) Vaughn, D. A., "X-Ray Diffraction Study of the Nitrides of Uranium", J. Metals, 8, 78-79 (1956); Trans. AIME, 206, 78-79 (1956).

(6) Paprocki, S. J., Keller, D. L., Cunningham, G. W. , and Foulds, A. K. , "Development of Uranium Mononitride-Stainless Steel Dispersion Fuel Elements", BMI-1365 (1959).

(7) Chiotti, P., "Experimental Refractory Bodies of High-Melting Nitrides, Carbides, and Uranium Dioxide", J. Am. Ceram. Soc., 35, 123-130 (May, 1952).

(8) Tripler, A. B., Snyder, J. M., and Duckworth, W. H., "Further Studies of Sintered Refractory Uranium Compounds", BMI-1313 (1959).

(9) Newkirk, H. W. , and Bates, J. L. "The Melting Points of Uranium Dioxide, Uranium Monocarbide, and Uranium Mononitride", HW-59468 (1959).

(10) Edwards, R. K. , "Studies of Materials at High Temperatures", AECD-3394 (1952).

(11) Kempter, C. P., and Elliott, R. O., "Thermal Expansion of UN, $\mathrm{UO}_{2},\left(\mathrm{UO}_{2} \mathrm{ThO}_{2}\right)$ and $\mathrm{ThO}_{2}$ ", J. Chem. Phys., 30, 1524-1526 (June, 1959).

(12) Newkirk, H. W., "Chemical Reactivity of Uranium Monocarbide and Uranium Mononitride With Water at $100 \mathrm{C} "$ " HW-59408 (1959). 